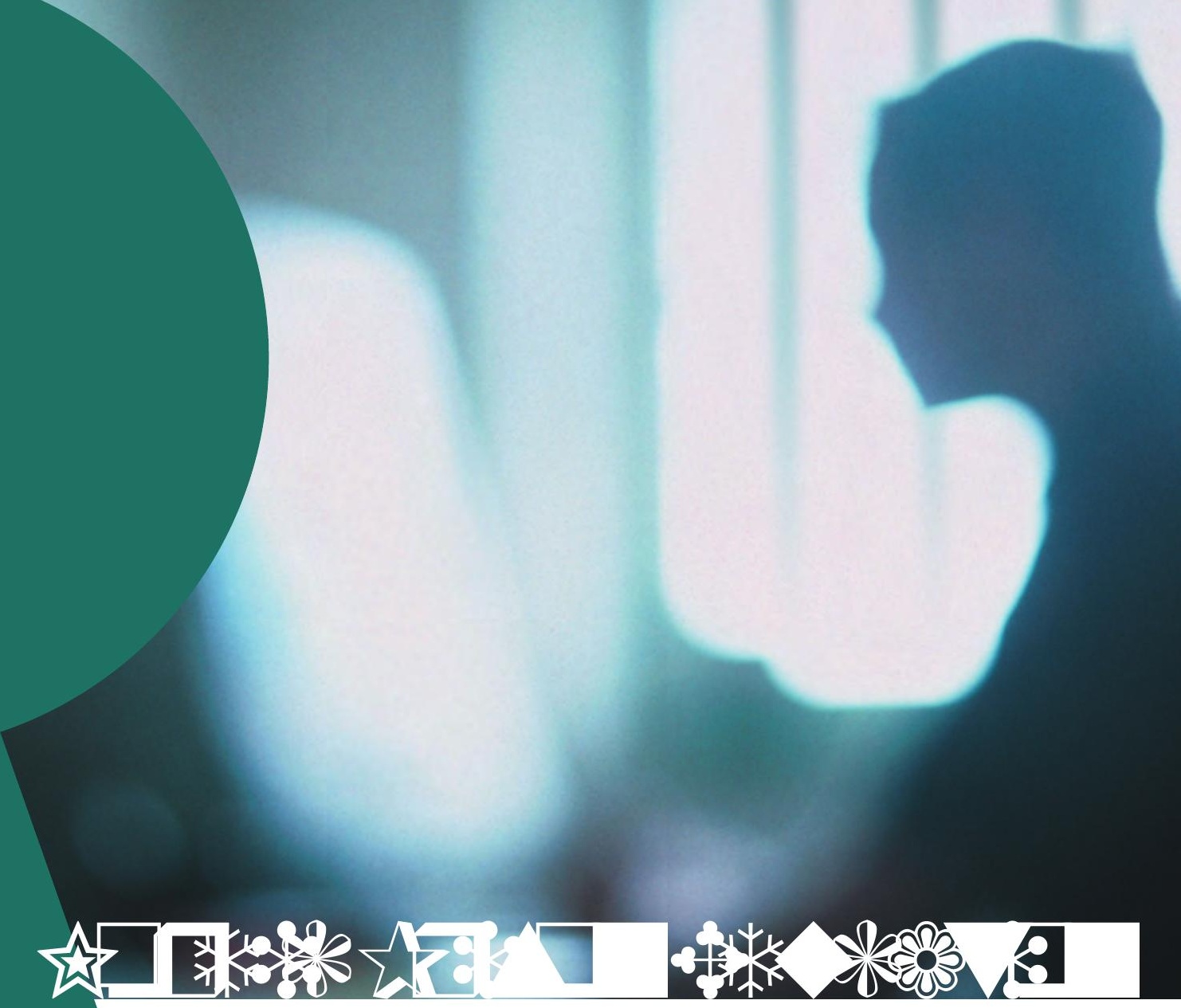

Editors: Torfinn Langelid, Marianne Mäki, Kaj Raundrup, and Svenolov Svensson

Erlendur S. Baldursson Vuokko Karsikas Kirsti Kuivajärvi

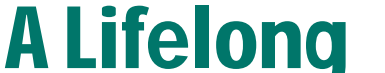
*

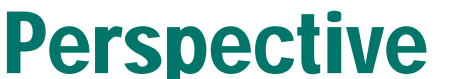







\section{Nordic Prison Education - A Lifelong Learning Perspective}

Editors: Torfinn Langelid, Marianne Mäki, Kaj Raundrup, and Svenolov Svensson

Erlendur S. Baldursson

Vuokko Karsikas

Kirsti Kuivajärvi 
Nordic Prison Education

- A Lifelong Learning Perspective

TemaNord 2009:536

(C) Nordic Council of Ministers, Copenhagen 2009

ISBN 978-92-893-1872-3

Print: Arco Grafisk A/S

Cover: Kjell Olsson/Jette Koefoed, PubU, NCM

Layout: Publications Unit, NCM

Cover photo: INA / O.W.Nickel

Copies: 1400

Translation: Linda Schenk

Printed on environmentally friendly paper

This publication can be ordered on www.norden.org/order. Other Nordic publications are available at www.norden.org/publications

Printed in Denmark

\section{Nordic Council of Ministers}

Store Strandstræde 18

DK-1255 Copenhagen K

Phone (+45) 33960200

Fax (+45) 33960202

\section{Nordic Council}

Store Strandstræde 18

DK-1255 Copenhagen K

Phone (+45) 33960400

Fax (+45) 33111870

www.norden.org

\section{Nordic co-operation}

Nordic cooperation is one of the world's most extensive forms of regional collaboration, involv ing Denmark, Finland, Iceland, Norway, Sweden, and three autonomous areas: the Faroe Islands Greenland, and Åland.

Nordic cooperation has firm traditions in politics, the economy, and culture. It plays an importan role in European and international collaboration, and aims at creating a strong Nordic communit: in a strong Europe.

Nordic cooperation seeks to safeguard Nordic and regional interests and principles in the globa community. Common Nordic values help the region solidify its position as one of the world' most innovative and competitive. 


\section{Contents}

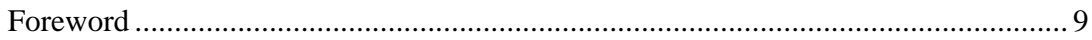

Summary and recommendations

by Torfinn Langelid, Marianne Mäki, Kaj Raundrup, and Svenolov Svensson ................. 13

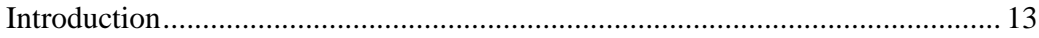

The Nordic prisoner and his or her educational background................................. 13

The right to education and training ..................................................................... 15

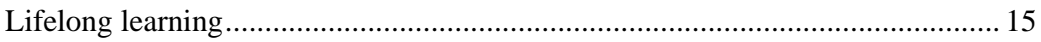

Education and training options.............................................................................. 16

The role of the teacher and methods ................................................................... 16

The role of education and training in the Prison and Probation Services .............. 18

Administrative cooperation .............................................................................. 18

Documentation and research ........................................................................ 19

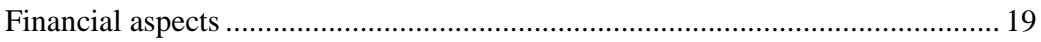

International recommendations and conventions on imprisonment ...................... 20

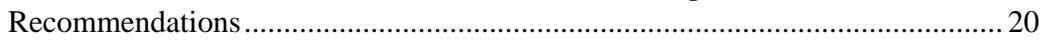

1. Descriptions of prison education in the Nordic Countries ...................................... 25

2. Denmark

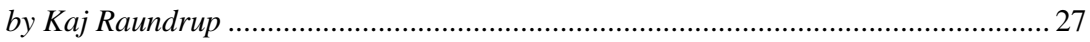

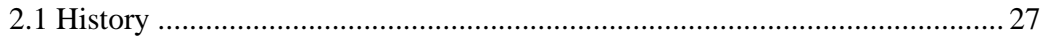

2.2 Legislation and regulatory documents.............................................................. 31

2.3 Description of prison education and its relation to the state

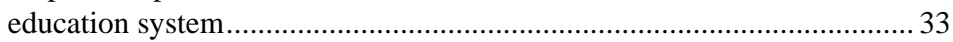

2.3.1 Description of prison education................................................................ 34

2.3.2 Education for individuals held in remand .................................................36

2.3.3 Education for convicted prisoners ............................................................ 37

2.3.4 The transition from prison education to education in the state school system............................................................................. 43

2.3.5 Financial aspects ........................................................................................ 45

2.4 The results of prison education .................................................................. 45

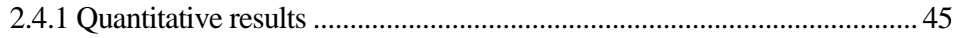

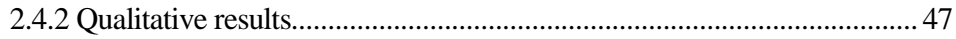

2.4.3 Greenland and the Færoe islands............................................................ 48 
3. Finland

by Vuokko Karsikas, Kirsti Kuivajärvi, and Marianne Mäki ................................... 51

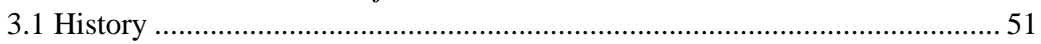

3.2 Legislation and regulatory documents ...................................................... 54

3.3 Description of prison education and its relationship to the state education

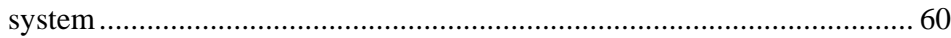

3.3.1 Description of prison education and its relationship to society at large ...60

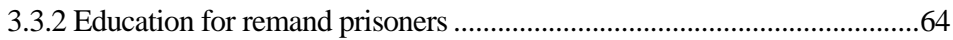

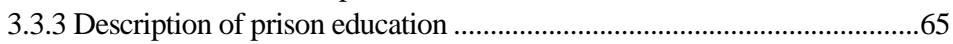

3.3.4 The transition from prison education to education in the community......68

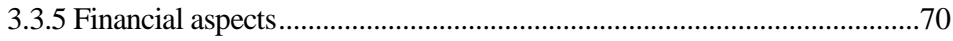

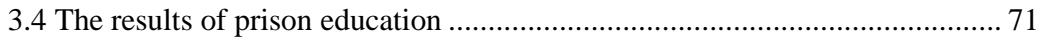

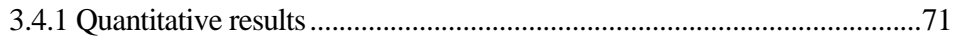

3.4.2 Qualitative results ..................................................................................... 71

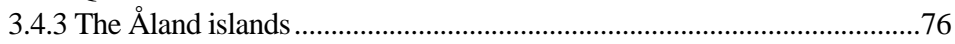

4. Iceland

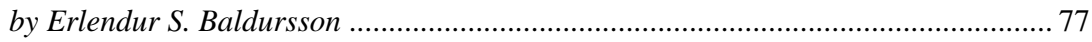

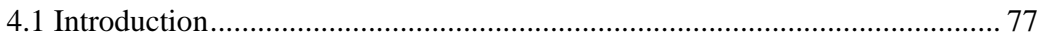

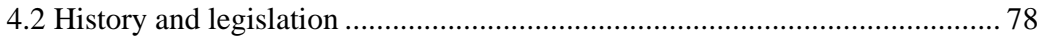

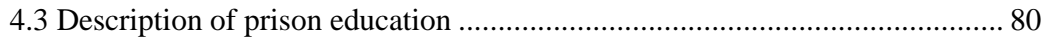

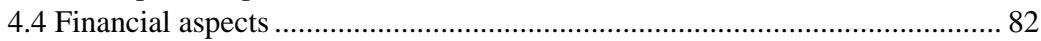

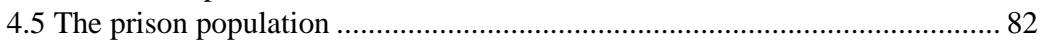

5. Norway

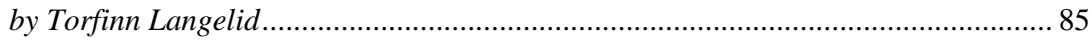

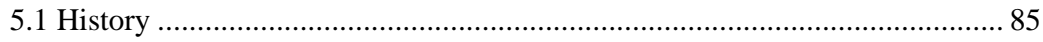

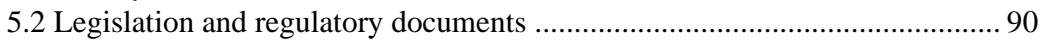

5.2.1 The principles underpinning the work of the Prison and

Probation Service..................................................................................99

5.2.2 The 2002 Enforcement of Sentences Act ..............................................92

5.2.3 The Education Act.....................................................................................99

5.3 Description of the relationship of prison education to the state

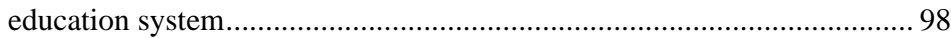

5.3.1 Description of prison education .............................................................98

5.3.2 Education for individuals in remand ...........................................................104

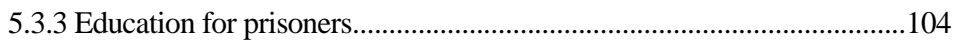

5.3.4 The transition from prison education to education/work in

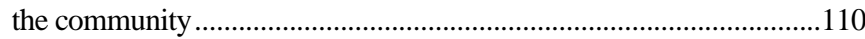

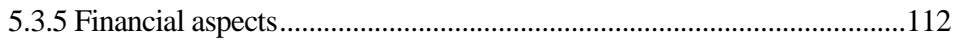

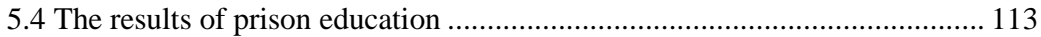

5.4.1 Quantitative results ..............................................................................113

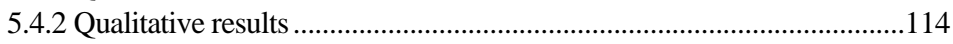


6. Sweden

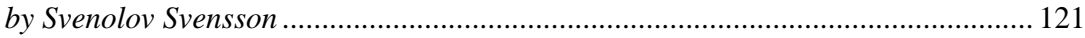

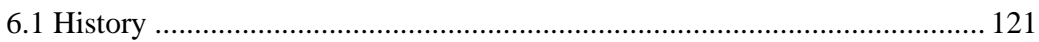

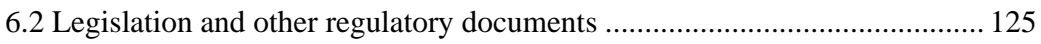

6.3 Description of prison education and its place in relation to

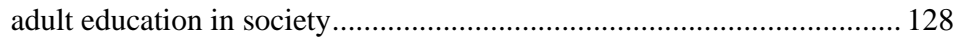

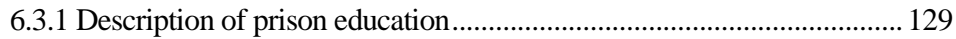

6.3.2 Education for individuals in remand ......................................................... 130

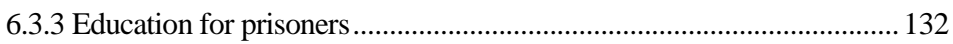

6.3.4 The transition from prison education to education in the community ... 135

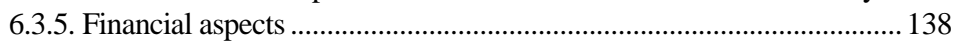

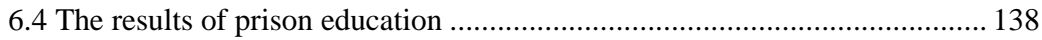

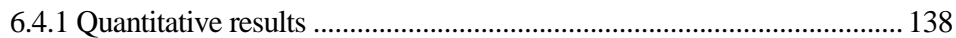

6.4.2 Qualitative results........................................................................................ 140

7. The prison population

by Erlendur S. Baldursson, Torfinn Langelid, Marianne Mäki, Kaj Raundrup, and

Svenolov Svensson ............................................................................................. 143

7.1 Descriptions of the prison populations in Denmark, Finland,

Iceland, Norway and Sweden................................................................. 143

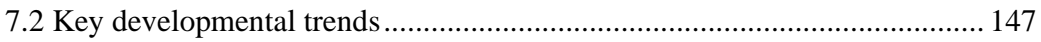

8. Relevant international recommendations

by Torfinn Langelid, Marianne Mäki, Kaj Raundrup, and Svenolov Svensson ............... 149

8.1 The European Prison Rules (2006)........................................................... 149

8.2 Education in Prison (1989)......................................................................... 150

8.3 UNESCO Recommendations for adult education (UNESCO 1985) ............. 152

8.4 The United Nations Convention on the Rights of the Child (1989) ............. 153

8.5 The European Convention for the Protection of Human Rights and Fundamental Freedoms

9. Evaluation, analysis and recommendations

by Vuokko Karsikas, Kirsti Kuivajärvi, Torfinn Langelid, Marianne Mäki,

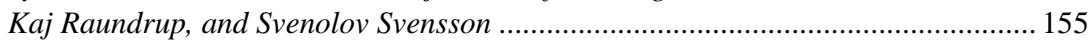

9.1 Legislation and prisoners' rights to education............................................ 156

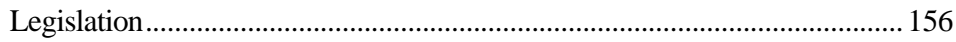

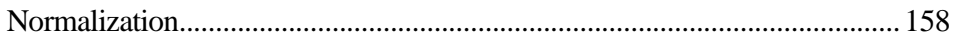

9.2 Models for implementation of education in prisons .................................... 159

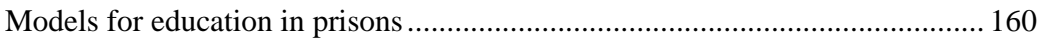

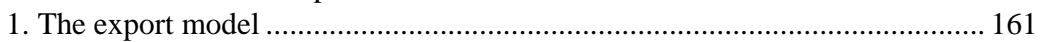

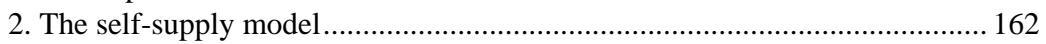

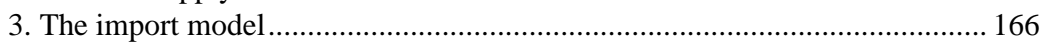

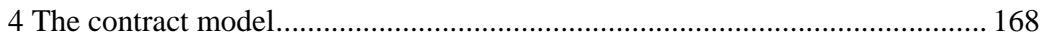

5. The combination model: Teachers employed by both the Ministry of

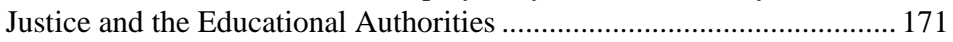

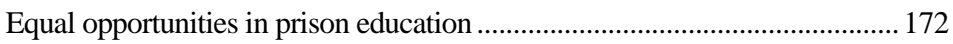

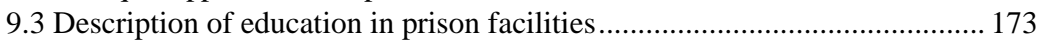

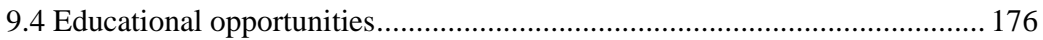

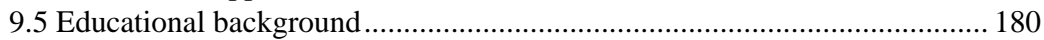

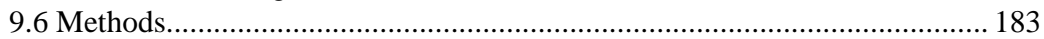


9.7 The place of education in the Prison and Probation Services....................... 188

9.8 Options and needs for lifelong learning .................................................... 191

9.9 Documentation and research .................................................................... 193

9.10 Cooperation between the prison and probation services and other

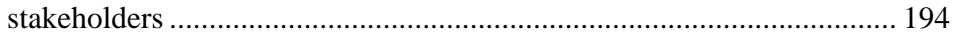

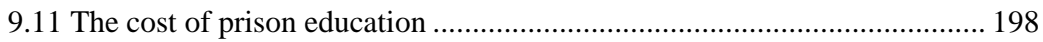

10. Joint Nordic recommendations

by Torfinn Langelid, Marianne Mäki, Kaj Raundrup, and Svenolov Svensson .............. 203

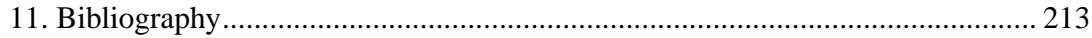

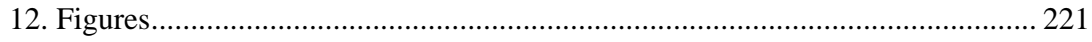

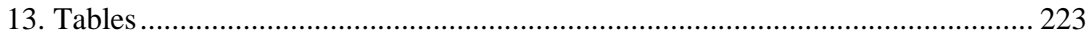




\section{Foreword}

\section{The assignment to the project group}

In 1999, the Nordic Council adopted a recommendation (16/1999) on prison education in a Nordic perspective by which the Nordic Council recommended to the Nordic Council of Ministers that: “... a study be made of the possibilities of cooperating on projects relating to prison education in a Nordic perspective, and that the results of the study presented to the Nordic Council include proposals for measures to be implemented.” (A 1199/nord)

In light of this recommendation, the Nordic Council of Ministers issued the following statement:

In 2000, the Nordic Council of Ministers adopted a position in favor of the earmarking of funds for a systematic survey of the work done by the prison and probation service of each respective country.

The authorities responsible at national level for prison education in the Nordic countries cooperate closely through their network.

The Nordic Council of Ministers assigns this Nordic network to draw up the necessary basic material to enable a final decision to be made regarding joint Nordic initiatives in the area of prison education. A future-oriented Nordic survey with a lifelong learning perspective from the point of view of crime prevention might be one Nordic initiative. Education in the prison and probation service faces many of the same challenges as the entire state education system in relation to society as a whole, not least in terms of fulfilling the needs of the weakest target groups. It is therefore natural for a survey of education in prisons to describe and analyze the initiatives taken by each respective country as part of an exchange of experience, and to see developments in a holistic perspective in relation to the general education system and to what is being done to meet the needs of the weakest groups there. 
The contributions of the Council of Ministers will take place as cooperation between the relevant areas of both education and legislation, and will result in a Nordic report.

At a meeting on 26 September 2001, The Steering Group for Nordic Adult Education Cooperation (FOVU), the Nordic Executive Committee on Education \& Research (EK-U) and the Nordic Senior civil servants' committee for legislation (EK-LOV) adopted the decision that a Nordic level study would be made regarding education and the correctional services.

In accordance with the project description, each country appointed one member of the project group, as well as a reference group to assure the quality of the material. The project has been directed by the County Governor of Hordaland, Norway. The Nordic report was published in 2003, and the first English edition in 2005.

The members of the first project group were:

- Project director Senior Adviser Torfinn Langelid, the County Governor of Hordaland, Norway.

- Education Manager Kaj Raundrup, Danish Prisons and Probation Service,

- Chief Inspector Vuokko Karsikas (15 April 2002-15 August 2003), Finnish Criminal Sanctions Agency and Chief Inspector Kirsti Kuivajärvi (17 January 2002-17 March 2002), Finnish Criminal Sanctions Agency

- Regional program coordinator Svenolov Svensson, The Swedish National Prison and Probation Administration, Regional office in Göteborg.

According to information from the Nordic Council of Ministers, the first Nordic and English editions are both out of print. The English edition was issued to every ministry of education and justice in Europe, as well as to the relevant authorities in the United States, Canada, and Australia. Presentations were also made at a large number of Nordic and international conferences, and the Nordic project group has had a great deal of positive feedback, and requests for a second edition. In the context of prison education, the Nordic correctional services have attracted interest for their 
ability to offer a wide range of educational activities at the same time as they safeguard the security of life and property. For these reasons, the Nordic Network for Prison Education decided to apply to the relevant Nordic correctional and educational authorities for funding to revise the first edition of the report. Funding was granted, and the Nordic Council of Ministers agreed to publish the new version.

\section{The Nordic Network for Prison Education}

On the basis of long, excellent informal collaboration amongst the Nordic countries that began in the 1970s, the Nordic Network for Prison Education was formally established on 1 January, 2006. Its members work in key positions in the prison and probation services and at the educational authorities with specific responsibility for prison education in the Nordic countries. For further information, please see the website: www.fengselundervisning.net

\section{Revision of the report}

The project group responsible for revising the report consisted of:

- Project Director, Senior adviser Torfinn Langelid, County Governor of Hordaland (delegated the national responsibility for prison education in Norway).

- Education manager Kaj Raundrup, Danish Prison and Probation Service,

- Marianne Mäki, Senior Specialist Finnish Criminal Sanctions Agency

- Svenolov Svensson, regional program coordinator, Swedish Prison and Probation Service, regional office for Western Sweden.

Iceland was not represented in the project group, but Erlendur S. Baldursson, assistant director general of the Icelandic State Prison Administration contributed the chapter on prison education in Iceland. The report also contains brief reports on prison education in Greenland, the Færoe Islands, and the Åland Islands. 
The revisions in this second edition the report concern updates in relation to research, surveys and developments in the Nordic countries since 2003.

The more recent Nordic Report: Education in Nordic Prisons: Prisoners' Educational Backgrounds, Preferences, and Motivation (Eikeland, Manger, and Asbjørnsen (eds.) 2008) was particularly important in this respect. The majority of the statistical material included is from 2006 and later. Chapter six in the 2005 edition, Crime Prevention in the short and long term, has been eliminated in this edition.

In my capacity as project director, I would like to thank the representatives of each country and the prison and probation services and the education authorities of the Nordic countries for their practical and financial contributions that have enabled us to revise the report. I am also very grateful to Senior Adviser Klaus Munch Haagensen from the Nordic Council of Ministers for all his help and support throughout the process.

Bergen, Norway, November, 2008

Torfinn Langelid

Project Director 


\section{Summary and recommendations}

by Torfinn Langelid, Marianne Mäki, Kaj Raundrup, and Svenolov Svensson

\section{Introduction}

The purpose of the project Education, Training and Prison and Probation Service in a Lifelong Learning Perspective, a Nordic Study of Structures and Models, has been to provide a concise, overall and updated comparative view of education and training in prisons in Denmark, Finland, Norway and Sweden, as well as a brief description of the situation in Iceland. Based on these observations, general analyses of strengths and weaknesses were made in order to identify a common basis for progress in the field. The project group has put forward joint Nordic recommendations for improvements. The results and recommendations can also be applied to the adjacent areas, as well as to other countries, in their efforts to develop their prison education systems.

The statistics are primarily from 2006 and 2007. Statistics and reporting methods differ in the various countries but the project group has tried to make the material as comparable as possible.

\section{The Nordic prisoner and his or her educational background}

The typical Nordic prisoner can be described as over 30, having left school quite early, with a very little experience of the labor market and, in many cases, a substance abuse problem. Not a surprising picture, and readily recognizable. 
The Nordic survey (Eikeland, Manger, and Asbjørnsen (eds. 2008)) of prison education demonstrates that the educational systems of the five Nordic countries have common elements, but also some variations.

According to the findings of that study, depending on country, between seven and sixteen per cent of prisoners have completed some level of education. The study also indicates that it is generally the youngest Nordic prisoners who have the weakest educational backgrounds.

The percentage of prisoners who do not participate in any prison educational activities is very similar in all the Nordic countries. Iceland has the lowest number of non-participants (55\%), while Denmark has the highest, with three out of every four prisoners not participating in any prison educational activities. The main reasons given for not participating were either that the prison in question did not offer any educational activities or that those on offer did not suit the needs of the prisoners. Many prisoners expressed a preference for more vocational training.

Prisoners who did participate were generally satisfied with the activities offered and with the teaching. Inadequate (or inadequate access to) ICT equipment was stated by the prisoners in all five countries as being the main problem with or obstacle to completing prison educational activities.

Although many prisoners need formal education and training, the present report also identifies a need for training in informal skills (life mastery, teamwork skills, functioning in the community, the family, etc.). Official efforts to promote lifelong learning in society must also encompass individuals serving prison sentences under the auspices of the Prison and Probation Services. (See also 9.7)

The overall question is: what type of education and training do contemporary prison populations need?

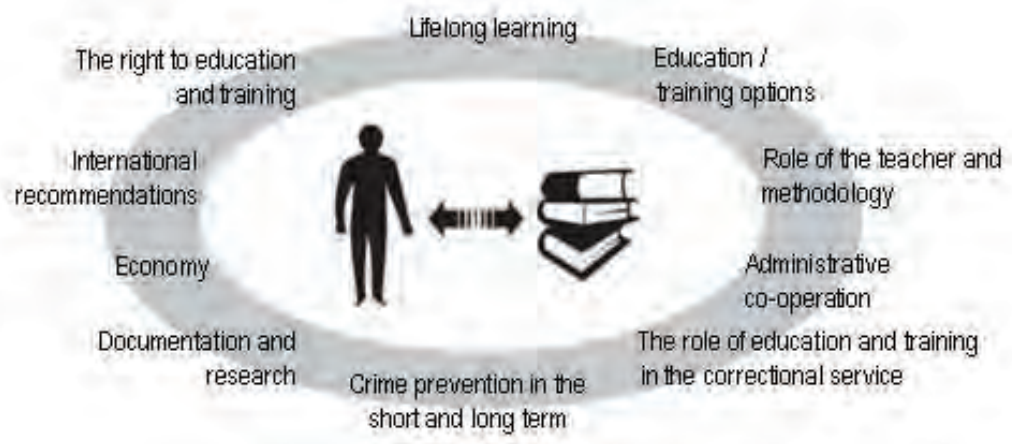

Figure 1.1 Prisoners and prison education in relation to society 


\section{The right to education and training}

If prisoners are to receive education and training on the same terms as the rest of society, then it is a basic prerequisite that their rights are clearly stipulated in the legislation. While the authorities in all of the Nordic countries actively advocate lifelong learning and skills enhancement for adults, our study reveals that prisoners' rights to education and training are less clearly defined. Legislation governing prison and probation services must also stipulate, therefore, that the only thing of which a prisoner is to be deprived is his or her liberty. In principle, all other rights must be upheld.

Based on the principles of normalization, integration, openness and responsibility, the project group advocates prisoners taking part in the general education system to a much larger extent than today by increasing the use of day release privileges, etc. This would allow prisoners to participate in the ordinary school system, and experiences different approaches than used in prison educational activities. There is also a greater range of choice in the community educational system.

\section{Lifelong learning}

At European Union level and in the individual European countries, efforts are being made to ensure that young people and adults obtain the knowledge and skills they need to face new employment situations in a society in a state of constant change. It is clear that without these skills and this knowledge, individuals will be excluded from the ordinary educational system and the labor market. The prison population is a vulnerable group in this respect. One precondition for meeting the needs of the different groups of prisoners for education and training is that the educational authorities possess the tools to assess their needs and the options available to them. 


\section{Education and training options}

Prison education and training must reflect the ordinary educational system. Research shows that many prisoners have had inadequate schooling compared with the rest of the population. In terms, for example, of the right to education and training, the humanitarian perspective, and rehabilitation, education and training in prisons should be broadly defined. Good prison education and training is considered an investment in crime prevention in the sense that it will increase the number of prisoners who continue their education and find jobs after release.

Our study of prison education and training in the Nordic countries shows that definitions vary from country to country. Considering the importance attached to lifelong learning and the attention paid to the need for continuous skills enhancement and to the increasingly multicultural nature of Nordic society, all these elements need to be acknowledged in prison education and training.

Despite their different models, a joint Nordic starting point does exist in the sense that education and training are perceived as being both for the benefit of the individual prisoner, for personal development, and as a step on the way to the ability to cope upon release - hopefully to a life free from crime and drugs. The organization, courses, methods and prioritizations should, therefore, be based on the prisoner's situation.

Education and training needs may be formal in nature to a great extent, but a major need for informal skills has also been identified (life skills, the ability to function in a team at work, in society, in the family, etc.). Official efforts to promote lifelong learning must also include prisoners.

\section{The role of the teacher and methods}

Prison teachers need special skills to satisfy the particular needs of the prison population for education and training. They must be able to recognize the different learning needs of the individual prisoners, and be able to handle foreign prisoners' needs in terms of language, religion and culture. They must be certified teachers, and also be given updated information regarding the prison and probation services, in order to promote proper pedagogical dialogue and avoid institutionalization. 
In Denmark most of the teaching in prisons is done by full-time teachers appointed by the local prison management. Over half of the teaching in county prisons is provided by prison staff teachers, and the remainder by part-time teachers appointed by the local authorities. In Finland, most of the teaching is done by teachers appointed by local education institutions, but there are also teachers appointed by the Ministry of Justice (in three prisons) and contracted teachers (very few). In Norway, all prison teachers are either full or part-time teachers appointed by the educational authorities. In Sweden, teachers are employed by the prison and probation services at "Learning Centers" at each prison.

Is there a dimension to teaching in a prison setting that distinguishes the prison teacher from other teachers? In spite of the fact that a great deal of prison education is at basic levels, the teaching must always be carried out on the basis of the pedagogy of adult education. The mean age of prisoners ranges from 31 to 36 .

According to Skaalvik et al. (2005), if there were a spectrum with the students' points of departure at one end and long-term goals at the other, it would also span the spectrum of opinions about the objectives of prison education amongst prison school administrators, teachers, and other prison staff.

\begin{tabular}{|c|c|c|c|}
\hline $\begin{array}{l}\text { Individual points } \\
\text { of departure }\end{array} \rightarrow$ & 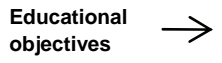 & $\begin{array}{l}\text { Formal } \\
\text { objectives }\end{array}$ & $\begin{array}{l}\text { Long-term } \\
\text { objectives }\end{array}$ \\
\hline $\begin{array}{l}\text { - Feeling comfortable } \\
\text { in the classroom } \\
\text { - Motivation } \\
\text { - Self-confidence }\end{array}$ & $\begin{array}{l}\text { - Knowledge } \\
\text { - Skills } \\
\text { - Social } \\
\text { development } \\
\text { - Attitudes }\end{array}$ & $\begin{array}{l}\text { - Diplomas } \\
\text { - Course } \\
\text { certificates }\end{array}$ & $\begin{array}{c}\text { - Mastering } \\
\text { life skills }\end{array}$ \\
\hline
\end{tabular}

Figure 1.2 The objectives of prison education seen over time

For the teacher, the person who works with the students in practice, it is essential to be familiar with the individual's point of departure in order to find the appropriate means of achieving the long-term objectives. For the prison school administrator, on the other hand, coming from experience of the state school system, "formal objectives” are central. In any case, each new prisoner must be approached with awareness of all this in mind, and from the perspective of lifelong learning, without bias, and in an honest attempt to see where on the spectrum he or she is starting out, in order to utilize the most appropriate methods in working with that indi- 
vidual. For one prisoner working towards a specific goal may be just right, while for another the most important thing may be to start with basic skill improvement. It is very likely that prison teachers face greater challenges than "regular" adult education teachers when it comes to finding the right keys to unlock each individual student's learning abilities.

Thus in the prison setting, too, optimal education will help the student develop as a person, have more self-confidence, be better able to solve problems, be creative, better able to learn new things, and find and assess information.

\section{The role of education and training in the Prison and Probation Services}

A prison sentence is one of the ways in which society can react to undesirable actions. This reaction builds on the instruments available to the prison and probation service to promote the reintegration of the prisoner into society. Many different professional categories contribute to this effort. In other words, institutions run by the prison and probation services are staffed by representatives of various stakeholders who may also have different, contradictory, objectives. The educational authority is one of the national agencies meant to ensure that convicted prisoners receive the education to which they have a legal right. The prison and probation services have responsibility for coordinating the measures implemented by the various state authorities so that prisoners have well-organized, positive options.

\section{Administrative cooperation}

Close cooperation between the correctional service and the various authorities is an important prerequisite for satisfying prisoners' needs regarding education and training. Strategic plans are needed for the extension of prison education and training. Close cooperation and good internal planning will provide a broader view of the needs of the different prison groups for education and training, help develop good programs, and ensure better utilization of resources. 
From the perspective of society as a whole, it is important to encourage co-ordination of efforts that will make it easier for prisoners to return to society.

\section{Documentation and research}

All the Nordic countries have carried out national surveys concerning the educational backgrounds, needs, and preferences of prisoners. The Nordic Network for Prison Education took the initiative to a Nordic survey of prisoners' educational backgrounds in 2006, with financial support from the Nordic Council of Ministers. This study involved research environments in all five Nordic countries, and revealed the similarities and differences amongst the Nordic countries with regard to these questions.

The national surveys and the overview survey of the Nordic countries led to greater attention being focused on prison education on the part of both politicians and decision makers, with resultant changes. There remains, however, an overall need in the Nordic countries for quality assurance in educational activities on the basis of various kinds of reporting, evaluations, and research, to ensure agreement between the resources allocated and the educational activities offered, and to obtain a clear overview of what educational activities are being offered at any given time.

\section{Financial aspects}

At present, demand far outstrips supply. Those with the greatest need are often a group also difficult to reach on the outside. Therefore, it is a high priority to make a start towards fulfilling society's ambition of enhancing these individuals' skills and encouraging them to join in the process of lifelong learning while they are serving prison terms. At present, education and training accounts only for a small fraction of the total cost of each prison place. It would probably be more profitable in purely socioeconomic terms to increase investments in education and training in prisons.

The cost of prison education and training is small compared to the total cost of a prison place, in spite of the total cost of the education and training in the Nordic countries being millions of Euro. The proportion of 
total costs is approximately 3-9\%. In other words, the prison and probation services in the Nordic countries provide prison education and training for roughly the price of one pack of cigarettes per prisoner per day.

\section{International recommendations and conventions on imprisonment}

Legislation is often based on international recommendations and conventions. Existing and future prison education and training must comply with international recommendations and conventions.

\section{Recommendations}

The project group has drawn up a number of recommendations for the future of prison education and training in the Nordic countries (for further details see chapters 9 and 10). The project group has made the following core recommendations:

\section{Legislation}

The project group recommends that the educational authorities in the Nordic countries ensure that their legislations clearly state the legal right and obligation to provide prisoners with the same right to education as other citizens, ensuring that the legislation of each country is in line with international conventions and recommendations. The legal authority stipulated in their Education Acts should also be stipulated in the legislation of the different countries relating to enforcement of sentences. When the right to education has been elucidated, this will have consequences in terms of resource allocation.

\section{Educational opportunities}

The project group recommends the following proposals to meet the need for formal and informal skills. The findings in the national and Nordic surveys stress the need for more vocational training. Such training must 
be integrated to a greater extent with external companies, in consideration of the potential for helping the students to find a place on the labor market after release. The educational activities offered must also satisfy the educational needs of prisoners, not least those with special needs, who will only be recruited to the educational system if they receive particular attention.

\section{General education}

- Basic education.

- Special/remedial education, with a particular focus on the prisoners with the most inadequate educational backgrounds (the period spent serving a prison sentence is a unique opportunity to devote time to and motivate such individuals).

- Adult upper secondary education, with course options as extensive as those offered in the community.

- Studying with day release privileges is an important option, giving the individual more freedom of choice, and the prisoner the opportunity to spend time in a "normal" study environment.

- Formal and informal educational competence assessments must become a consistent aspect of general education in prison.

- Education to satisfy the needs of foreign prisoners.

- Remote or distance learning (Internet-based courses) with some personal tutoring can play a role in satisfying individual needs.

\section{Vocational training}

- Vocational training in collaboration with the employment service to offer training to prepare individuals for the labor market.

- Cooperation should be encouraged between schools (theory) and prison workshops (practice). As a result of such cooperation, prisoners could earn educational credits for some activities. When educational needs are assessed, prisoners' previous experience should also be taken into account. This can mean a great deal to individuals who do not have many positive testimonials.

- Formal and informal educational competence assessments must become a consistent aspect of vocational training in prison. 
- Some vocational training could be given in other languages. This could be useful to prisoners who are going to be deported after release, who could thus gain competence that will be of value to them when they return to their home countries.

- Digital competence. It is important that a marginalized group such as prisoners have the same opportunities as others to acquire digital competence.

- ICT courses of the same kinds offered in the regular schools in the community (both to master the techniques themselves and to use the new technologies in other subject studies. ICT is also a necessary tool to be able to access various educational options outside the prison - a natural tool in relation to the expanding range of Internet-based adult education possibilities in society, not least through links to educational institutions in foreign prisoners' home countries.

Creative activities, libraries, etc.

- Education in the arts with a view to improving self-development, life skills and motivation, to raise individuals' social skills. Participation in both creative activities and well-rounded physical activities often encourage prisoners to go on to other kinds of education.

- There should be access to a well-stocked library and its services in collaboration with the library services available in the community.

\section{Women prisoners}

- All the items above apply equally to women prisoners who, precisely like their male counterparts, must be offered a wide range of educational opportunities adapted to their individual needs. For women, who otherwise run the risk of being considered a small, costly target group, the new technologies may be particularly important in terms of opening up a large number of options (unless the possibility of mixing men and women in prison education groups is considered). 
Education as one piece of the puzzle

- Education can become more effective if it is combined with work, treatment programs, and other approved activities. Very few prisoners can cope efficiently with full-time studies. Great flexibility and "tailor-made" weekly schedules should be available for each prisoner. Education is one important piece of a larger puzzle. If that piece falls into place, it may be decisive both for the success of the prisoner's schooling and for his or her life as a whole. The national surveys and the joint Nordic survey all highlight the need for individual study plans, as well as good guidance and counseling concerning educational opportunities.

Facilities and equipment

- There must be access to purpose-suited facilities and state-of-the-art equipment equivalent to that available at community adult education facilities or elsewhere in society.

\section{Administrative cooperation}

The project group proposes that concrete plans and routines be drawn up for cooperation between the Prison and Probation Services and the various stakeholders at national, regional and local levels.

\section{Documentation and research}

The project group proposes that systematic reporting, evaluation and research on education in prisons be carried out with a view to:

- documenting the work being done on education in prisons in comparison, for example, with treatment programs and other activities,

- evaluating whether the range offered as prison education corresponds to the educational needs of the prison population,

- obtaining a clear picture of which prisoners do and do not participate in, how students are recruited to prison education,

- assessing teaching methods and quality, 
- obtaining a systematic evaluation of prison workshops in relation to the applying curricula,

- determining the place of prison education in the correctional services. 


\section{Descriptions of prison education in the Nordic Countries}

Chapter 2, 3, 4, 5 and 6 describes the five Nordic countries: Denmark, Finland, Iceland, Norway and Sweden separately. In this chapter, each section is divided into subsections accounting for historical developments from the mid-nineteenth century until the present day, the legislation and regulatory documents applying to prison education, the educational options currently available, and the transition arrangements in anticipation of release and return to society. The concluding subsection of each section details the costs of prison education, the sources of funding, and the results achieved. The statistics and research results referred to mainly come from national reports not available in English. These references are given in brackets in the running text, at first occurrence, by their author and year of publication and with an English equivalent title, by way of information. They are detailed in the bibliography in their original languages, see page 213 . 



\section{Denmark}

by Kaj Raundrup

\subsection{History}

In the second half of the 1850s, children under the age of 15 could be placed in houses of detention for reasons of education and correction. At the time, the minimum age of conviction for a penal offence was 10 . In 1905 the minimum age was raised to 14 . Prison education was offered during the winter half of the year, while during the summer season young offenders worked the prison farms and gardens.

The Danish Criminal Code, which came into force in 1866, established two types of long-term deprivation of liberty, known as penitentiaries and houses of correction. It was generally accepted that when an individual was sentenced to a house of correction this was intended not only to safeguard society from the criminal, but also to fill a cautionary function of general prevention. While houses of correction were dormitory-like facilities, penitentiaries were prisons with cells. Prison education began at the penitentiaries, where the teachers were staff members. Prison education is still an important aspect of sentence enforcement, although over the years its form has changed in relation to the prevailing theories of education and the practical facilities available.

\section{Youth penitentiaries}

Organized prison education moved into a new phase on 15 April 1930, when the Danish Civil Penal Code was adopted (Lov af 15. april 1930: Lov om ikrafttrceden af borgerlig straffelov m.v. Gads forlag), resulting in the establishment of youth penitentiaries in 1933. The underlying princi- 
ple was to have a treatment system for young offenders, between the ages of 15 and 21, who were considered as requiring counseling and guidance and, not least, vocational and educational training, in order to become law-abiding citizens.

At youth penitentiaries, education was compulsory. Prison teachers taught Danish, mathematics, writing, etc. The new insight underpinning the introduction of compulsory education was that many prisoners had serious problems, attributable to various factors including inadequate educational backgrounds.

The educational options focused on the basics, for the reasons given above, as well as on expanding prisoners' horizons by strengthening their self-confidence, ability to reflect, and self-image, began as individual teaching in the prisoners' cells. Classroom teaching began at Danish prisons in 1932.

\section{Open prisons}

During the years after World War II, for reasons of capacity, a large number of new, open prisons were constructed. These facilities had a good geographical spread, and housed the majority of convicted prisoners. There were advantages to having open prisons in terms of criminal policy: prisoners were able to utilize the educational and vocational options available in the community to a much greater extent than previously.

\section{Regulations regarding education}

Not until 1952 were regulations for prison education adopted, stating that:

....as a rule education is to be offered on a group basis and, whenever possible, outside working hours. All prisoners under the age of 30 are required to participate in the basic education courses in written and oral proficiency in Danish, and in mathematics, writing and civics, arranged by the prison where they are serving their sentences. The prison Governor may determine, after consultation with the head teacher, to include other subject areas in the obligatory courses.

In addition to the establishment of remedial education, the regulations also ensured that credit-giving courses would be offered, as well as short vocational courses. 


\section{Criticism of sentences of indeterminate length}

The treatment regime described above was subject to increasing criticism in the 1950s and 1960s from criminologists and experts and gradually also from politicians, particularly in relation to prisoners sentenced to serve sanctions of indeterminate length. Thus the way was paved for abolition of some of the sanctions of indeterminate length, and eventually the entire Criminal Code was revised. The revised Code was adopted in 1973.

The 1973 report of the Danish government commission on education In 1968, the Ministry of Justice announced the appointment of an education commission whose task was to analyze the scope, content and organization of educational activities for prisoners, including vocational training and the problems associated with how prisoners spend their nonworking hours. The report of the commission was published in 1973. It was written mainly from a societal point of view, based on the assertion that although recent years had seen major developments regarding access to education for young and old, prison education had not kept pace owing to resource constraints. The authors of the report formulated the following objective:

The prison authorities should strive to provide prisoners with a range of educational options corresponding to that available to the citizens in society at large. Whenever possible, this teaching should take place as participation in courses, etc. held outside the prison. However when necessary, for reasons of security or other special, prison-related considerations, educational opportunities should be offered on the prison premises.

The commission also proposed that the educational options described should be offered all year round and during the day, as full-time schooling. Thus the foundation was laid for education to be on equal terms with other prison activities, and for abolition of compulsory education.

\section{The Skadhauge plan}

In 1971, a working party was asked to draw up a proposal for establishment and implementation of an educational reform in and outside prisons.

In August 1974, after referral to and comments from many different parties, the proposal was adopted. It was known as the "Skadhauge plan", named after the educational consultant employed by the Prison and Pro- 
bation Service. The main proposal was that prison education should be integrated into the state educational system, primarily by prisoners being granted day release privileges from open prisons, so they could participate in the educational opportunities available in the community. The secondary proposal was that a corresponding educational system would be established in closed prisons. The Skadhauge plan was influential in the 1970s and 80s not only in the Nordic countries but in the rest of Europe as well.

\section{The 1986 AUF report}

The "AUF" report (AUF stands for the Danish words Arbejde, Undervisning og Fritid, meaning "Work, Education and Leisure Time") was published in 1986.

This report proposed that there should be equivalence of work and education in terms of the allowance paid for participation. It was also included in the recommendation on prison education from the Council of Europe in 1989.

The 2002 report on activities for convicted prisoners

Spring 2002 saw the publication of yet another report on activities and treatment for prisoners under the auspices of the Prison and Probation Service. The proposed reorganization of all areas of activities described below, with more integration of work, education and treatment, was actually never adopted. Implementation of the recommendations in the report was postponed owing to financial constraints, but was recommenced in 2005. In recent years, the Prison and Probation Service has extended the number of programs, adding cognitive behavioral treatment and substance abuse treatment programs to the range:

- Lower and upper secondary education

The report recommends that education of prisoners in the custody of the Prison and Probation Service should be carried out part-time and on the basis of the same principles as govern other lower and upper secondary education. The aim of the recommendation regarding part-time education is to ensure that relevant educational options are offered to as many prisoners as possible. 
Flexible, adapted teaching

Many adult education centers have experimented in recent years with different kinds of flexible, adapted teaching, with a view to tailoring the education to the changing living and working conditions of the population. Such new approaches in prison education include, for example, staggering of course starts, since prison sentence serving is not scheduled in consideration of the school term, and enabling individuals who are about to be released can sit their exams. After release, former prisoners will be able to continue the courses that were tailored to fit their needs at local adult education centers, sit exams there, and get their grades.

ICT as integrated into teaching (referred to below as "distance courses") ICT can be used as an integral part of the education sector. In many curricula today, this is already assumed to be the case. In open prisons, ICT can be one aspect of education in prison classrooms, which is not possible in high security prisons today. The report recommends that security aspects be worked out so as to enable even prisoners in high security prisons to use personal computers with Internet access as part of their educational work. The multiannual agreement to which the Prison and Probation Service is a party covering 2008-2011, funds have been earmarked for the establishment of computer networks to be set up in purpose-built facilities at open prisons, closed prisons and the twenty largest remand facilities, on the condition that Internet access is properly installed from a security point of view.

Giving priority to ICT as an independent subject

Because ICT skills are increasingly needed for anyone wanting to be active on the labor market or in society in general, the report proposes that IT should be given priority as a separate subject, rather than being considered an integral part of prison education.

\subsection{Legislation and regulatory documents}

The Enforcement of Sentences Act

The right to education is stipulated in Article 38 of the Act on Enforcement of Sentences, etc.: 
A prisoner has the right and obligation to be occupied with participation in work, education or other approved activities.

(Act 1337, 3 December 2007)

\section{General Adult Education}

There is a long tradition of cooperation between prison education and the state education system, and thus there is a link to the Ministry of Education. For many years, prisoners have taken the same exams and been graded on the same grading scale as other adults in society.

When the Adult Education Act came into force (in 2000), the Prison and Probation Service gained a status of its own under the auspices of the Ministry of Education (see also Article 3, paragraph 2 of the Act): "Subject to the approval of the Minister of Education, other educational institutions, including those within the Prison and Probation Service, may offer general adult education”. Most prison schools have been granted the status of "local adult education centers". Staff members employed by the Directorate of the Prison and Probation Service serve as directors and assistant directors of these centers. All the teaching and all exams are structured for adult target groups (ages 18 and over), in order to be purpose-oriented and relevant.

\section{Preparatory Adult Education}

The Act on Preparatory Adult Education (Act no. 16, 7 January 2005) gave the Prison and Probation Service a special status in that all prison schools can now develop and phase out preparatory adult education (cf. Chapter 6, Article 13 of the Executive Order): "Preparatory adult education may be offered by educational institutions operating under the aus-

pices of the Prison and Probation Service. These institutions may also run examinations".

In accordance with Act. 557, 6 June 2007, it is possible to obtain a waiver from the age requirement. This means that prisoners under the age of 18 can now participate in preparatory adult education.

As of 1August 2008, English is now an optional subject in preparatory adult education.

\section{Cooperation with the state education system}

In the area of the labor market, the Executive Order stresses that prisoners nearing the end of their sentences may participate in labor market courses 
for unskilled laborers on equal terms with other citizens. Prisoners in halfway houses who are studying (see section 2.3.4 below regarding the transition from prison education to education in the state school system) have the same right to a study grant as other students, when the course they are taking makes them eligible for support under the Danish Students' Grant and Loan Scheme. Thus cooperation with the state education system is a basic element of the ambition of the Prison and Probation Service today, with a view to integrating prisoners in the vocational and educational options in the community whenever possible. This is most clearly expressed in the Program and Principles for Prisons and Probation Work in Denmark from1993, where the activities of the Prison and Probation Service are described in line with six principles: normalization, openness, exercise of responsibility, security, least possible intervention, and optimum use of resources (see below section 2.3) as well as, most recently, in the Act on Enforcement of Sentences, etc. mentioned above.

\subsection{Description of prison education and its relation to the state education system}

The program and principles for prisons and probation work in Denmark

The Prison and Probation Service has given special priority in recent years to adapting to the rapidly changing society in which we live. From a treatment point of view, it is important for sentence enforcement time to be as "normal" as possible for the prisoner, in order to avoid harmful effects of imprisonment. The monotony which is one element of everyday life in prison may give the prisoner a sense of the futility of prison life, in sharp contrast to the world to which he or she will be returning, and the demands society places on its citizens. The Prison and Probation Service continues working to adapt, and to be constantly ready to change in ways that will benefit the prisoner. One aspect of prison life considered extremely important today is prison education. This is described in detail in the program and principles for prisons and probation work in Denmark.

In relation to the principle of "normalization", the Prisons and Probation Directorate defines prison education as follows: 
Normalization:

1. The Directorate will strive to ensure that prisoners are given the opportunity to exercise their civil rights and to the greatest possible extent are given equivalent opportunities as other citizens for training and education, with a relatively broader range of options to compensate for the fact that they have to attend school behind bars.

2. On the basis of the "proximity principle", the Directorate will strive to disburse resources so that all prisoners have the same educational options.

3. The Directorate will strive to ensure that educational materials and all other materials correspond to and are in agreement with the conditions at institutions of education under other auspices than those of the Prison and Probation Service.

4. The Directorate will strive, wherever possible, to ensure that the community education system is used, via day release privileges or the import model. When it is impossible for prisoners to make use of community services, the Prison and Probation Service will endeavor to provide prison education in collaboration with institutions of education in the community.

5. The Directorate will ensure that prisoners held in solitary confinement or in special wings are offered education.

6. The Directorate will strive to ensure that the educational activities offered are adapted to the needs of the prisoners.

Education for prisoners is thus acknowledged as a rehabilitating factor, and put into practice by actively involving prisoners in planning their educational work, offering them a wide range of options, and enabling them when possible to have day release privileges and leave the premises to attend school. Education is also offered at the 37 Danish remand centers (as prison education for individuals in remand) and at eight open and five closed prisons (as prison education for convicted prisoners).

\subsubsection{Description of prison education}

Danish prisoners are required to work. This requirement can be satisfied in various ways, including participation in prison education. Prisoners make their own choices, of course often under the influence and motivation of the staff. Prisoners have many good reasons to become involved in educational activities. Some have drawn up very detailed "sentence plans" which include education, and are very goal-oriented. Others may choose to attend school because they think it is a good idea but with no specific plans of what they would like to do with a better education - 
although such plans may materialize as they study. There are also prisoners who elect education as the least distasteful of the various activities being offered to them by the prison.

\section{Recruitment of prison teachers}

In order to be employed as a prison teacher, an applicant must be a qualified teacher with a degree from a college of education or the equivalent. Experience of adult education is often an advantage, particularly from working with adults in a social service capacity, since being a prison teacher required social commitment as well as educational skills.

\section{The role of the teacher}

A higher degree of social commitment is often required of the prison teacher than of many other teachers at adult education institutions, because prison teachers tend to have other functions beyond simply being classroom teachers. A "holistic" interest in the individual as a person rather than simply as a student or course participant is a desirable characteristic.

\section{Case management work}

Teachers are expected to attend regular wing meetings where issues relating to individual prisoners' sentence serving are discussed, including leave, day release privileges, transfer and release on parole. Teachers are also very much involved in working on the "sentence plan", which extends beyond release:

The institution shall also, in cooperation with the prisoner himself, draw up a plan ("sentence plan") as soon as possible after the prisoner begins to serve his or her sentence, to cover both the sentence enforcement time and the time after release. This plan is to be regularly revised to be kept relevant to the sentence serving and, if necessary, be adapted to changes in the prisoner's situation.

\section{Employment of teachers directly or imported teaching}

The Prison and Probation Service has traditionally employed prison teachers whose duties include both teaching and participation in case management. In May 2008, there were approximately 83 prison teachers/specialist teachers including administrators, with responsibility for day-to-day management, adaptation and phasing out of prison education. 
In addition to the staff teachers mentioned above, there are also a large number of teachers working in prisons on an hourly basis. Part-time teachers in remand centers and prisons amount to the equivalent of 18 additional full-time positions. In addition, there are ten specialist teachers, who teach prisoners either on their free time or at the workshops.

\subsubsection{Education for individuals held in remand}

There are 37 remand centers in Denmark, usually in the main provincial towns. The largest is the Copenhagen remand center, with a capacity of 523 places. Three of the closed prisons also have "remand halls".

Day-to-day management of each provincial remand center is in the hands of a director, who is responsible to the local chief of police, with the exception of the Copenhagen remand center, which is run like a state prison, with a prison Governor and deputy director. The school at the Copenhagen remand center is also structured along the same lines as the schools at the state prisons, with the status of a local adult education center.

In addition to individuals in remand, these centers house convicted prisoners serving short terms and convicted prisoners pending transfer to state prisons. The duration of a stay at a remand center may vary greatly from a few days to many months.

Many of the older, smaller remand centers have no proper educational facilities. This means that teaching often has to take place in the prisoner's rooms, and is therefore on a one-to-one basis. Sometimes this is advantageous, but often it means missing out on the dynamic, social side of the classroom situation. Newer remand centers have much better facilities for education.

The larger remand centers have staff teachers, while the smaller ones use teachers hired on an hourly basis. Individuals being held in remand have shown very positive interest in education. This can, of course, be seen as a desire on the part of prisoners to show that they are on their best behavior, but the need for a social context is probably also a major factor. Individuals in remand often sit locked up for most of the day, and their only contact is with the prison officers when they need something. For this reason, education provides individuals in remand with some relief. In addition to learning, they also have the opportunity to talk with someone they do not consider a member of the remand center staff. 
The educational options offered at remand centers are primarily for individuals in remand who need basic education in Danish and mathematics. In addition to learning these subjects, they also gain motivation to continue their education when they go on to serve their sentences. When the teacher comes from one of the state prisons, it becomes particularly natural to ensure that the individual goes on with an educational program after being transferred, thanks both to the fact that the teacher will have known them personally in advance, and to the fact that the teacher can prepare the individual with information about the school at the state prison where he or she is employed.

Some individuals in remand are able to take a correspondence course or pursue some other kind of independent study under the tutoring of the remand center teacher. However, it requires great mental fortitude to be able to concentrate on independent studies in this phase of incarceration, often experienced as the most difficult.

\subsubsection{Education for convicted prisoners}

Prison education is available in all Danish prisons where convicted prisoners are serving sentences. In both open and closed prisons, day-to-day administration is carried out by a director of prison activities in consultation with a trained director of education, deputy director of educational activities (with a degree from a college of education). The course modules offered generally follow the same pattern of start and end dates as for state adult education in the community.

\section{Open prisons}

Prisoners in open prisons participate, as a rule, in educational programs in the community on the basis of day release privileges. Such privileges are generally associated with the last part of a prison sentence, and so prison education on site is still needed for the early part of the sentence. Thus even open prisons have staff teachers and/or hourly teachers working on the premises. This education takes the individual prisoner's abilities as its point of departure. This means that the open prisons therefore offer remedial education and short introductory courses as well as both on site and external examinations organized in collaboration with the local adult education center. 
In the last few years, a number of open prisons have introduced mixed open and closed cell halls. These halls tend to have a full-time teacher on staff. Prisoners in these halls have the same possibility of obtaining day release privileges for work or school as other prisoners in open prisons, unless there is an evident risk of drink or drug abuse.

\section{Internet-based education}

Most educational programs now consider ICT, particularly use of the Internet, as an essential tool. For prison education, there is an inherent contradiction between the need of the educators to use the Internet as an integral aspect of teaching, and the reservations of the administration in terms of the risk of abuse of the system and other associated security risks.

On the basis of the recommendations of a working party on educational issues, in 2000 the Prisons and Probation Directorate adopted a decision that on-line Internet access should be set up in the educational facilities at open prisons (In Danish. English equivalent title: On use of the Internet in education, Prisons and Probation Service Directorate, 2000). This approval, however, had a number of conditions attached relating to security, with a view to avoiding abuse of the system.

Of course, the acceptance of the use of the Internet in teaching in open prisons must be seen in light of the opportunities for prisoners to exercise day release privileges in order to attend educational institutions where there is substantial need to use the Internet, not only in the classroom situation but also in order to complete assignments. This being the case, some prisoners in open prisons have been given permission - usually in conjunction with schooling - to have Internet access in their own rooms. Such permission is now also granted if the prisoner wishes to take a correspondence or distance course in the form of guided independent study in a subject the prison school is unable to offer On Prisoners' Right to Bring with them Possess and Dispose of their own Property and Money in the Institutions of the Prison and Probation Service (Property Order, no. 735, 25 June 2007).

The multiannual agreement to which the Prison and Probation Service is a party covering 2008-2011, funds have been earmarked for the establishment of computer networks to be set up in purpose-built facilities at 
open prisons, closed prisons and remand centers, on the condition that Internet access is properly installed from a security point of view.

\section{Closed prisons}

With one single exception, all the closed prisons in Denmark were constructed in the late nineteenth and early twentieth centuries.

This means that the physical facilities in many prison schools are far below the level required in the twenty-first century in terms of the classrooms and their furnishings, group rooms, facilities for other kinds of study (tutoring), ICT and audio visual aids. Prison schools, therefore, may find it difficult to offer their students the same range of options they would have outside the prison. Security considerations in closed prisons also affect the everyday running of prison schools, of course, and are frequently an inhibiting factor in terms of adapting education to the prisoner's needs, such as, access to the Internet, which is a prerequisite for most educational programs today, including programs offered by prison schools (adult education, upper secondary education, etc.). The prison schools have to find alternative, often very unusual, solutions, which may weaken the position of prisoners in anticipation of their continued education.

\section{Educational options}

All closed prisons offer comprehensive adult education, equivalent to primary and lower secondary school (pursuant to the Act on General Adult Education). The courses offered always include the basics of Danish, mathematics and English. Some prisons offer other subjects as well.

The courses are concluded with tests developed and checked by the Ministry of Education, and corrected by censors appointed by them, or censors from other adult education centers. Completed basic adult education makes a person eligible for a large number of vocational and educational programs at upper secondary level.

The Act on Preparatory Adult Education from 2000 has resulted in new possibilities for prison schools and prisoners. Education may be offered in two subjects - reading and mathematics - at two and four levels, respectively, in short intensive courses (60-80 teaching hours). The courses are concluded with national comprehensive tests. Their aim is to raise the functional level of the participants in the two subject areas so that they will be able to satisfy the basic requirements of the labor market. 
Preparatory adult education under the auspices of the Prison and Probation Service was evaluated in 2004 (Preparatory Adult Education in the Prisons, by Mette Lindgaard Adamsen in cooperation with Kaj Raundrup and Irene Olsen).

Remedial teaching (for individuals with dyslexia)

Numerous studies have shown that many boys and men have literacy difficulties. This applies not least to male prisoners who, for various reasons, often have inadequate educational backgrounds. There are also prisoners who have been diagnosed as dyslexic. It is a major challenge for prison schools to interest these individuals in school and, not least, to keep them attending. All Danish prisons have allocated teacher's working hours to dealing with the problem, although different strategies are being used.

There are also numerous examples of prisoners whose prison education began as remedial work and who have gone on to remarkably high levels.

\section{Upper secondary school adult education diploma}

An upper secondary school adult education diploma entitles the holder to apply for higher education. This diploma program can be completed by prisoners in the form of independent study with tutoring or as study groups. Very few prisoners manage to complete the program while serving their sentences, but many of them continue first on day release privileges from the prisons and then, after release, at adult education centers in the community.

\section{Education for foreigners}

Foreigners comprise an increasingly large proportion of the prison population, resulting in a growing number of prisoners with special needs for courses in Danish. Some foreigners in Danish prisons have never lived in Danish society. Others have taken the occasional language course or only have basic education in Danish. All these considerations are taken into account, of course, when prison schools adjust their course options to the relevant groups of prisoners. Some of the foreigners attend remedial education with Danish prisoners. Others attend courses in Danish for foreigners, like those offered by language schools. Experience indicates that 
some foreign prisoners go on to compulsory or even upper secondary school.

In 2005, a working party submitted an opinion paper on ethnic minorities in the Prison and Probation Service. Prisoners with non-Danish ethnic backgrounds comprised, respectively, $23 \%$ of the population of open and closed prisons and remand centers $12 \%$ of the individuals in the other facilities of Prison and Probation Service.

The working party submitted recommendations in a number of areas with a view to supporting and motivating prisoners of other ethnic origin than Danish. The recommendations included initiatives for these prisoners and clients concerning:

- Educational activities - including the possible development of special cognitive behavioral treatment programs.

- Work - including the possible development of special projects oriented towards the labor market.

- Expansion of the existing mentoring program.

- Treatment - providing more motivation than at present for prisoners from ethnic minority backgrounds to participate in treatment programs.

- Free time - development of more and more focused recreational activities.

- For prisoners pending expulsion, it was recommended that their opportunities for repatriation be improved.

One of the measures for which the Prison and Probation Service has been allocated funding on the basis of these recommendations is a project known as "MÅL", with a special focus on helping young prisoners of non-Danish ethnic backgrounds prepare for their return to the community. "MÅL" stands for:

- Motivation: the desire to change.

- Alertness: attention to themselves and others.

- Leadership: taking our lives into our own hands.

The aim of the project was to provide individual help to young offenders from ethnic backgrounds other than Danish to retain their cognitive skills 
and to further develop their competence for action, so as to achieve a life without crime. To be eligible to participate in MÅL, young prisoners between the ages of 15 and 25 have to have participated in a cognitive behavioral treatment program.

\section{Independent study}

There will always be prisoners with particular abilities and needs regarding education, which the prison school is unable to satisfy immediately. These individuals can be offered an independent study option after concrete, educational assessment and in collaboration with study counselors from educational institutions outside the prison. Experience indicates that a great deal of discipline is required by a prisoner to complete independent studies, and that not all subjects are suitable. Usually, independent study is realistic for further and higher education. It is followed up with day release privileges for study at the educational institution that provided the independent study material.

\section{Vocational training}

In the past, prisons have been able to offer individually-adapted vocational programs. However, owing to technological developments, prisons are now unable to satisfy the necessary requirements. If a prisoner wishes to pursue a vocational program while serving his or her sentence, this has to be done in cooperation with an industry outside the prison. Often it is possible for the prisoner to complete the first parts of the program at the prison workshop and later have day release privileges to work in the industry in question.

In 2007, a pilot project began between one open prison - Statsfængslet Møgelkær - and a vocational school located nearby, with a view to improving prisoners' qualifications so they will have better opportunities on the labor market after release. In the "Møgelkær model" - later known as VOKS - (Vejledning og Kompetence System, meaning Guidance and Competence System) prisoners receive detailed counseling and competence testing before beginning a basic vocational training program either at a prison workshop or at the community vocational school near the prison.

VOKS was evaluated at the end of 2007. The prison workshops were mainly used, and the supervisor of the prison workshop was also the director of the vocational program. When the prison did not have the neces- 
sary facilities (machinery), the training took place at the vocational school on the basis of a contract. Prison workshop supervisors needing further training in education were offered courses at the vocational school as well.

On the basis of the positive experience from the first year of using the VOKS model, the Prison and Probation Service decided to expand implementation of VOKS to other prisons.

\section{Labor market training schemes}

At one closed prison, short courses in welding are offered by the labor market training authorities. These courses follow a credit-giving syllabus and are concluded with an examination. The courses are between one and three weeks in length. They are held at a purpose-built "workshop school”, and run by specialist teachers.

Prisoners with day release privileges can attend a broad range of labor market training courses outside the prisons.

\section{Summer activities}

Prison schools follow the same school terms as the state school system, with vacation periods including a six or seven week summer holiday. Many prison schools offer alternative activities for prisoners during these periods, mainly sports activities run by the prison teachers in collaboration with teachers from the outside, employed on an hourly basis. There are also courses for prisoners with an interest in the creative arts.

\subsubsection{The transition from prison education to education in the state school system}

\section{Day release privileges}

Day release privileges for school or work are important elements of the efforts being made to provide smoother transitions from prison to release. The time frame for permission to have day release privileges is described in detail in the Act on Enforcement of Sentences, etc. According to these stipulations, a prisoner may be allowed day release privileges when the purpose is clearly established as being for education, work, treatment or family needs or other personal consideration. 
One of the main justifications for the introduction of day release privileges is the importance of encouraging prisoners to develop a social identity, for instance by studying alongside other students. However, the subject matter is restricted, and the subject must be one the individual has both the personal and the educational ability to complete.

A prerequisite for all kinds of day release privileges is that the institution receiving the prisoner makes a staff member available to supervise the prisoner to the required extent.

\section{Cooperative education}

A study of the educational environment in open and closed prisons indicates that cooperative education is the main factor affecting recidivism (Andersen, S.E. Holstein, Bjørn E., and Skadhauge, Flemming B. English title: The Educational Setting in Open and Closed Prisons, 1979). Cooperative education in conjunction with day release privileges for schooling outside the prison led to better self-esteem, confidence in the future and relieved the boredom of sitting in a prison room. One of the main elements of cooperative education is "learning something about yourself while you are in prison by attending school”.

Prisoners in the closed system felt primarily like prisoners even while they were in the classroom. Only rarely did they glimpse themselves as students, or as individuals wanting to get an education. They felt there was no difference between themselves and the other prisoners either when they were in the classroom or when they were in the cell hall, in spite of the assurance from the prison teachers that they were receiving quite individualized teaching. The prison staff - in both closed and open prisons - were quick to point out that they did not distinguish in other prison-related respects between prisoners attending school and other prisoners.

Prisoners in open prisons had a very different situation. They attended educational institutions where they were treated exclusively as students. They experienced personally that they were treated exactly the same as the other students by their teachers. "At home" in the prison, on the other hand, they felt like nothing but prisoners and, as mentioned above, they were treated by the prison staff in precisely the same way as all other prisoners. 


\section{Stationing}

Prisoners who satisfy the requirements for day release privileges can also be transferred to halfway houses: (Executive Order on Leave for Prisoners Serving a Sentence of Imprisonment or Safe Custody in the Institutions of the Prison and Probation Service (Leave Order, 13 September 2007)).

A prisoner may be stationed at a halfway house for up to four weeks of the last part of his or her sentence enforcement or, when special circumstances call for it, for up to 3 months. If the offender is under the age of 21 at the beginning of his or her sentence serving, more time may be spent in a halfway house when special circumstances call for it. While stationed at a halfway house, a prisoner is subject to the particular rules and regulations applicable to that establishment.

\section{Electronic supervision (electronic shackles)}

In 2005, some prisoners were given the option of finishing serving their sentences at home, with intensive surveillance and supervision. Initially, only individuals convicted of violation of the Road Traffic Act had this opportunity. In July 2008 the arrangements were extended to apply to all prisoners serving sentences of three months or less. Prisoners may only be included if their housing and work situations are in order. Consequently, for example, prisoners participating in educational activities may continue to do so even while serving their sentence with electronic shackles.

\subsubsection{Financial aspects}

The Ministry of Justice is responsible for financing all prison education. Allocations are disbursed to the individual correctional institutions via the Directorate of the Prison and Probation Service.

\subsection{The results of prison education}

\subsubsection{Quantitative results}

Number of students

There are 460 full-time educational places in Danish prisons, although more prisoners attend educational activities, since 45 of the equivalent of 
full-time places are occupied by prisoners studying part-time. This figure does not include individuals in remand, who usually only have a few hours of education per week. Approximately 100 prisoners per day have day release privileges for education. (See section 2.3.4.)

According to the report by Peter Koudahl (2007), the number of places for vocational training in Danish prisons is 75.

The figure today is substantially higher and expected to rise as the VOKS - model is implemented (see Vocational Training in section 2.3.3).

\section{Dropout rates}

There are no statistics regarding dropout rates from prison schools. Students who choose to terminate a course often do so because of lack of motivation. Prisoners can also be suspended from education if substance abuse or disciplinary problems arise. The general impression is that dropout rates from prison schools are not higher than from other adult education institutions.

\section{Number of tests/examinations}

Current experience regarding prisoners who take tests and examinations indicates that many prisoners choose not to complete their courses if it means taking an exam. The report from the Ministry of Education referred to above states that there is a 32\% general dropout rate in Denmark for students who take a whole course of study but not the final exam, a figure the Ministry finds excessive. The dropout rate does not seem to be higher in prisons, if anything lower, but a large number of prisoners still decide at the last moment not to take a final test or examination.

For education provided pursuant to the Preparatory Adult Education Act, which came into force in 2001, the rate of prisoners completing the final test or examination has increased dramatically. It is still too early to say whether this is attributable to the fact that the only grades given for education pursuant to this Act are pass and fail.

The Prison and Probation Service has no statistics regarding tests or examinations taken by prisoners who attend school outside the prison on day release, and who continue their education after release from prison. 


\subsubsection{Qualitative results}

It is difficult to pinpoint the qualitative results of prison education. Although prisoners completing their final exams do get grades reflecting their knowledge of the subjects, these grades cannot tell us whether the student is able to apply that subject knowledge in other contexts. The general impression is that attending school improves prisoners' social skills and that they learn about society, with a long-term effect of discouraging recidivism. There are research results showing that schooling on the basis of day release privileges has a recidivism-reducing effect. (Andersen, Holstein, and Skadhauge 1979. In Danish. English equivalent title: Research report 10 - On the educational settings in open and closed prisons). This study concludes that there is a clear correlation between day release privileges and recidivism - the longer the period of day release privileges, the less recidivism.

In a report on prisoners in Denmark, (Koudahl, P. In Danish. English equivalent title: Education and educational preferences). published in April 2007, 69.5\% of all the prisoners in Danish prisons at the time (a total of 3,461) answered a questionnaire containing factual information regarding their age, sex, and the crime for which they had been convicted, as well as information regarding their educational background and what types of educational activities they would like to participate in while serving their sentence. The response rates should be considered in light of the fact that these institutions have many prisoners who are not Danish speaking, many prisoners serving short sentences, and many prisoners whose sentences include an expulsion order. Thus one can assume that the levels of motivation of these prisoners are low.

One of the findings from the questionnaire survey was that more than $20 \%$ of the prisoners participate in some educational activity while serving their sentence. The report concludes with a number of recommendations on the basis of the findings, the main ones of which are given below. The recommendations were: that improvements are needed concerning information to prisoners about the educational opportunities available to them while in prison, that initiatives must be taken to better enable prisoners to begin or even complete a vocational training program while in prison, that extra resources should be devoted to ensuring that all prisoners - with particular emphasis on young offenders - be given the opportunity to study to a level equivalent to graduation from compulsory 
school, that educational activities be developed to improve the selfconfidence of prisoners, motivating them to go on to further education and, finally, that prison teachers be given full opportunity to regularly raise their own levels of competence and qualification.

In light of the findings in this report, the Prison and Probation Service has requested prisons to increase their focus on various areas, including how information is given to prisoners concerning educational opportunities, more attention to prisoners in the age group 18-25 who have not completed compulsory level education, offering more vocational training, and stimulating and motivating prisoners who participate in educational activities to also take the relevant examinations.

Peter Koudahl, The Danish School of Education, Aarhus University, is also currently conducting a pedagogical follow up to another report also published in April 2007, entitled "Indsatte i danske fængsler, uddannelse og uddannelsesønsker” (in Danish. English equivalent title: Danish prisoners: education and educational preferences). The objectives of this qualitative study are to focus on how prisoners (at prisons and remand centers) experience their prison educational activities and why only $20 \%$ of the prisoners participate at all while serving their sentences. The aim of the (interview) study is to contribute to developing future measures enabling prison education to satisfy prisoners' needs to an even greater extent than today.

\subsubsection{Greenland and the Færoe islands}

Denmark has the overall responsibility for judicial matters in Greenland and the Færoe islands. Greenland has a Criminal Act rather than a Prisoners' Act, where the framework for the correction of individuals who violate the law is set out. In the Færoe Islands, the regulations in the older Danish Criminal Code are followed, as the Act on Enforcement of Sentences, etc. has not yet come into force there.

The total number of places in the three open prisons in Greenland is 93. In the Færoe Islands there is a remand center with 14 places. Prisoners sentenced to sanctions of long duration are transferred to prisons in Denmark.

In Greenland, day release privileges for schooling outside the prison are more the rule than the exception. One of the prisons offers 20 hours of 
prison education per week. The remand center in the Færoe Islands offers 4-6 hours of prison education per week.

The Danish parliament is in the process of working out a draft bill covering, for example, the construction of one closed prison in Greenland, which only has open prisons to date. The main reason for doing so is to respond to the request of prisoners from Greenland, now serving their sentences in the Herstedvester prison in Denmark, to be able to serve their sentences in Greenland. The draft bill has been drawn up on the basis of a government commission report from the Greenland Judiciary Commission (Den grønlandske Retsvcesenskommission).

The Prison and Probation Service has initiated a study intended to prepare the decision concerning how much is to be allocated for this project. A project group has also been appointed to analyze the detailed requirements for such an institution, which would have both closed, open, and semi-closed places. It is estimated that the construction work on the closed prison will be completed by 1 January 2013 . 



\section{Finland}

by Vuokko Karsikas, Kirsti Kuivajärvi, and Marianne Mäki

\subsection{History}

Education has been provided for all children in Finland since 1898. According to the constitution, enacted in 1919, the public administration is obligated to organize or fund general education, vocational training and higher education. In 1921, legislation on compulsory education saw the light of day. Later, the system underwent a number of reforms, and compulsory education was extended to six years. After four years of primary education, some pupils were selected to go on to five-year secondary school and threeyear upper secondary school. In the 1970s, primary and secondary school were merged, and nine years of compulsory education introduced under the designation of “comprehensive school”. (www.minedu.fi).

Religious education central to the reform of the penal system

According to the Philadelphia model, central to the nineteenth century reform of the penal system, prisoners could be fostered to become honest working people and upstanding citizens through discipline, compulsory work and religious education. The absence of religious and ethical upbringing was considered a breeding ground for criminality. The use of imprisonment as the only sanction required the building of new prisons and a more efficacious system for enforcement of sentences. A progressive system was introduced, by which prisoners who demonstrated good behavior while serving their sentences gained more and more privileges, in accordance with a strict structure. Early in the sentence serving period, it was considered important to keep prisoners isolated in solitary confinement, in 
order to eliminate the bad influence these individuals were considered to have on each other. As a rule, convicted prisoners came from the lower social classes, which meant that they were often illiterate. The general opinion was that they needed, above all, to gain the skills they required to function as citizens, as well as vocational training (Kallinen, 1982. In Finnish. English equivalent title: Educating and centralizing).

Prior to the mid-nineteenth century, the only prison education was provided by the prison chaplain, in addition to his other duties. The Act on Enforcement of Sentences, adopted in 1866, stipulated that prisoners were to receive elementary education. However, as there was a shortage of teachers, this gave rise to practical difficulties. Classrooms were crowded and sentences short (Kallinen, 1982). Beginning in 1889, prisoners were obliged to work while serving their sentences, and education was not set on equal terms with work. Prisoners sentenced to a house of correction or a prison for more than three months were to receive religious education or education in other school subjects. In addition, they were to receive training in a vocation the prison found suitable, preferably according to the individual prisoner's abilities or the job he or she might be expected to hold after release. Prisoners who were illiterate or over the age of 40 were not subject to compulsory education. This regulation remained unchanged until the reform in 1975. The Prison Administration Decrees of 1925 and 1936 established that the objective of education was to increase prisoners' knowledge and awaken their interest in uplifting reading and individual studies.

\section{Vocational training for young prisoners began in the 1940s}

During the 1940s, special attention was paid to providing young offenders with training in a vocation that corresponded to their abilities and talents. Young prisoners were also subject to the obligation to work, although those who had not completed comprehensive school were sent to school. All prisoners were also given general education in civics (Mohell 2002).

The Act on Vocational Training in Institutions entered into force in 1942. The new law made it possible to establish vocational training in prison. A mechanical engineering workshop was opened in 1948 at the juvenile unit of the Riihimäki Central Prison. The school provided vocational training mainly in metalwork until the 1960s, when a program for automotive and engine technology was set up. (Hartoneva \& Kuivajärvi 
\& Muilu 1999, In Finnish. English equivalent title: The vocational Training of Prisoners 1948-1997).

Normalization in the 1970 s

In the 1970s, the general trend in society was to expand adult education. In 1978, the Finnish government adopted a decision to plan and develop a system for adult education based on the principle of lifelong learning and regular returns to the classroom. A flexible educational system was established, which provided citizens with access to suitable education throughout their lifetimes.

The orientation of criminal policy also reflected the economic, political, and spiritual structures of society. A period of reform of the Prison Service began. The idea that prisoners could be "cured" was abandoned, and focus shifted to determining how a prisoner could be best integrated into a pluralistic society (Numminen 1995). (In Finnish. English equivalent title: The development of education in Huittinen Open Prison in 1935-1995).

In 1975 there was a comprehensive reform of the enforcement of prison sentences in Finland. This was the end of the penitentiary and progressive system, as well as the authoritarian principles that underpinned them. The new ambition was to modernize and develop the system of work, educational options, vocational training, and rehabilitation. In accordance with the principle of normalization, these functions were to reflect society at large.

The new legislation retained the principle by which prisoners were obliged to work, adding the obligation to participate in vocational training. Prisons were to offer suitable vocational training and any other teaching they found necessary. A government bill (1972) stressed that instead of the previous emphasis on elementary education in prison schooling, the emphasis was to be shifted to vocational training.

It was argued that various other countries had found that providing prisoners with vocational training was one of the most effective means of reducing recidivism. Consequently, it was proposed that vocational training should be offered on regular working hours. The bill also stipulated that it would be made possible for prisoners to work and study outside the prison. 
A government commission on prison regulations proposed in 1975 that the regulations applying to education throughout society, including the quality of education, course options and textbooks and other pedagogical aids, should also apply to prison education (In Finnish. English equivalent title: Prison regulation commission report). Since 1985, it has been possible to arrange general educational courses for prisoners in collaboration with adult upper secondary schools.

\subsection{Legislation and regulatory documents}

The Prison Service and the Probation Service are part of the criminal sanctions system of Finland. Their common goals are to contribute to security in society by maintaining a lawful and safe system of enforcement of sentences, and to assist in reducing recidivism and preventing the development of social exclusion, which promotes criminality. According to the Act on Imprisonment (767/2005), the goal of the enforcement of prison sentences is to increase the prisoners' abilities to adopt a life without crime by promoting their life control skills and reintegration into society as well as to prevent recidivism during the term of the sentence. Sentences are enforced so that the enforcement is safe for society, the staff and the prisoner. The prison conditions correspond to the prevailing living conditions in the society as far as possible, and the prisoners are able to maintain their health and functioning capacity. The enforcement of a sentence may not restrict the rights or circumstances of prisoners in any other manner than that provided in the law or necessary owing to the punishment itself.

The basic principles of the work of the Prison Service and the Probation Service are justness and respect for human dignity. The work is also guided by the notion of the potential of an individual to change and grow.

The commitment to these values means:

- safeguarding the basic rights and human rights;

- treating convicts humanely, appropriately and equally; 
- observing the legality of all activities and complying with justice and fairness; and

- carrying out enforcement in a manner that supports the convicts' personal growth and development as well as their intentions to live without crime.

\section{Regulations regarding education}

Prison education is governed by the general statues on education. The Finnish constitution establishes the universal right to basic education free of charge. According to the constitution, every citizen has an established, subjective right to basic education at no cost to him or herself. The right to other forms of education is not correspondingly established as a subjective right. However, this stipulation obligates society to ensure that citizens of lesser means are actually able to receive basic education.

\section{Basic education}

Education is compulsory for children from the year they turn 7 until approximately the age of 17 if they have not previously completed the curriculum for comprehensive school (primary and lower secondary). Municipalities must offer basic education to children of compulsory school age living in the municipal catchment area. Very few prisoners are of compulsory school age, owing to the fact that unless there are very special circumstances, offenders under the age of 18 are not sentenced to serve an unconditional prison sentence. Some 6.3\% of Finnish prisoners have not completed comprehensive school. Prison education is organized as adult education, because adult education methods are generally best suited to the education of prisoners. Both basic and upper secondary education are usually offered under the auspices of adult education upper secondary schools, or state upper secondary schools with special programs for adults.

The Ministry of Education may authorize a municipality, a group of merged municipalities, or a registered association or foundation to offer upper secondary education. This education may be offered partly or entirely as independent study, classroom education, or distance study. Course or subcourse examinations may be arranged under the auspices of an approved educational institution. 


\section{Vocational training}

The Ministry of Education grants authorization to the vocational training providers to arrange vocational training under the educational administration. The authorization includes, among other things, the possible fields of study, the maximum student number, and the special educational duties. Education providers plan the supply of study subjects within the scope of their authorization and answer for the contents of their curricula, which are based on national core curricula. The vocational training arranged for prisoners has educational goals and, irrespective of venue, education has to be arranged so that it is consistent with the goals concerning both its quality and content. Vocational qualifications have been reformed so that their goals and content better correspond to the skill requirements of working life.

An individual who has completed the basic education syllabus or corresponding former syllabus or who has adequate aptitude to complete the education, can be accepted to education leading to a vocational qualification. A qualification can be obtained in form of education in an educational institution, a competence-based qualification, or apprenticeship training. A qualification takes approximately two to four years to complete. The time required for completing a qualification depends on the independent study path, prior studies, and possible work experience. All vocational upper secondary qualifications include on-the-job learning, which means learning in a genuine working environment at a workplace. Prison workshops provide a good environment for on-the-job learning.

Apprenticeship training is defined as contract-based vocational studies carried out at a workplace and implemented as practical work, combined with theoretical studies. Apprenticeship training may be arranged for basic and further vocational training for young people or for adults. Local management and supervision of the training is the responsibility of the municipalities. Apprenticeship training arranged for prisoners is not based on an employment contract and thus the training can differ from the provisions concerning, for example, the employment contract, the working hours, and the annual holiday.

Adult students can complete basic education, general upper secondary school and vocational upper secondary education at an upper secondary school or a vocational institution for adults or a folk high school. Vocational adult education is divided into vocational upper secondary educa- 
tion and training and continuing training. Vocational adult education is carried out as training for competence-based qualifications. A qualification can be completed one part at a time. Vocational skills are demonstrated through practical assignments, which may be complemented with oral, written, or other assignments if necessary. The content and duration of the training are determined based on prior education, competence, and work experience. In Finland, adult education is also offered under the auspices of the employment services and its main aim is to improve adults' vocational skills and thus their ability to get a job or to be kept on at their workplace, as well as to promote access to skilled manpower on the labor market. Today, employment training is only a small part of prison education, although it was a very important aspect of prison education in the 1970s and 80s.

\section{Special provisions regarding education for prisoners}

According to the Act on Imprisonment, prisoners are obliged to participate in activities arranged or approved by the prison on the confirmed working and activity hours (duty to participate). The purpose of activities arranged or approved by the prison is to promote the prisoners' placement in society. The activities include work, education, or other activities promoting the abilities of the prisoners. During the fixed working or activity hours, prisoners have to be provided with the possibility to fulfill their duty to participate in an activity promoting the implementation of the sentence. This general obligation to participate in activities applies to both open and closed prisons alike. Prisoners can be fully or partly exempted from the obligation to participate if it is required for reasons of health, functioning capacity or age.

Prisoners may participate in training arranged in the prison or outside it. Prisoners who have not completed compulsory comprehensive (primary and lower secondary) education have to be provided with the opportunity to do so. The studies of prisoners have to be guided and supported and the progress of their studies has to be monitored. The certificate issued for the studies must not indicate that the studies have taken place in prison. 


\section{Remand prisoners}

In Finland, remand prisoners are held in ordinary prisons, or in other facilities approved by the Ministry of Justice. Remand facilities are not part of the prison system in Finland, but of the Police Administration. This report only takes into account education given to individuals held in remand in ordinary prisons. Remand prisoners are not obligated to work or to participate in any activities. However, should they wish to take part in an activity, they are to be given the opportunity to do so if possible.

\section{Developmental goals in educational policy}

Promoting equality and preventing social exclusion have long been the central goals of the education policy of Finland. In a Government report on educational policy submitted to the Parliament in April 2006, the goal was to add equality and developments of positive attitudes towards education, and to increase the opportunities for underrepresented groups in adult education. (In Finnish: English equivalent title: Ministerial report to the Parliament regarding educational policy 2006:24)

This plan is based on the goals of education and science policy as stated in the government policy. One of the focus points of the development is to ensure the availability of skilled manpower, for which reason more emphasis is put on actions to speed up completion, improve the correspondence between education and the labor market, and reduce the number of people without a vocational training. The possibilities of completing vocational upper secondary qualifications are diversified so that, in the future, a qualification leading to professional competence required by the labor market will be able to be completed one part at a time and the opportunities to improve one's vocational skills while studying will be extended.

The development plan for education and research for the period 20072012 also includes a policy concerning the vocational training of prisoners. The aim is to develop the vocational training of prisoners by enhancing the quantity and variety of vocational training offered to prisoners and to establish cooperation with the providers of vocational training involved in prison education when arranging prison educational activities. 


\section{Reformed imprisonment legislation and organizational structure}

The new legislation concerning the enforcement of sentences entered into force on 1 October 2006. At the same time, the structure of the Prison Service was reformed and, hence, five district prisons and a national health care unit, "the Prison Health Care Services" were established. The new legislation required new structures and methods. Some of the jurisdiction was transferred from the Criminal Sanctions Agency to the prison districts. The district prisons consist of both closed and open prisons, as well as an assessment and allocation unit, which is in charge of the sentence plans prepared for prisoners, and the allocation of prisoners within the district.

Imprisonment is seen as a planned process, which is based on a sentence plan prepared by the assessment and allocation unit. The sentence plan consists of an individual risk and needs assessment and an evaluation of the prisoner's working and functioning capacities. The purpose of activities arranged or approved by the prison is to promote the prisoners' return to society by:

- promoting their abilities to live without crime,

- maintaining and improving their professional skills and competence as well as their working and functioning capacities, and

- supporting a substance-free lifestyle.

In the first phase of planning a sentence term, prisoners' risks of recidivism are evaluated and their criminogenic needs determined with the help of a risk and needs assessment. Influencing the individual risk factors forms the basis for arranging activities in accordance with the sentence plan for each prisoner. The aim is to affect criminal behavior with the help of rehabilitation programs, which teach prisoners new skills that improve their coping abilities. Treatment programs for substance abuse and criminal behavior need to be supported by the normal activities in society, such as work and education. Education promotes prisoners' reintegration into society and improves their abilities to cope. Obtaining education has an indirect connection to recidivism. Research indicates that lack of education or professional skill is a criminogenic factor (see Eikeland, Manger, and Asbjørnsen, eds., 2008). 
The realization of the goals of the sentence plan is evaluated regularly. The main principle is that the goals can only be achieved with the help of activities arranged in prison. In the release phase, the realization of the goals of the sentence plan is reviewed, the prisoner's aptitude to cope in society is assessed, and a release plan is drawn up. The release plan is based on the assessment of the need for services. Prisoners released on parole will also receive a supervision plan prepared by the Probation Service. Prisoners' reintegration into society is promoted by preparing further actions in cooperation with different interest groups, such as municipal social welfare authorities, mental health services, health care services, employment services, and education providers. The prisoner's situation and need of support services, for example if there is need for education or if the prisoner has already been accepted for education, are assessed when preparing the release plan.

The Ministry of Justice initiated a development project concerning the prison services and, in June 2007, commissioned development of the organization of the criminal sanctions field. The development project was launched in November 2007. The project is divided into two sections: the first section consists of guidance and leadership and the second of productivity and service. The aim is to form a stable foundation for an effective sentence enforcement organization, to provide services, and to create an overall organization for the criminal sanctions field. The administrations of the Prison Service and the Probation Service will be merged from 1 January 2010.

\subsection{Description of prison education and its relationship to the state education system}

\subsubsection{Description of prison education and its relationship to society at large}

\section{Objectives of prison education}

Sanctions are to be enforced so as to promote, if possible, or at least not to exacerbate, the adaptation of the prisoner to society. The only deprivation is the deprivation of liberty. Prison education can promote prisoners' individual growth and development, improve their skills concerning coping in society, and assist them in living a life free from crime. Prison 
education is an activity in line with the principle of normalization, and with the same objectives as all adult education.

\section{Organization}

In Finland, most prison education is organized by educational institutions under the administrative management of the educational authorities. Teachers are employed by the educational institution. In 2007, a total of 39 educational institutions arranged teaching in prison facilities. The institutions include eight upper secondary schools for adults, 19 vocational adult education centers, eight institutions for vocational training, and four vocational special education institutions. Three prisons have qualified staff teachers who are employed by the prison. In these prisons, education is also organized in cooperation with and under the supervision of educational institutions. In addition, a number of prisoners from open prisons have day release privileges to study outside the prison at various educational institutions.

\section{Prison education and its relationship to society at large}

Prison education is basically organized as part of the regular education system, which means that it stands in a close relationship to society at large. However, some courses are organized by members of the prison staff in cooperation with the education institutions.

As a rule, prison education follows regular school curricula. Certificates and grades issued correspond to those issued outside prisons. Studies pursued by prisoners will be credit-giving at schools they attend after release. Certificates of course completion are issued by the cooperating institutes of education.

Prisoners with day release privileges for education receive student grants according to the national student grant system. In some cases, prisoners who are studying are also eligible for student benefits under the Social Insurance Institution of Finland. When prisoners receive student benefits, these are taken into account when the prison pays their activity or expense allowances.

Number of teachers and teachers' roles

In 2007, approximately 300 external full or part-time teachers were involved in prison education. Teachers are recruited by the cooperating 
educational institutions. The same eligibility requirements apply to prison teachers as to all other teachers. The cooperating educational institutions are responsible for pedagogical guidance and management of the teachers. Some teachers work both in prison schools and at other schools, some only at prison schools. In prisons, teachers are not normally involved in the case management of prisoners except in relation to their education, and so they do not generally attend staff meetings. However, teachers and the prison staff have regular cooperation meetings.

Three prisons have some trained vocational teachers on staff. Approximately 80 ordinary prison staff members, generally not trained as teachers, also help with teaching and tutoring of the prisoners. All but one of the closed prisons have a study counselor who helps prisoners draw up study plans, provides tutoring, and serves as a liaison officer between the prison and the cooperating institutes of education. Some prison workshop supervisors are also involved in on-the-job training, as workplace trainers. The assistant prison director of each prison is responsible for education administration.

\section{Prison education and its relationship to other prison activities}

Since 1975, daytime educational activities have been accepted as an alternative to work. Other types of rehabilitation activities have been accepted as an alternative to work since 1995, when prisoners' obligation to work was replaced by prisoners' obligation to participate in activities. According to the Act on Imprisonment, which entered into force on 1 October 2006, prisoners are obliged to participate in activities. These activities include work, educational activities, or other ability-promoting activities.

Traditionally, prisoners have only participated in one activity at a time. With the new Act on Imprisonment, the emphasis has changed. Rehabilitation work requires close cooperation between various personnel groups, as well as integration of activities. The needs of prisoners are satisfied in different ways including, in addition to work or education, substance abuse rehabilitation, social rehabilitation, or family work (which includes supporting prisoners' regular contacts with family meetings or special programs for prisoners and their families). When prisoners are assigned to activities, attention is paid to their individual sentence plans, the order and security of the prison, and security in society. Several 
methods may be used simultaneously to implement the sentence plan, and the methods can be prioritized. For example, substance abuse rehabilitation may be the primary method and education only the secondary method of supporting a given prisoner's reintegration into society.

Study counselors represent the prison at planning discussions with the educational institution. They also cooperate with the staff members responsible for the enforcement of sentences in order to have the necessary information regarding sentence duration and the possibility of studying outside the prison. Cooperation with the supervisory staff is also necessary in order to determine security needs in relation to educational options.

Vocational training and prison work have always gone hand in hand. In recent decades, a closer relationship has developed between prison education and prison work activities, in pace with the increased use of apprenticeship training. Under such arrangements, practical vocational training is given by the supervisor of the prison workshop, while the educational institution is responsible for the general education.

The Finnish National Board of Education evaluated prison education in two prisons in early 2003. Their report indicates that prison staff members have generally become more positive about education in recent years. Prison managements are supportive of arranging education and striving to develop educational options. (Assessment report on prison Education, Unpublished report Finnish National Board of Education, 2003).

\section{The Prison Service}

The Prison Service is responsible for the enforcement of prison sentences and conversion sentences for unpaid fines imposed by the courts, as well as the enforcement of remand imprisonment. The Criminal Sanctions Agency, established in 2001, is the central administrative agency of the criminal sanctions field in charge of the direction and administration of the enforcement of community sanctions and prison sentences.

The Prison Service comprises five district prisons (Southern, Western, Eastern, Southeastern, and Northern Finland) plus a national health care unit, the Prison Health Care Services. District prisons consist of an assessment and allocation unit and prisons. The assessment and allocation unit is responsible for the imprisonment process. The unit specializes in assessing the activity and security needs of prisoners and planning the sentence term 
so that it increases the abilities of prisoners to adopt a life without crime. The assessment and allocation unit also determines the allocation of prisoners. The prisons are responsible for arranging activities for the prisoners in accordance with the sentence plans and ensuring that prisoners can serve their sentences safely. There are a total of 26 prisons under the management of the Prison Service. Ten of the prisons are open prisons (1,032 open places) and 16 are closed prisons (2,575 closed places). There are also open prison units operating under some of the closed prisons. The total average number of prisoners in 2007 was 3,551.

Remand prisoners are allocated to a different prison or to a different ward than sentenced prisoners. Separate placement may, however, be derogated from if the remand prisoner requests it for the purpose of participating in activities or if it is necessary for security reasons. In practice, remand prisoners and sentenced prisoners participate in activities together. There are no separate figures for these two categories.

\subsubsection{Education for remand prisoners}

The average daily number of remand prisoners in Finnish prisons in 2007 was 506. This figure is substantially higher than just a few years ago. Remand prisoners are sent to prisons located in the district where their cases are being heard and, as a rule, as close to their municipality of domicile as possible. The average duration of a remand period in Finland is close to three months.

If remand prisoners wish to participate in prison activities, they are allowed to do so whenever possible, unless there is a need to hold them in isolation from other prisoners.

Comprehensive and upper secondary education are arranged by upper secondary schools for adults or education centers in approximately half the prisons where remand prisoners are also held. In the other prisons, equivalent education can be arranged as independent study with tutoring. Tests are given and grades issued by a local educational institution.

University education and other higher education can be pursued as Internet-based distance courses in some prisons. Virtually all prisons where individuals are also held in remand offer some form of vocational training, such as short ICT courses. Other courses include preparatory vocational courses or courses, for example, on communication, marketing, 
business administration, electronics, and decontamination of industrial sites.

Remand prisoners are not allowed day release privileges, and their studies must take place in the prison. This may restrict their course options in comparison with those of convicted prisoners. Because their status is unclear they may also find it more difficult concentrate on studying.

\subsubsection{Description of prison education}

The term "prisoners" as used here covers remand prisoners, prisoners whose fines have been converted to prison sentences, and convicted prisoners sentenced to imprisonment. The latter category includes young offenders, lifetime prisoners and prisoners in solitary confinement. The majority of individuals participating in prison education activities (75$80 \%)$ are convicted prisoners. However, the statistics given below also include remand prisoners, since there are no separate statistics for the two categories.

In 2007, an average of 58\% of the prisoners participated in activities during working hours. Participation rates were highest in open prison units and lowest among remand prisoners. An average of $10 \%$ of the total prison population participated in educational activities.

In 2007, an average of 58\% of the prisoners' total use of time was used for participation in activities. Participation rates were highest in open prison units and lowest among remand prisoners. In 2007, the share of education of the prisoners' total use of time was about $10 \%$ and, on average, 311 prisoners participated in an educational activity every day.

A total of 1,737 prisoners participated in educational activities in 2007. The main focus was on obtaining or improving vocational competence, for which there is a broad range of course options. Hence, $55 \%$ of the students studied vocational subjects. According to an evaluation report (Koski \& Mäki, 2006) published by the Finnish National Board of Education in 2006, there is, however, poor correlation between the educational options offered and the real interests of individual prisoners. What tends to govern the vocational options offered is more the work situation in the prison, its traditions, and the professional backgrounds of the staff members. According to one Nordic study on prison education (Koski \& Miettinen, 2007. In Swedish. English equivalent title: Prisoners in educa- 
tional activities: a study of prisoners' participation and learning skills and strategies, as well as the quality of the educational activities), prisoners want more vocational training, especially apprenticeship training in various fields.

\section{Vocational training}

Vocational training and preparatory courses for vocational training are arranged at virtually all prisons as short course modules that can be combined into credit-giving segments for inclusion in a qualification.

In 2007, vocational and preparatory courses were offered in 17 different fields of education, such as architecture and construction; mechanical, metal, and energy engineering; process and materials engineering; crafts and design; business and commerce; computing and software; automotive and transport engineering; agriculture; horticulture; forestry; beauty care; hotel and catering; rehabilitation and sports; as well as nature and the environment.

\section{Education given at workplaces (apprenticeship training)}

This type of education has become an integral part of the work activities offered at prisons since 1994. The prison workshop supervisor is responsible for the work training, while a teacher from an external educational institution usually teaches the general educational courses. Because the practical teaching tends to take place as part of the work activity in the prison, prisoners basically learn a future occupation by doing it in practice.

\section{General education}

It is possible to receive comprehensive and upper secondary education at almost all prisons. At eleven prisons, education is arranged by upper secondary schools for adults or adult education centers. At other prisons, education is arranged as independent study with tutoring. Some prisoners, mainly prisoners serving their sentences in open prisons, have day release privileges to study at an institution of higher education, i.e. a polytechnic or a university.

\section{Education for women prisoners}

Female prisoners are in general allocated to a district prison determined on the basis of the prisoner's home municipality. Eight closed prisons and 
three open prisons have places for female prisoners. There is less education available for female prisoners than for male prisoners, mainly basic education and general upper secondary education, which are arranged at Hämeenlinna, Oulu, Pelso, and Turku prisons. Oulu prison has a virtual school, where both female and male prisoners can complete basic and general upper secondary studies. Independent study is also possible at most prisons. Education is usually arranged in mixed groups for both men and women. vocational training for female prisoners is arranged only at Hämeenlinna and Turku prisons.

\section{Education for young offenders}

In Finland, a young offender is defined as an individual who has been convicted of a crime committed between the ages of 15 and 20. Juvenile punishment, as stipulated in the Penal Code, is a specific sentence for offenders under the age of 18. The court can sentence an offender to juvenile punishment for 4 to 12 months. Juvenile punishment can be the sanction if the accused has committed the offense between the ages of 15 and 17. In the scale of sentences, juvenile punishment is comparable to a conditional sentence. It consists of supervision, activities and programs promoting social functioning capacity, and an orientation to employment and work. The supervisors of young offenders are officials of the Probation Service.

Most young offenders are placed in prisons where they can receive comprehensive education arranged by an upper secondary school for adults.

\section{Education for foreign prisoners and Roma prisoners}

In Finnish prisons, there are foreign prisoners from approximately 40 different countries. Foreign prisoners may participate in all prison educational activities for which their language skills suffice which, in practice, is quite restricted. A small number of prisons offer courses in Finnish for foreigners. Literacy courses for Roma prisoners as well as courses in their language and culture and in civics are offered at some prisons. Education for Roma prisoners is financed mainly by the Finnish National Board of Education. 


\subsubsection{The transition from prison education to education in the community}

\section{Day release privileges}

The Act on Imprisonment prescribes that a study permit, i.e. day release privileges permitting the prisoner to study outside the prison, may be issued on condition that the permit promotes the implementation of the sentence plan, compliance with the terms of the permit may be deemed likely, compliance with the terms of the permit can be supervised in a suitable manner, and, with the consent of the prisoner, the Prison Service authorities can, when necessary, contact authorities as well as private organizations and individuals to clarify the prisoner's compliance with the terms of the permit. The preconditions for a permit also include that the prisoner commits to abstinence from drugs and alcohol and complies with the other necessary terms, issued in writing, relating to moving and participating in an activity outside the prison.

In practice, individuals eligible for day release privileges for studies at schools outside the prison are prisoners in open prisons and prisoners approaching the end of their sentence terms. In 2007, a total of 150 prisoners had such study permits. On average, 54 prisoners studied outside the prison daily. Prisoners most commonly attended courses at vocational schools and vocational adult education centers. Study permits were also issued for studies at polytechnics and universities.

\section{Placement at an external facility}

Since 1999, prisoners with drug or alcohol abuse problems or who have special problems related to managing life in society can be placed in an external facility. According to the Act on Imprisonment, prisoners who have substance abuse problems or who are assessed as having special problems in coping with freedom may be placed, for a fixed period of time, at an outside institution or a corresponding unit, where they participates in substance abuse rehabilitation or in other goal-oriented activities to improve their potential to cope (placement in an outside institution). Prisoners may also be permitted, under sufficient supervision, to participate in activities outside the prison, arranged or approved by the prison, which support the prisoners' rehabilitation, contacts, and placement in society (permission to pursue supervised outside activities). 
Continued studies and employment after release

If prisoners are participating in a course of study at the time of release, they are encouraged to continue it in the community. Prisoners studying in a program that could lead to a diploma draw up a study plan together with the prison staff to ensure completion of the program. According to the survey of the Finnish National Board of Education (Koski \& Miettinen, 2007. (In Finnish. English equivalent title: Prisoners in education. Study on prisoners' participation in education and on their learning abilities and strategies as well as on the quality of education), most prisoners studying in prison (over $70 \%$ ) consider their studies interesting and useful, and the same proportion believe they will complete them. However, very few have been accepted for studies in the community during the release phase. In 2007, a release plan was made for every third prisoner. Only 5\% of the prisoners had been accepted for studies when they were released, whereas more than one fifth needed education. In practice, according to the 2006 evaluation report from the Finnish National Board of Education, more active support is needed after release to encourage former prisoners to go on with their studies. (Koski \& Mäki, 2006. In Finnish. English equivalent title: Report on the vocational training of prisoners).

Introductory courses are offered at some prisons to give an overview of different occupations, teach prisoners how to acquire information about the labor market and working life, and gain the necessary skills for applying for work.

Under certain conditions, prisoners may be granted day release privileges for work in civil society. In 2003 a total of 92 prisoners had such privileges. The daily average number of prisoners working outside the prison was 39.

\section{Release}

In good time (at least three to four months) prior to release, an assessment of each prisoner's need for services is made and a release plan, which is part of the sentence plan, is drawn up in cooperation with various interest groups. In open institutions, which function as release units, the release plan is prepared for almost every prisoner. In particular, plans are drawn up for young offenders, prisoners who have been in substance abuse rehabilitation, and prisoners who are going to be placed on probation, in cooperation with a service network. The Probation Service prepares a 
supervision plan continuing the target-oriented work in accordance with the sentence plan for released prisoners who are under supervision.

Based on the new Act on Imprisonment, on certain conditions, prisoners can be assigned to in supervised probationary release a maximum of six months before their release on parole. Probationary release requires a release plan, which includes information on, e.g., the housing and livelihood of the released person, the obligation to participate in an activity, the daily schedule, as well as supervision of the probationary freedom, for which the prison is responsible. Prisoners are obliged to participate in an activity, such as education or work. In 2007, a total of 103 prisoners were assigned to supervised probationary freedom, and the daily average was 22 prisoners. The aim is to increase the number of prisoners assigned to supervised probationary release in future.

\section{Internet-based education}

The Act on Imprisonment prescribes that prisoners may, for special reasons, be granted permission to maintain contact with the outside world using electronic communication, telecommunications, or similar connections, provided that this contact does not endanger the security of the prison, and that the use of these connections can be supervised.

Finnish prisoners do not have Internet access at the time of writing. Only prisoners with day release privileges are allowed access to the Internet, and only at their schools. Prisoners have access to on-line textbooks for "distance courses" of study at upper secondary school level but only if the prison's study guidance counselor prints the material for them. The study guidance counselor can also download other study materials from the Internet for prisoners. In the prison education strategy for the years 2008-2012, it is stated that during the period to which the strategy applies the use of the Internet will be made possible in the context of prison education at open prisons, and Internet-based education will be appropriately piloted at closed prisons.

\subsubsection{Financial aspects}

The education arranged in prisons under the auspices of external schools or vocational institutes is financed by allocations from the educational authorities with supplementary funding from the prison budgets. Courses 
may be funded partially or totally by the educational authorities. In 2007, the educational authorities defrayed $75 \%$ of the total costs of prison education and The Prison Service approximately 25\%.

\subsection{The results of prison education}

\subsubsection{Quantitative results}

Education formed approximately $10 \%$ of the total use of time of prisoners in 2007. In addition to education, many prisoners participate in various rehabilitation programs or recreational activities that promote social skills. Preparatory employment courses give basic skills for the labor market. Thus, far more prisoners are involved in learning than the numbers involved in prison education in the narrow sense of the term.

In 2007, a total of 576 prisoners participated in general education, 459 participated in orientation courses and rehabilitation training, 701 participated in vocational upper secondary and further education and training, and 374 prisoners participated in other education. Some students participated in more than one of the above. All in all, 2,100 general or vocational courses were taken in 2007, of which $93 \%$ were completed successfully. Only 3\% of the participants failed a course and $4 \%$ dropped out.

Quite often, prisoners are unable to complete a course during their prison term, not least because the sentence is too short to allow for completion. Transfer to a different prison or changing from one course of studies to another are counted as dropping out. The evaluation performed by the Finnish National Board of Education in two prisons in 2003 indicates that student performance otherwise corresponds fairly well to that in society in general.

\subsubsection{Qualitative results}

Prisoners' backgrounds and needs

Examining the sentence plans drawn up in 2007 (In Finnish. English equivalent title: The clientele, work processes and rehabilitation of the criminal sanctions field, Criminal Sanctions Agency, Working group Report 5/2008) made it possible to draw up a longitudinal profile for 
every new prisoner. Over half of mainly long-term prisoners had both inadequate work experience and needs related vocational training or vocational skills. These problems caused them significant trouble related to earning a livelihood:

- Approximately $70 \%$ of the prisoners had been living on social welfare benefits and could not manage their expenses with their own income, at the time they arrived in prison.

- Only $23 \%$ of the prisoners were working, and 3\% were studying.

- Lack of self-control and impulsive violence caused problems for over $50 \%$ of the prisoners.

- Two thirds had insufficient problem-solving skills.

- Substance abuse increased prisoners' risk of recidivism substantially.

- Female prisoners were more motivated than male prisoners to get treatment for their alcohol problems.

- Two thirds of male prisoners wanted substance abuse treatment.

- Having a circle of friends that promoted a criminal lifestyle was assessed as having a strong impact on recidivism: about $60 \%$ of female prisoners and $70 \%$ of male prisoners had problems associated with their circles of friends.

- About half of the male prisoners but only slightly over one fifth of the female prisoners had pro-criminal attitudes.

According to the preliminary results of the health research on prisoners, $90 \%$ of male prisoners have some form of substance dependence, $70 \%$ have some form of personality disorder, and $50 \%$ have an antisocial personality disorder. In addition, 15\% have been diagnosed as psychopathic and every second prisoner has hepatitis C (Annual Report of the Criminal Sanctions Field 2007). Prisoners' needs for services are related to substance abuse treatment services, education and employment services, as well as to services dealing with improving the thinking and behavior of prisoners. Owing to reduced working capacity, many prisoners need also work rehabilitation.

Prisoner's opinions of prison education

According to the survey carried out by the Finnish National Board of Education (Koski \& Miettinen, 2007) most prisoners participating in 
educational activities are satisfied with the quality of their prison educational activities. The motivation for starting studies include the usefulness of studying, the will to study, and the desire to be in better control of one's life after release. Additionally, the majority of the respondents consider improving their prospects on the labor market after release a good reason to start to study. Education also gave their time in prison a greater meaning. They stated that the studies corresponded to their expectations and that they considered the teachers competent. Many teachers were able to individualize in a way that was supportive for the students.

A study counselor at one prison has described the objective of her work as "to encourage prisoners to leave their cells and become interested in what the classroom has to offer". Initial positive classroom experience and communication with a prison teacher can also promote an interest in independent study. Studying contributes to making everyday life fuller for prisoners, and gives them new things to think about. The ambitions underpinning studies are for students to explore their potential and to perceive the links between life in civil society, their individual futures, and their goals regarding the time spent in prison. Later it should be possible to work on self-esteem, personal resources, growth, self-confidence, and interaction skills (Toivonen, 2002. In Finnish. English equivalent title: Studying in prison - maximizing misery or providing a key to better future?).

Results from a study carried out by the Finnish Criminal Sanctions Agency indicate that prisoners who study while serving their sentences cope better after release. Studies resulting in certificates also pave the way for entry into new areas of the labor market. Prisoners who study also have better potential for coping well after release because, in terms of background, they tend to have better employment history, better finances, better family relations and better living conditions than other categories of prisoners. Prisoners who study are, as a group, both in better physical and mental shape and have fewer housing problems than other categories of prisoners. Studying while serving a prison term contributes to maintaining both mental and physical health. Studies also appear to be more motivating than other activities, with less absenteeism and more development of positive attitudes. (Hypen, Kimmo 1/2004. In Finnish, Official English title: The released from prison in Finland 1993-2001 and the re-entered). 


\section{Learning difficulties}

Prisoners have considerably weaker educational backgrounds than the population in general. One explanation is the high extent of learning difficulties, which can be either innate or caused by lack of practice, among prisoners. Based on a study by Helena Salo (2006. In Finnish. English equivalent title: Dyslexia is a social risk: Literacy difficulties among Finnish male prisoners), nearly half the Finnish male prisoners (43\%) involved in the study have considerable difficulties with reading, whereas only about eight per cent of pupils in the last grade of compulsory school (age 16) with the same amount of education have similar problems. Approximately one third of the prisoners (33\%) in the study have word decoding difficulties relating to dyslexia, and every tenth prisoner has difficulties relating to weak reading skills, resulting from negative life factors and lack of practice.

According to Kivi and Malmberg, at least one third of the prisoners have serious literacy difficulties, and with the exception of a very few well-educated prisoners, virtually every individual who ended up in prison had some kind of learning skills disorder, dyslexia being most widespread (Kivi \& Malmberg, 2002. In Finnish. English equivalent title: Out and participate. Rehabilitation experimentation in Riihimäki Prison).

According to the preliminary findings in a PhD dissertation by Tiina Tuominen (2007. In Finnish. English equivalent title: ADHD features, dyslexia and cognitive capacity among Finnish male prisoners), nearly half the prisoners involved in the study (49\%) had literacy difficulties and $16 \%$ had extensive problems. This study was carried out among 77 longtern prisoners in a closed prison. According to the study, ADHD features are ten times more common among prisoners than the general public. Approximately half of the prisoners involved in the study had clear ADHD features.

Based on the survey by the Finnish National Board of Education (Koski \& Miettinen, 2007), only about one fifth of prisoners consider themselves to have literacy difficulties, while one third assess themselves as having some numeracy difficulties. Prisoners evaluate their own skills more optimistically than what has been found in previous studies of prisoners.

In recent years the Prison Service has begun to pay increasing attention to the learning difficulties of prisoners. Prisoners detected as having learning difficulties or whose learning difficulties need further clarifica- 
tion are identified in connection with the sentence planning and prisoners' risk and needs assessments. When arranging activities in accordance with the sentence plan, the aim is to take learning difficulties into account by introducing, among other things, different teaching methods, individual and group rehabilitation support measures, and technical aids. Vocational special education institutions with expertise on supporting individuals with learning difficulties arrange prison education at six prisons.

\section{The study environment}

The report of the Finnish National Board of Education (Koski \& Mäki, 2006) includes an evaluation of the prison learning environments as well as the equipment used in prison education. The staff at prisons and educational institutions are generally fairly satisfied with their classrooms and other facilities. The differences between prisons are considerable. In old prisons that have not been renovated the learning environment may be a space not originally designed for teaching purposes. The lack of the genuine on-the-job training environments needed in vocational training is also problematic. Prison workshops, where professional or work activities or orientation courses take place, are used as on-the-job training environments. Additionally, the age of the machinery and equipment causes problems, especially ICT equipment. Many educational institutions bring ICT equipment with them to the prison teaching premises for use in the classroom situation.

Based on a questionnaire distributed to prisoners (Koski \& Miettinen, 2007), two thirds of prisoners participating in educational activities find access to ICT equipment inadequate. More than one third of prisoners consider their ICT skills to be poor or very poor, partly for this reason, and as the same number again consider their ICT skills average. A shortage of literature is also considered to make studying more difficult.

\section{Need for education}

Prisoners who have not completed the compulsory education syllabus (6.3\%) have to be offered basic education. As regards upper secondary education, the educational background of prisoners is also substantially lower than that of the general population. The need for orientation courses, rehabilitation programs and instruction preparatory to vocational 
training or work and independent life is clear from the scope of learning disabilities.

The sentence plans prepared for prisoners in 2007 made it clear that there is a need for prison guidance and counseling activities. The goals stated in the sentence plans for $75 \%$ of prisoners were education and employment (Statistics of the Criminal Sanctions Agency 2007).

According to the questionnaire given to prisoners (Koski \& Miettinen, 2007), $40 \%$ of the respondents stated that they did not want to study in prison. Their reasons included the absence of suitable subjects and of study opportunities, and too little if any information about the study options. The prisoners' primary educational preferences concerned vocational training. A study form based on practical work, such as apprenticeship training, would be especially suitable for prisoners, but very few prisoners have the opportunity to participate in such training today. Nearly half of the prisoners stated that they would like to participate in apprenticeship training in different vocational fields.

Coordinated planning of the study subjects offered and information about the range of educational activities needs to be further developed at national prisons and district prisons.

\subsubsection{The Åland islands}

The Finnish Prison legislation is also applicable to prisoners from the Åland islands, where there is no prison. Prisoners from the Åland islands serve their sentences at prisons in mainland Finland. 


\title{
4. Iceland
}

\author{
by Erlendur S. Baldursson
}

\subsection{Introduction}

By way of introduction to prison education in Iceland, a few words about the relationship between prisons and Icelandic society as a whole are in order. There are five prisons in Iceland, four of which are very small, with 10-22 places, and one larger one with 87 places. The duration of a sentence is determined in consideration of many factors, including age, sex, and previous convictions. One of the prisons is in Reykjavik, one in nearby Kópavogur, while the remaining three are rural. The largest one, Litla-Hraun, is located approximately 60 kilometers from Reykjavík. On an average, there are some 135 men and 6-7 women in prison in Iceland at any given time. Women prisoners are always incarcerated at the twelve-place Kópavogur prison, housing both men and women. Although small prisons like the Icelandic ones have many advantages over large prisons with hundreds of places, prison education is one of the problematic aspects of small establishments, for various reasons. The small number of prisoners/students may be extremely varied in terms of age, previous education, duration of sentence, state of health, etc. All this means that the educational options have to be highly individualized, and that both teachers and students need to be very flexible.

Only two of the Icelandic prisons, Litla-Hraun and Kópavogur, offer organized education, with teachers coming from nearby upper secondary schools. 


\subsection{History and legislation}

Prison education in Iceland began as a pilot project at the Litla-Hraun prison in the 1970s. Vocational training, tuition in individual subjects and basic comprehensive education were all offered. While the general teachers came from the local comprehensive school in the nearby village of Eyrarbakki, prison officers provided the practical training in, for example, woodworking and welding. Since 1978 all the prison education at LitlaHraun has been organized under the auspices of the vocational school in nearby Selfoss. In 1979, in accordance with an agreement on co-financing between the Ministry of Justice and the Ministry of Education, the latter took responsibility for teachers' salaries and the former covered all other expenses related to educational activities.

In 1981 the school in Selfoss became a combined comprehensive and upper secondary, and since that year this school has also organized all the prison education at Litla-Hraun, with the prison teachers commuting daily between the village school and the prison. In the early years, the facilities for education at the prison were very sparse, and for this reason some of the prisoners were allowed day release privileges to attend the local school. In 1990, school facilities on the prison premises were inaugurated, and since then most education for prisoners has taken place there. In special cases, prisoners are allowed to attend school outside the prison to study subjects not available at the prison school.

There has been schooling on a regular basis at the Kópavogur prison since 1997. Since then, the combined comprehensive and upper secondary in nearby Kópavogsby has run the prison school as well.

Article 19 of the Icelandic Prison Act (no. 49/2005) stipulates, inter alia, that prisoners have the right to education, as well as that regular educational activities in prison can replace the obligation to work. It also states that prisoners attending educational activities are eligible for an allowance. Textbooks and all study materials are also paid for by the prison.

Article 47 of the Icelandic Prison Act states that a prisoner must have served one third of the sentence, but at least one year before he or she is permitted to attend school outside prison. If the prisoner has been in prison for four years, it is also possible to apply to attend school outside 
prison. In exceptional cases, exceptions may be granted regarding this time limit.

Prisoners serving sentences of long duration may be allowed to serve a maximum of the last 12 months at a halfway house from which they may, for example, apply to attend school. Unless the prisoner's behavior prevents it, such applications are normally granted.

\section{Greater attention to prison education}

Prison education and educational options have received increasing attention from the Icelandic prison administration in recent years. At the recommendation of the Director General of the Icelandic State Prison Administration, the Minister of Education appointed a committee in May 2006, comprising individuals from the Prison Administration, the Ministry of Education, the Ministry of Justice, and the Icelandic National Agency for Education. The brief of the Committee was to propose measures in the following areas, among others:

- More vocational training in prisons.

- ICT courses in prisons.

- Focus on prisoners with little or no completed education.

- Focus on foreign citizens in Icelandic prisons.

- Courses to train learning about life and life mastery skills.

- Formal and non-formal educational competence assessments.

In December 2007 the committee submitted a report to the Ministries of Education and Justice. The members of the committee were unanimous in their finding that prison education plays a key role in the rehabilitation of prisoners. The committee put forward the following proposals:

- It is essential that the full scope of the European Prison Rules be taken into account when organizing prison education.

- It must be possible to participate in educational activities at all prisons, and they must have educational counselors, ICT equipment, libraries, and monitored Internet access.

- A study counselor is to be employed at the prisons, to ensure, among other things, that there is effective collaboration between the Icelandic National Agency for Education and the Prisoners. 
- Prisoners are to be encouraged to participate in educational activities while serving their sentences. They should be supported through the drawing up of study plans, real competence assessments, and planning for continued education after serving their sentences.

- Prisoners are to be offered a range of prison educational activities with a view to increasing their life mastery skills and competence.

- The rules regarding hourly wages for education are to be revised so that the pay for participation in educational activities is made the same as for normal prison work. Prisoners participating in remote learning are also to receive pay for this participation.

- An investigation should be made of the possibility of providing Internet access in the prisoner's cells for specific purposes. Internet abuse is to be treated in the same way as other forms of abuse in prison.

- Because it is essential to improve prison vocational training, efforts are to be made to enable prison workshops to be used for practical work experience in vocational training.

- Foreign prisoners are to have the same rights to education as Icelandic prisoners, and should be offered Icelandic language courses.

The proposals of the committee were well received, and many of them have already been implemented in practice. Thus a study counselor for the prisons is now employed, and prisoners receive higher pay for participating in prison educational activities. Supervised use of the Internet has been introduced in one open prison, and the opportunities for participating in remote learning have been substantially improved.

\subsection{Description of prison education}

Iceland was the second Nordic country to carry out the joint Nordic survey of prison education. Two researchers from the University of Iceland were engaged, and submitted their final report describing the situation in Iceland in May 2007. The conclusions of their report include, inter alia, that:

- Approximately one third of the prisoners in Icelandic prisons participated in some form of prison educational activity. 
- Approximately one third of the prisoners stated that they had not completed compulsory level school.

- Fifty-three per cent stated that they had numeracy difficulties.

- Approximately $30 \%$ stated that they had literacy difficulties.

- The prisoners requested more types of vocational training.

- The prisoners requested better access to ICT equipment and the Internet.

- Approximately 85\% considered participation in prison educational activities a very sensible way of using their time.

- Half the prisoners considered it an important way of preparing for further education after release.

- Nearly $60 \%$ were satisfied with their prison educational activities.

The upper secondary schools with responsibility for prison education at Litla-Hraun and Kópavogur, respectively, have appointed prison school administrators, who come to the prison a few weeks before the beginning of the school term. In 2008 the Ministry of Education employed a study counselor whose tasks include helping prisoners at all Icelandic prisons to organize their studies. Prisoners interested in benefiting from the prison educational activities apply to the director of education or the study counselor, stating their needs and preferences. They then draw up a study plan in consultation with the prisoner. In practice, all prisoners have access to educational activities, although the subjects offered may vary from term to term.

At both prisons, educational activities take the form of modules of varying lengths, as well as remote learning. The students are therefore able to choose the modules they wish to study and that are in accord with their own abilities, in consultation with the school administrator and the study counselor. Prisoners with literacy difficulties are offered remedial education. The three small prisons offer Internet-supported remote learning. The average number of prisoners at the Litla Hraun prison in 2007 was 78, including individuals in remand. The spring terms saw 26 of these prisoners begin some educational activity, 13 completed one or more examination. The autumn terms saw 25 prisoners start schooling, and 16 completed one or more examinations. Four of the 25 prisoners studied using remote learning. 
Generally, an average of $35 \%$ to $40 \%$ of the prisoners begin studying one or more subjects at the prison school, and approximately 20\% complete the examination in one or two subjects. In most cases, dropping out is voluntary on the part of the prisoners, although there have been cases of suspension owing to disciplinary problems. In cases where a prisoner is released before the end of the school term, the school administrator sees to it that examinations are arranged in the subject(s) the prisoner was taking. In other cases, examinations outside the prison are arranged for released prisoners.

The average number of prisoners at the Kópavogur prison in 2007 was ten. Two to six prisoners attended school daily, and six completed one or more examinations that year. In all other respects, the prison school operates in the same manner as described above for the Litla-Hraun prison. At Litla-Hraun, other courses than traditional school courses are occasionally offered. These courses have been primarily financed by the Prison and Probation Service, and have included courses in navigation for vessels up to 30 tonnes and construction equipment. The aim of these courses is to prepare prisoners for life after release.

\subsection{Financial aspects}

As mentioned above, the costs of prison educational activities are shared by the educational authorities and the Prison and Probation Administration. The former finance teachers' salaries, the latter covers all other expenses. In 2007, funding for all aspects of prison education amounted to EUR 200,000. A raise of 20 percent is expected in 2008.

\subsection{The prison population}

The average number of prisoners in incarceration facilities per 100,000 inhabitants in Iceland in 2007 was 40, including individuals being held in remand and individuals whose fines were commuted to serving time in prison. The averages for recent years have fluctuated between 35 and 41 .

The average age is 33 , and in $2007,26 \%$ of the prisoners were 25 or younger, the youngest being 17 . 
In 2007, 7\% of Icelandic prisoners were women. The percentage of women has fluctuated in recent years between $5 \%$ and $9 \%$.

The average number of unconditional prison sentences to be enforced by the Prison and Probation Administration in recent years has been 400 per year, of which $12-19 \%$ are sentences of longer than one year's duration. Approximately $50 \%$ of the individuals who begin a prison sentence each year have served time previously.

In conclusion, it is noteworthy that the prison population in Iceland is substantially smaller in relation to the general population than in the other Nordic countries, and that one of the reasons is probably that Iceland uses more alternative sanctions. 



\title{
5. Norway
}

\author{
by Torfinn Langelid
}

\subsection{History}

The first Norwegian house of correction was established in Trondheim around 1630 (Lie, Magnus, 1934. In Norwegian. English equivalent title: Three Centuries of the Waisenhus Foundation in Trondheim,1635-1935). From the very outset, education has been an important aspect of the prison system. Educational methods have always been one of the instruments used to socialize prisoners, as well as to give them new knowledge. The prison authorities have always had responsibility for prison education.

In the eighteenth century houses of correction, the socialization approach was the main strategy. In accordance with the prevailing international theories of penal sanctions, at the four houses of correction built in Norway between 1735 and 1789 the penal and correctional functions completely overlapped. Many underprivileged children were sent to houses of correction in preparation for church confirmation.

\section{Penitentiaries - places for isolation and prayer}

By the mid-nineteenth century, the idea that a prison term would lead to correction of those who had violated the law had become firmly rooted. In 1841, a government commission report on prisons was published, and was extremely critical of the prison system, finding the enforcement of sanctions not sufficiently intimidating. Prisoners lived under such free conditions that there was no way they could come out of the system having undergone any improvement, and improvement was one of the objectives of a prison terms. The principles underpinning the new Criminal Act 
from 1842 were those of the American "Philadelphia model", the cornerstone of which is solitary confinement. Other bearing elements of the system were acclimatization to work and an orderly lifestyle, as well as religious and ethical education and upbringing. The operative word was "discipline".

The prison established of this model and opened in 1851 was the first prison in Norway to operate on the basis of clearly established objectives, and with a true focus to its educational aspects. This was the first attempt to use an educational method as an instrument of prisoner correction. According to the regulations, prisoners were to have daily instruction in reading, religion, bible history and "when circumstances allow and when it is found potentially useful, Writing and Arithmetic". The curriculum developed more or less in accordance with the national education legislation. Prison education was to be in line with that of the regular school system.

In the late nineteenth century new regulations were issued in relation to education at prisons for men. The central objective was that every prisoner who had not completed comprehensive (primary and lower secondary) school should do so. Prisoners were systematically assessed to determine their educational backgrounds. Prisoners were tested at the beginning and end of their prison terms in religious studies, reading and writing, and there are statistics through 1918/19 regarding the number of prisoners who were literate upon entering and leaving prison, as well as concerning their knowledge of religious studies. The 1903 Prison Act established that individuals under the age of 18 should always have education while in prison.

\section{From accountable to disturbed}

The late nineteenth century saw a shift in the view on sanctions, criminality and prisoners. In contrast to the position that a person who violated the law was accountable for his or her actions, and therefore to be imprisoned as a punishment, according to the new view a person who violated the law was disturbed, and thus more or less destined to break the law. Deprivation of liberty was considered a way of treating the sick individual for the disease of criminality. The "treatment philosophy" underpinned various penal strategies developed well into the early twentieth century, including the 1928 Act on Correctional Treatment of Young Offenders. 
This legislation led to the setting up of "prison workshops schools", in order to give young offenders, between the ages of 18 and 23 who had committed relatively minor crimes, correctional treatment (to improve their behavior) and vocational training. For various reasons, no "prison workshops schools" were actually opened until 1951. Although they were intended to be an alternative to serving one's sentence in a closed prison setting, it gradually became clear that the young men placed there experienced the schools as prisons and as punishment. The legislation was revised in 1963, and the schools renamed "youth custody centers". These centers were disbanded in 1975, in conjunction with a legislative reform.

New Prison Act - more education

A new Prison Act was passed in 1958. Vocational training became an important issue both in the preparatory documents for the legislation and in the Act itself.

Educational activities on the whole, however, received surprisingly little attention and ambiguous treatment in the new Act in comparison with the emphasis placed on them in the preparatory documents. In the Act, the main emphasis was on work activities, which were to be pursued as daytime activities, whereas educational activities were to take place outside working hours.

In contrast, however, both the Norwegian Parliament and the Ministry of Justice adopted decisions as a consequence of which cooperation between the prison and educational authorities was to be strengthened, and efforts to this end were undertaken beginning in the 1950s and 60s. The Ministry of Educational, Cultural and Church Affairs granted approval for certain educational options for prisons to be credit-giving as vocational training. At the larger prisons, instead of having teachers employed as part of the prison staff, more and more teachers were hired externally and worked on an hourly basis.

1969 - a milestone year

In 1969 the educational authorities took over responsibility for prison education. The objective was to provide education for young offenders of school age and for young offenders with inadequate educational backgrounds.

This objective was adopted after a long struggle regarding both the content and administration of education. While the Ministry of Justice 
argued forcefully that the responsibility for prison education should be put in the hands of the educational authorities, the Ministry of Educational, Cultural and Church Affairs was not overly eager to have yet another institutional sphere added to its brief. The Ministry was already quite overwhelmed by all its responsibilities and was not being proactive about taking on new ones. It was, however, responsive to criticism, and gradually came to see how important prison education was for the return of prisoners to the community upon release. The great need of education for young offenders became evident to individuals working in the prison system. They succeeded in making their voices heard and their expertise clear, and their arguments eventually took root at the Ministry (Langelid 1982, in Norwegian. Equivalent English title: Punishment and Pedagogy - two socialization systems in conflict? The development of educational options at two Norwegian prisons, and White Paper no. 23, 1991-92).

\section{Prisoners' right to education}

When the Ministry of Educational, Cultural and Church Affairs took over responsibility for prison education, this was in line with general developments in society. The 1960s was the decade that saw the initiation of educational activities at many social and medical service institutions. The Ministry found itself taking on more and more educational responsibilities. One new target group at psychiatric wards, drug abuse clinics and prisons was very young people, who had previously often been school dropouts with no follow up. These young people were often already long-term abusers with very little work experience and weak educational backgrounds. This latter factor became a forceful line of reasoning when the prison service argued for prison education to be taken over by the educational authorities. At the time, special arrangements and classes were also the object of criticism, and integration became the operative word: individuals with all kinds of learning difficulties were to be mainstreamed back into the regular school system. The argument put forward in relation to prisoners was that they had an inalienable right to the same social services as other citizens, despite the fact that they were in prison. (Langelid 1982).

\section{The import model}

Criminologist Nils Christie launched the import model in a presentation held in autumn 1969 entitled "Models for prison organization" (Christie 
1970). Christie considered the import model as a way of opening up the system, but placing responsibility for all functions not related to prison care outside the prisons. According to Christie, the most dangerous aspect of the self-supply model is the likelihood that various groups of professionals will lose contact with the general expertise in their disciplines, as well as losing their own identities by becoming too adapted to the security measures applying in prisons. This philosophy paved the way for putting medical, library and many other services offered in prisons in the hands of external providers in the community, as is clear in a Norwegian parliamentary report On Prison and Probation Services from 1997-98.

1988 - full control by the national authorities

The agreement convened in 1988 regarding national funding of prison education, and implying that there would be $100 \%$ reimbursement of all approved operational costs, marked the end of a long struggle between the municipal and county authorities on the one hand and the national government on the other. According to this agreement, the state covers the cost of all approved operational expenses for comprehensive, vocational and upper secondary education for prisoners, including the "followup classes" for prisoners wanting, after release, to complete a course of study they began in prison, and which were established in various parts of the country. The Ministry of Justice also has responsibility for school premises, which it delegates to the Prison and Probation Service.

The county authorities take over subject content and administrative responsibility

State subsidies were paid out retrospectively, after submission of accounts, on the basis of a budget adopted by the Ministry in advance. Today the system has been revised so that the county authorities are given a budget framework for educational activities, and these budgetary restrictions must be observed. Since this revision, county authorities have also taken over the subject content and administrative responsibility for comprehensive education. 


\section{Parliamentary report on prison educational activities}

In April 2005 the government submitted a report to the Norwegian Parliament on education and training in the correctional services. This was the first parliamentary report ever on the subject. (Short Version of Report no. 27, 2004-2005, Education and Training in the Correctional Services "Another Spring" from the Ministry of Education and Research, henceforth referred to as Another Spring).

The report put forward a new road map for education and training in the correctional services, which is likely to have consequences in various areas. If the right to education is to be genuinely fulfilled, education and training must be offered at every prison.

\subsection{Legislation and regulatory documents}

The governing principle of the Norwegian Prison and Probation Service is that prisoners are to have access to the same services as other citizens, provided by other authorities than the correctional services. The import model, or administrative cooperation as it is more commonly known today, is to result in normalization to the greatest possible extent, and in openness in an otherwise closed system. This is also a way of ensuring that other authorities are held accountable for, and take their responsibility in, the reintegration of prisoners into society.

\subsubsection{The principles underpinning the work of the Prison and Probation} Service

\section{Principles}

In autumn 2008, the government submitted another report on the correctional services to the parliament (Stortingsmelding no. 37, 2007-2008, published English summary entitled Punishment that Works - less crime - a safer society, henceforth referred to as Punishment that Works). The objective of this report was to improve and develop the correctional services, and it states that the activity of the Norwegian Correctional Services rests on five pillars: 
- what the Legislator has said is the purpose of the punishment,

- a humanist approach to human nature,

- the principle of due process and equal treatment,

- the principle that convicted persons have paid their debt to society when the sentence has been served,

- the normality principle.

In the report, the government points out that "public safety is a paramount objective of the Government's crime policy This objective dictates the frameworks for the penal implementation and the return to society”. The report emphasizes that: "The needs of public safety shall inform policy, the statutory and regulatory systems and the day-to-day exercise of discretion". One overarching perspective is that sanctions should be implemented so as to ensure that fewer offenders relapse into recidivism. "The objective of the Norwegian Correctional Services' professional activity” is that when a convict has served his sentence he will be:

... able to read, write and do arithmetic; has a chance on the labor market; can relate to family, friends and the rest of society; is able to seek help for any problems that may arise after his release; and can live an independent life. The Government considers that a good point of departure on release increases the probability of inmates succeeding in living a life without crime. (Punishment that Works)

To achieve this objective the serving of sentences must have a suitable content and all measures must be based on documented knowledge. The traditional instruments in this context are work training, school, cultural facilities, leisure activities and motivation programs, and it is the ambition of the government to further develop and raise the quality of the significant efforts made in these areas.

\section{Rights}

One important principle in this context is that prisoners are to be ensured of all their rights as citizens according to the law. This applies, for instance, in relation to the health and social services sector, the employment services and the educational system, and makes access to work, education, recreational activities and physical education important elements in paving the way for a way of life free from crime. In order to accomplish 
this, according to the Ministry of Justice, it is therefore essential that it be possible for other administrative bodies than the Prison and Probation Service to be able to provide the services to prisoners, while they are serving their sentences, to which they are entitled by law.

Prison education is to be implemented in accordance with the guidelines applying to the educational system in society at large. Individuals on probation are to be integrated into the regular educational system in as far as is possible, in accordance with the principle of normalization, although with the necessary exceptions.

\subsubsection{The 2002 Enforcement of Sentences Act}

The civil rights of prisoners are stipulated in Article 2 of the Act (formally referred to in the English translations from Norwegian as the Penal Implementation Act), and detailed in the preparatory documents, which states that prisoners have the same rights to services and activities, and the same obligations and responsibilities, as the population at large. It is thus up to the Prison and Probation Service, whenever possible, to ensure that cooperating authorities are able to provide prisoners, including prisoners serving sentences of long duration, with the services to which they are entitled.

\section{Regional and local responsibility}

Since 1 January 2001, the Prison and Probation Service has been divided into a national administration plus regional and local administrations. Since this restructuring, the Ministry has become a more strictly political secretariat, and much of the work previously done by the Central Prison Administration has been delegated to the regional and local levels. The Prison and Probation Service has been divided into six regions, each of which is responsible for all types of prison and probation services.

The new legislation gives greater clarity regarding the overall division of responsibility. Each regional Director is responsible for ensuring that a differentiated range of activities is offered to prisoners in the region, based on the objectives and activities plans drawn up for the national and regional services. At local level, the activities most appropriate for each prisoner are to be determined by the prison in cooperation with the prisoner and the relevant authorities. 
In Punishment that Works, the government discusses possibility of moving the current Directorate, the central administration of the Prison and Probation Services, from the Ministry of Justice and establishing it as an independent organizational entity. The report also proposes considering a restructuring of the regions into Prison and Probation Centers, which could cooperate on administrative matters.

\section{Prisoners' responsibility for their own rehabilitation}

The new legislation puts equal emphasis on the responsibility of the Service and of the individual prisoner for ensuring that a sanction is enforced in a way that encourages a return to a crime-free life. The law stipulates that all prisoners must be involved in activities while serving their sentences. These may include:

... work, community service, education, programs, etc. with a view to discouraging a return to criminality (Article 3 of the Enforcement of Sentences Act).

It is the responsibility of the Prison and Probation Service to ensure that prisoners are offered a range of daytime activities. The term "activities" is new, and includes work, education, programs, and other activities. All these activities are considered equivalent, and as satisfying the requirement by which prisoners are obliged to participate in activities.

\section{Different kinds of sanctions}

The Enforcement of Sentences Act stipulates the following forms for implementation of all kinds of sentences involving deprivation of liberty:

- imprisonment with a high level of security (closed prisons),

- imprisonment with a lower level of security (open prisons),

- halfway houses,

- outside prison with special conditions pursuant to Article 16, or

- on parole under the conditions stated in Article 43, second indent.

These forms determine what activities can be offered. In accordance with the instructions for the legislation, in the majority of cases enforcement of any prison sentence or sanction involving deprivation of liberty begins in a closed prison. It is, however, up to the discretion of the regional Director to assess whether an individual who has been convicted to a sentence 
of two years or less, but not yet incarcerated, could be placed directly in an open prison.

\section{Rural prisons}

In the report to the parliament (2007-2008) the government proposes testing the idea of "rural prisons" on a pilot project basis. This is in line with the principle of normality, and would give prisoners greater influence on significant decisions and their own lives by enabling them to:

- live as close to real society as possible, under supervision and with educational opportunities and guidance,

- pursue work training in a more realistic way, closer to society,

- have market-level pay,

- pay their own bills and purchase their own groceries,

- practice living in society,

- participate in group meetings and train conflict management

The objective of opening such a prison would be that, in comparison with traditional prisons, it would minimize the harm a prisoner often experiences while serving his or her sentence. The institutional way of life would be replaced with natural, positive living environments, workplaces, administrative service offices, and all the other facilities required to manage an independent life. The Ministry of Justice wishes to establish one or two rural prisons on a pilot project basis.

\section{Sentence implementation with electronic supervision}

In autumn 2008 the Ministry of Justice initiated a pilot project as a new form of enforcement of sentences in six counties using supervision with electronic shackles. The Act had been amended to allow convicted prisoners with sentences of up to four months in prison or who have four months remaining to serve prior to anticipated conditional release to apply for sanction enforcement with electronic supervision. This form of enforcement enables convicted prisoners to maintain contact with their families. A prerequisite for serving a sentence with electronic supervision is that the individual has either a job or an educational activity to attend during the daytime. 


\section{Transfers}

The overarching principle of the Enforcement of Sentences Act is that, on certain conditions, prisoners may be transferred from closed prisons to prisons with lower levels of security. The Prison and Probation Service may, for instance, consider transfer to a prison with a lower level of security when there is one year remaining until a prisoner is eligible for parole. In addition, prisoners may be transferred from prisons with high or low security levels to halfway houses after having served part of their sentence. In assessing the possibilities for such transfers, planned and initiated activities, such as education or work with a view to reintegration after release are to be taken into account. The Prison and Probation Service is to contact the educational and social service authorities, the employment services, etc., to prepare a transfer being considered, and to ensure continuity of planning for the individual.

The activity options in a prison are to reflect, on a smaller scale, activities offered in society at large. On the basis of the principle of normalization and of the objective of giving prisoners access to the same services as other citizens, it is important to be aware of what it is possible, pursuant to relevant legislation, for prisoners to do in terms of participating in activities offered outside the prison. The Act offers two possibilities in this respect: enforcement of a sentence outside the prison on special conditions, and use of day release privileges.

Serving one's sentence outside the prison

"Enforcement of a sentence outside the prison on special conditions" is of particular interest in relation to education and work. The stipulations of the law are that when it is necessary and appropriate to ensure continued positive development and to counteract recidivism, the Prison and Probation Service may transfer a prisoner for implementation of a sentence outside the prison on special conditions after he or she has served half the sentence. On prerequisite for implementation of a sentence outside the prison is that the prisoner has a permanent domicile and is pursuing activities such as work, education, etc.

\section{Day release privileges}

Day release privileges make it possible for the Prison and Probation Service to give prisoners access to work, education, and other programs, 
outside the prison if there are no security considerations which speak against the use of privileges. Criteria for eligibility for day release privileges have been specified: the prisoner must have been deprived of his or her liberty for at least four consecutive months and must have served one third of the sentence duration. As a rule, day release privileges are not to be granted for longer than one year, with one exception: day release privileges for education may be granted for up to two years if the education in question is one aspect of the prisoner's comprehensive educational plan. As a rule, day release privileges are granted to prisoners at prisons with lower levels of security, or at halfway houses. In exceptional cases, however, it is possible for a prisoner in a high security prison to be granted day release privileges. In Punishment that Works, the Ministry of Justice examined the possibility of instituting day release privileged from day one of a sentence enforcement when it was defensible to do so from a security viewpoint. The report also states that young prisoners should be assessed for day release privileges as early as possible.

\section{Groups with needs for special arrangements}

The same parliamentary report specifies groups with needs for special arrangements, including: Remand prisoners, prisoners serving preventive detention sentences, prisoners who are not Norwegian citizens, female prisoners, children and young people, and prisoners with psychiatric conditions and major behavioral problems. According to the report, the Ministry would extend the range of activities offered, for example by focusing more on education, work, substance abuse rehabilitation, and programs to behavioral problems.

\section{Prisoners' activity allowance}

Prisoners serving prison terms may be granted a daily allowance for participation in work, programs, education, etc., all of which activities are to be considered on an equal footing. The central administration of the Prison and Probation Service carries out an annual review of the size of this allowance, currently EUR 6.5 per day, and of the detailed regulations applying. 


\subsubsection{The Education Act}

The Education Act that came into force in Norway in 1998 replaces the following previous legislation: the Primary and Lower Secondary Education Act, the Act on Upper Secondary Education and Vocational Training, and parts of the Adult Education Act.

New rights even for prisoners

All citizens have a right and an obligation to complete comprehensive school, and anyone who has completed comprehensive school has the right to three years of upper secondary, including vocational, education. The most recent amendments to the Education Act are of particular relevance for prison education under the auspices of the Prison and Probation Service. As of 1 August 2008, adults who have not completed comprehensive (9 year) education have a right, upon application, to upper secondary education. Pursuant to this amendment, the Act defines a person as being an adult beginning in the year of his or her twenty-fifth birthday. The majority of prisoners are between 21 and 40 years of age. The proportion of the prison population that has not completed comprehensive education is far higher than in the general population. The amendment gives more individuals the right to upper secondary education. Another amendment, which came into force on 1 August 2002, states that adults have the right to go back and supplement their comprehensive school, and that they have a right to special education. These amendments are of particular significance for Norwegian prisoners.

In addition, the Education Act has a separate chapter on "Upper secondary level education at workplaces”, which is relevant to prison education. Many of the workshops in Norwegian prisons have been granted the status of "educational workplaces", which means that prisoners can be taken on as apprentices and trainees (Article 4). The prison workshop (or the prison) receives a grant of a specific sum per prisoner/pupil accepted as an apprentice or trainee. If there is good cooperation between the prison school and the prison workshop, prisoners receive general education in the classroom and practical training in the workshop. This makes it possible for the prison schools and the prisons to make a larger number of educational options available. 


\subsection{Description of the relationship of prison education to the state education system}

\subsubsection{Description of prison education}

Objective of prison education

The objective of education in the Norwegian Prison system, as stated by the Ministry of Education and Research, is to give comprehensive and upper secondary education to prisoners in Norwegian prisons. In addition, courses that do not result in formal competence should also be offered. Individuals wishing to pursue education beyond upper secondary level, such as university or higher education, are outside the remit of this definition, and must manage on their own or with the support of the Prison and Probation Service. According to the Ministry of Education and Research, it is up to prisons, in collaboration with the Labor Market Agency and local educational institutions to find the solutions that give rise to as few practical obstacles as possible and that open up for participation in prison educational activities to the largest extent possible. (Another Spring).

According to Another Spring, one of the new objectives is to make more prison educational activities vocationally oriented. This is also in line with the findings from the survey concerning the educational preferences of prisoners, which indicated that nearly two thirds $(63.4 \%)$ of prisoners would like to participate in vocational training (Eikeland, Manger, and Diseth. 2006. In Norwegian. English equivalent title: Prisoners in Norway: Education, educational preferences, and right to education.). Another focus is to offer more short courses that raise prisoners' competence in various areas. Special attention is also to be paid to the needs of women prisoners for vocational training.

In the national "Knowledge Promotion Program" (Læreplanverket for Kunnskapsløftet. Midlertidig utgave juni 2006) the use of digital equipment is mentioned as one of the five basic skills. Another Spring also highlights this area. Practical and esthetic subjects are considered important, not least to motivate prisoners and to give them opportunities use their creative potential constructively.

If resources are to be used effectively, the Prison and Probation Service must ensure that there are good facilities for education in prisons. It is their responsibility to provide purpose-suited classrooms and fittings 
(Circular G-1/2008 Circular on administrative cooperation between the education sector and the prison and probation services).

Another Spring also specifies that in order to satisfy prisoners' educational needs, educational activities must be offered year round to as great an extent as possible. The report also advocates increasing the number of projects aimed at increasing our knowledge and experience of the full spectrum of prisoners' educational situations. These include evaluation of formal and informal competence, follow up after release, ICT in the classroom situation, surveys of prisoners' educational background and rights in terms of education, and their various learning disabilities. Other areas include measures to support individuals with minority languages in the prison education setting. Administrative collaboration among the various government agencies also needs to be developed and improved. The Ministry also put forward proposals concerning initiation of remote learning/web-based studies, projects for further development of prison workshops, and pilot projects for year-round educational activities.

\section{Following up on educational activities after release}

In an overall societal perspective, follow up after release is important, and a great deal of attention was paid to this issue in the Another Spring. In the report itself as well as in the parliamentary debate, proposals were put forward concerning a pilot project based on the model of the "KrAmiproject" in Sweden, in which the educational authorities take responsibility for following up former prisoners after release. The Norwegian project was inaugurated during autumn 2008.

\section{Assessment of formal and non-formal education}

Pursuant to the Education Act, adults who have the right to pursue upper secondary education also have to right to have their formal and informal competence assessed, and a certificate issued. Routines should be implemented to enable the non-formal learning of each prisoner to be assessed. This would enable prisoners to participate in the opportunities available through the recent "non-formal learning reform". The Norwegian concept of "realkompetanse" refers to all formal, non-formal and informal learning acquired by adults. In practice, this means the sum of all overall skills individuals have acquired through the education system, paid and unpaid work, participation in associations, and family life/life in society. The 
adult education authorities have granted the formal authorization to carry out these competence assessments to upper secondary schools.

Another Spring proposed initiating a project on the subject of formal and informal competence assessments. Vox (the Norwegian Institute for Adult Learning) was commissioned by the County Governor of Hordaland to carry this project out at national level. The objective of the project is to circulate information concerning the concept of formal and informal competence assessment and to promote its implementation by the Prison and Probation Service, with a view to resulting in educational activities that are more overarching and purpose-suited. The project encompasses six prisons and five schools, and will run through 31 December 2009. For further information, see http://www.vox.no/templates/CommonPage.aspx?id=2475.

\section{Information and Communication Technology (ICT)}

According to the new curricula, ICT is to be one of the five basic skills to be mainstreamed throughout basic education. Another Spring stresses, for example, that remote learning should be able to be used for individuals who wish to participate in higher education. Remote learning/web-based learning can also extend the range of educational options available to prisoners. The County Governor of Hordaland is directing a national pilot project concerning web-based learning, the objective of which is to establish regular remote/web-based educational activities for all prisoners in low security prisons (open prisons), and for all students in follow-up classes. Five low security prisons and two follow-up classes are involved in the project, which will be completed in 2010 .

\section{Linguistic minorities}

The parliamentary report advocates measures to improve the Norwegian language teaching for minority language prisoners in Norway. The National Centre for Multicultural Education (NAFO) is running a national pilot project involving two schools, which will be completed in 2009.

\section{Development of prison workshops}

In order to increase the number of vocational training activities, good, close cooperation between the prison workshops and the prisons schools is needed. For example, it should be possible to take the general educa- 
tion courses for vocational training at the school and gain practical work experience in the prison workshop.

\section{Year-round learning}

The parliamentary report pointed out that prison education has been run in accordance with the traditional schedule for the school year, and with regulated time off and vacation for the staff. This structure is in poor accord with the needs of prisoners, not least prisoners serving short sentences. A working committee has been appointed by the County Governor of Hordaland, with representatives from several prison schools, to develop good models for year-round prison educational activities. The committee will present its report early in 2009.

\section{Organization}

The Ministry of Education and Research has delegated national responsibility for education to the County Governor of Hordaland. These responsibilities include: on the basis of specific criteria, to disburse the annual budget as adopted by the Norwegian parliament to the county authorities. In its capacity as supervisory authority, the County Governor of Hordaland is to audit the annual accounts of the county authorities and submit an annual report of activities. The County Governor of Hordaland is also to stimulate pedagogical and developmental work in the area of prison education. Another area of responsibility for the County Governor of Hordaland is follow up regarding the overarching objectives and projects described in Another Spring.

With the exception of prison education in Oslo municipality, where responsibility for prison education rests with an adult education center, prison education is organized as follows: one upper secondary school takes the overall responsibility for the education offered in each prison, and the prison school operates as a branch of that main school. Formally, the teachers are employed by the main school, which also issues testimonials and certificates for the prison school students. The same administrative system applies to the teaching given in follow-up classes outside the prison. 
The place of prison education in the Prison and Probation Service

Draft bills, parliamentary reports, and allocation assignments from recent years have all stressed the importance of cooperation amongst the relevant authorities - administrative cooperation. One of the overarching goals of this cooperation is to make the release process as positive as possible for the prisoner. This is only possible if other authorities beyond the Prison and Probation Service also undertake to reliably provide the services to which they are legally committed. These include the educational authorities, the prison chaplains, the municipal health and medical services, the county dental services and specialist services, the local social services, the library services and the employment services.

\section{Areas of cooperation}

The Prison and Probation Service has many different personnel categories. This makes it important to find areas of cooperation so that existing resources are well utilized for prisoners. In 2005, a circular was issued by the Ministries of Justice and Education and Research concerning administrative cooperation between the education sector and the Prison and Probation Service (G-5/2005). The circular was revised in 2008 (G-1/2008), to clarify the distribution of responsibility and tasks for agencies at national, regional and local levels. The following areas for cooperation can include stakeholders involved in prison education:

a) at national level - the prison and probation education coordination committee

The prison and probation education coordination committee was established in 1975, and has representatives from the Ministry of Justice, the Ministry of Education and Research, and the County Governor of Hordaland. At their meetings, strategic issues are discussed, and infor-mation about each other's activities exchanged (including information relating to the Education Act and the Enforcement of Sentences Act). Since 2001, the Ministry of Education and Research has delegated the appointment of its representative on the coordination committee, first to the National Board of Education and later to the Norwegian Direc-torate for Education and Training. 
b) at regional level

In order to strengthen cooperation in the regions, the County Governor of Hordaland has asked the other county governors to set up a specia-list forum in each region, with management level representatives from the board of education, the Prison and Probation Service, the county employment service, the police, and others. The objective is to bring these people together to discuss and develop prison educational activi-ties, to reinforce follow-up work, and to find good routines for cooperation.

As a follow up to Another Spring, the County Governor of Hordaland has requested all county governors to draw up mandatory three-year action plans for education under the auspices of the Prison and Probation Service. Their remit, on the basis of the current situation, is to:

- evaluate previous practices,

- set out recommendations for the content and organization of education, taking into account: the prison population (duration of sentence, convicted prisoners/individuals being held in remand, etc.), prisoner's educational needs, the labor market situation, the need for follow up after release, and

- set out proposals for cooperation routines for the parties involved.

To date, some counties have drawn up solid plans and set up professional networks that function well, while work in other counties has been less satisfactory. Where things have gone smoothly, efforts are now being made to find new solutions instead of concentrating on the impediments to progress.

Pursuant to Article four in the Enforcement of Sentences Act, concerning administrative cooperation, the Prison and Probation Service, in collaboration with other public agencies, is to ensure that convicted prisoners and remand prisoners receive the services to which they have legislated rights. In accordance with directive G-1/2008, the setting up of forums for collaboration at regional level is the responsibility of the Prison and Probation Service. This regional cooperation is intended to result in, for example, a differentiated range of prison educational options in the regions and ensure overall evaluation of regional educational activities. This type of administrative cooperation has to date been established in some but not all regions. 
c) at local level

According to directive G- 1/2008 routines and regular forums for cooperation between local school administrators and the prison and probation authorities are to be established. This cooperation is to cover dayto-day coordination and evaluation.

\subsubsection{Education for individuals in remand}

Norway does not have separate remand centers. Individuals in remand are incarcerated in the same facilities as convicted prisoners serving their sentences. Approximately one third of the individuals registered at these facilities each year are individuals in remand, and they occupy about one fifth of all the prison places available, and account for a large number of those involved in educational activities (Annual statistics from the Prison and Probation Service, 2007). In 2007, 20\% of all incarcerated individuals were individuals in remand, and this group represented approximately $16 \%$ of the individuals involved in educational activities.

No separate statistics are kept regarding which educational activities individuals in remand participate in. Individuals in remand may, under special conditions involving a ban on correspondence and visitation, and if need be, receive individual tuition. Individuals in remand who are not subject to restrictions can attend prison educational activities together with prisoners serving their sentences.

\subsubsection{Education for prisoners}

Since 1996, prison schools have submitted annual reports on a standard form to the County Governor of Hordaland. On the basis of the information given in these forms, the County Governor draws up an annual report on education in Norwegian prisons. The form has five main headings: the prison and the prison population, the prison school, prisoners/prisoners who have been released, the students, and prison education summary for the year.

Since 2001 the form has also contained qualitative questions on various aspects of cooperation with the prison, the standard of the school facilities, use of ICT, and other comments on educational activities. 


\section{Scope}

In 2007, there were prison schools in 46 of the 52 prisons in Norway. Since 2008, educational activities have been offered at all prisons covered by the obligation to provide education. There were also ten follow-up classes for prisoners after release, so that they can continue education they begin in prison. The total prison capacity in these 46 prisons was 3,164 places. There were 2,467 prisoners serving sentences and 628 individuals in remand. There were 1,263 full-time school places: 1,178 in prison schools and 85 in follow-up classes. The total number of teachers, working full and part-time, was 402, corresponding to approximately 245 full-time teaching positions. Just over one third were filled by women (38.8\%).

Since 1997 there has been a steady decline in the number of school places for comprehensive schooling. In 2007, only $3 \%$ of the places were for comprehensive schooling, as compared with $16 \%$ in 2000 . There are two possible explanations for this decline: either more prisoners have completed comprehensive school than used to be the case, or prison schools have become more flexible about adapting the educational options to the prisoners' needs, and this has happened at a time when most prison sentences are of short duration. Many prison schools, however, reported that although they had students doing upper secondary level courses, they actually spent a lot of time reviewing and brushing up basic knowledge from comprehensive school. Because many adults find going to comprehensive school de-motivating, it can be assumed that although many prisoners are registered as doing upper secondary level courses, a great deal of the teaching is actually basic.

\section{Educational options}

More than half of the study places offered as upper secondary level courses are in upper secondary level subjects. The group doing "other courses" has remained stable over the years.

The distribution of study places into educational options for 2007 was:

- Comprehensive school - 3\%

- Upper secondary school - 57\%

- Other courses - $40 \%$ (other courses are defined as short courses, often not for credit). 
Upper secondary level courses.

The three main study orientations at upper secondary level in prison education are general, business and administrative studies, engineering and mechanical trades, and building and construction techniques. These account for over three quarters of the study places. In addition, there are courses in woodworking trades, hotel and food processing trades, building and construction trades, agriculture, fishing and forestry, arts, crafts and design, technical building trades, and music, dance and drama. There has been an increase in the number of place for vocational training, which is in line with the recommendations in Another Spring.

\section{Other courses}

Under this heading, more, shorter courses are now being offered, with greater variation. These include arts and crafts, Norwegian as a second language, practice in residential skills, painting, welding, music, and computer studies. Courses in creative and practical subjects can be helpful in developing prisoner's self-confidence and motivation, and providing them with a sense of meaning. The fact that many prison schools are offering more and more short courses appears to be better in line with the needs of the prisoners who want to study. Short courses can also be good kick-offs, encouraging prisoners to take an interest in some subject that will, in turn, help them find it easier to go on to longer study programs. In prisons where short sentences are being served, the prison schools are encouraged to offer short, competence-raising courses that will qualify the prisoners for the labor market after release.

ICT

ICT has become and will remain for the foreseeable future, a subject requiring a great deal of attention on the part of both the educational and the prison and probation authorities. The Norwegian government gives high priority to education in and use of new technology in the classroom, see the ICT skills program 2004-2008 (from the Ministry of Education and Research, in Norwegian only).

The curriculum for the Knowledge Promotion Program describes five basic skills: reading, oral and written expression, mathematics, and digital competence. All students have the right to education in accordance with this curriculum, which functions as an administrative statute. Digital com- 
petence is defined as the ability to use ICT equipment, and learning this skill is mainstreamed into every subject area. One aspect of this basic competence is mastery of the Internet. Internet access has become an important educational instrument for all students in both comprehensive and upper secondary school. At almost all levels, prisoners, including those attending schools run under the auspices of the Prison and Probation Service, need Internet access in order to prepare for and take examinations.

Students who do not have full mastery of ICT skills will be severely handicapped on the labor market and in civil society. It is therefore important to find solutions that satisfy the needs of both the educational authorities and the Prison and Probation Service. For this reason, a National Forum for ICT/Internet in Prison Education (NFFIKT) was established in 2004, with representatives from the central administration of the Prison and Probation Service, the Prison and Probation Service's own ICT department, and the national educational authorities. The remit of NFFIKT is to propose solutions that satisfy the pedagogical needs in prison education and tackle the challenges associated with communication and security.

NFFIKT has now put forward a proposal for a national firewall that will give prison schools access to "safe" websites, and respond to both the pedagogical and the security challenges.

In Punishment that Works, the Ministry of Justice states the objective of establishing Internet connections for prisoners in all prisons. According to this report, Internet access would increase the range of educational options, not least in higher education. If the principle of normality is to be observed, Internet access is essential.

\section{European IT project}

In 2005, the County Governor of Hordaland took the initiative to applying for a Grundtvig 1 project, the objective of which was to test various types of ICT solutions in European prison education. The project was approved by the EU in autumn 2005, and has now been concluded, having run from December 2005 through December 2007. Norway was the coordinating country for the project, which included a total of nine countries: Denmark, the UK, Greece, Romania, Slovenia, Sweden, the Czech Republic, and Germany. For more information concerning the Pipeline project, please see www.pipeline-project.org 
Cooperation between vocational education and prison workshops

One recurrent problem for the Norwegian Prison and Probation Service has been how to organize smooth cooperation between prison schools and workshops. The position of the Ministry of Justice is that such cooperation is desirable so that various activities can be combined in a more goaloriented and flexible fashion. Many prison workshops are authorized educational institutions. This should facilitate cooperation and make it possible for prisoners to receive practical training in the prison workshop and general education in the prison school. The Prison and Probation Service has drawn up a strategy and action plan for 2005-2008 for the development of prison workshops. The objective is to make prison workshops more highly qualified, and better integrated into the rehabilitation efforts carried out at the prison.

Closer cooperation between the prison workshop, the prison school, the vocational training authorities and the labor market authorities will make it possible to offer a considerably larger range of educational options. In the 2007 annual report on prison education from the County Governor of Hordaland, more than four out of five (84\%) of the prison schools stated that they had good cooperation with their prison workshops.

\section{Cooperation between prison education and other stakeholders}

Briefly, cooperation differs greatly in different areas, being smoothest with the prison workshops. The employment service is also highlighted as a positive player in cooperation, while cooperation between the prison school and other program activities appears to be weakest. There is a need for better cooperation in relation to prisoners' sentence plans. Although there have been improvements in this cooperation, some prisoners still have no comprehensive plan drawn up by the Prison and Probation Service. The prisoner is the loser in these cases, having to decide about various options being offered from different providers without an overview. A great deal remains to be done in this respect, and responsibility for coordination rests with the Prison and Probation Service.

According to Punishment that Works, the government proposed a number of measures to reinforce administrative cooperation regarding prisoners serving their sentences, with a view to setting up mandatory structures for cooperation between convicted prisoners, the Prison and Probation Service, and other agencies that participate when prisoners are 
released, in order to reduce recidivism. In the report, the government also advocates a "return to society guarantee" for continuous follow up by various agencies after a prisoner is released, with a firm focus on getting these individuals onto the labor market or into further education, and with strict demands regarding rehabilitation and behavior modification.

\section{University and higher education}

Many prison schools are beginning to offer structures and counseling for prisoners who wish to take up university or other higher education. The social service officer at each prison can help arrange student grants for textbooks, and sometimes even supplementary tuition. Most prisoners who begin university studies are in closed prisons, and are often serving long sentences. In many prisons, a number of independent study places are allocated for higher education. In Punishment that Works, the Ministry of Justice particularly emphasized the potential inherent in remote education for individuals wishing to pursue higher education in Norway or elsewhere.

\section{Women prisoners}

In 2007, nearly half of the women prisoners were engaged in educational activities, which is a higher figure than in the past. A larger proportion of women than of men prisoners participate in educational activities. However, women prisoners have fewer other activity options than their male counterparts. For example, there are very few opportunities for women prisoners to participate in vocational training.

\section{Foreign prisoners}

Increasing numbers of foreign prisoners have access to prison education. In 2007, nearly one out of every four prisoners participating in educational activities was from non-Norwegian backgrounds. Approximately 50 percent of these foreign students were at the four largest prisons.

The rules for financing are ambiguous for this group. In spite of clear recommendations from the Council of Europe stating that special attention is to be paid to foreign citizens with language difficulties, the Norwegian regulations have shortcomings in this respect. Adult immigrants in Norway have a right to lessons in the Norwegian language and civics up to a certain level. It remains unclear, however, whether foreign prison- 
ers are covered by this stipulation. In Another Spring, the Ministry stated that the rights of non-Norwegian prisoners in the area of education must be strengthened, if necessary through legislation and statutes. The objective of such education is to qualify non-Norwegian prisoners for work or continued education in their home countries for those who are expelled.

\section{Ages}

Students in prison schools are adults. Nearly $70 \%$ of the prison students are between the ages of 23 and 49. Nearly half are between 31 and 50 . The age group 41-60 comprises $19 \%$ of the total number of students. The student group between 15 and 22 years of age comprised approximately $12 \%$ in 2007 . The age distribution in the follow-up classes is roughly the same as above.

\subsubsection{The transition from prison education to education/work in the community}

Prisoners have problems of many kinds to cope with, and being in prison only adds to them. The period approaching release is the most difficult. Problems include: finances, housing, school/work, leisure time, drink/drug abuse, health, and finding a secure, safe social context in which to live. A great deal remains to be done in terms of the transition phase. Beginning in the 1970s, and increasingly in the 1980s, follow-up classes were established in different parts of Norway. The subjects offered in the follow-up classes tend to be relatively restricted, with virtually only comprehensive and upper secondary courses given. Towards the end of their sentences, some prisoners also have day release privileges from low security facilities to schools in the community, adult education centers, universities, etc.

In Another Spring, the Ministry of Education and Research proposes that the well-functioning model for administrative cooperation should be developed, and experience shared with others. The Ministry pointed out the "Steinkjer model" as one that could be expanded on and used at different types of prisons. One of the follow-up classes at the Steinkjer prison has gradually developed good multi-agency cooperation, with the released prisoner in focus. The model is organized around meetings attended by the former prisoner and representatives of various agencies to 
discuss the individuals' present situation and plan for his or her future. The meetings are convened by the individual him or herself, and he or she also chairs the meeting and keeps the minutes. Thus the individual experiences being taken seriously, the various agencies have their accountability, and follow up becomes constructive (Ingebrigtsen. O., and og Susegg. B.A., In Norwegian, English equivalent title: With mastery as experience and society as an opportunity, 2006).

\section{The Government "Return Guarantee"}

In Punishment that Works, the government proposes establishing a "return guarantee" concerning prisoners' return to society after release, against the background of the fact that the period of release and the time thereafter is decisive to the future of an individual who has served time. A person's basic needs in terms of managing in society must be satisfied at the time of release. The "return guarantee" is a multifaceted instrument of criminal policy the aim of which is to reduce the problems associated with recidivism. Less crime means less loss of life and less ill health which, in turn, means socioeconomic savings. The objective of the guarantee is to ensure that prisoners and individuals convicted of crimes, who are often among the poorest and most vulnerable members of society, have access to the same rights as all other citizens in spite of their status as convicts.

In accordance with the terms of the guarantee, it falls to the responsibility of the Prison and Probation Service to inventory the service needs and rights of each individual convicted of a crime as early as when the judgment in the case has been handed down, to circulate information concerning these needs to the agencies that provide the services in question, and to do so in good time so that the agency will be able to make the services available well before the individual is released. At that point, the various agencies become responsible for providing the services to individuals convicted of crimes in the same way as to other citizens.

The main features of the "return guarantee" are:

- adequate housing

- education

- work, including assessment and qualification programs

- social services, including an individual plan 
- health services, including psychiatry and substance abuse programs

- financial advisory services and debt clearance counseling or debt recovery if necessary, and

- a predictable date of release.

In addition, to a greater extent than at present, the Prison and Probation Service in collaboration with NGOs, will help prisoners establish social networks after release.

Prisoners are to be held accountable and participate actively in their own rehabilitation processes. Each prisoner should be the convener of a personal responsibility group, among of the aims of which should be to call relevant partners in cooperation to meetings, to chair these meetings, and to write minutes from them. The Prison and Probation Service is to cooperate closely with its partner administrative organizations, to improve the quality of the sentence enforcement, whether it takes place in prison or in the community. This applies to prison workshops, programs, meetings between prisoners and their social workers, and educational activities.

\subsubsection{Financial aspects}

Most of the costs of prison education are covered by the educational authorities. However, the Prison and Probation Service pays the daily allowance to prisoners involved in educational activities as well as the costs for prisoners with day release privileges for educational activities.

The total budget allocated by the Norwegian parliament for prison education covers everything having to do with prison education and follow-up classes. Most of the funding (85-90\%), goes to teachers' salaries and administration. The rest goes to equipment, textbooks, skills enhancement, etc. 


\subsection{The results of prison education}

\subsubsection{Quantitative results}

Number of students

In 2007 the number of new prisoners registered in Norwegian prisons was 12,536 . The average number of students per day in prison education was 1,263 , with a total of more than 6,400 individuals (prisoners and released former prisoners) involved in educational activities of short or long duration. It is positive that so many individuals are able to take part in educational activities, and thus gain motivation to go on with their education. There are major differences between the prisons in terms of the stability of the student group. In large, closed prisons where many of the prisoners are serving long sentences, the same students may attend school for the whole year, while in small prisons where many of the prisoners are serving short sentences, there is considerable turnover.

\section{Dropouts}

The large number of people who participate in educational activities in relation to the number of study places reflects some instability in the school situation in may prisons. In 2007 there were a total of 2,001 dropouts from educational activities, an increase in comparison with the previous year. Half of these were individuals who dropped out at release. Transfers to other prisons or disciplinary sanctions accounted for $14 \%$ of the dropouts. The dropout rate owing to demotivation (particularly in prison schools) was approximately $7 \%$. Drink and drug abuse is a problem that often leads to dropping out of follow-up classes.

Number of certificates/diplomas issued

Nearly 700 students received one or more certificates or diplomas. Half of these were issued for upper secondary studies, mainly pursued in the prison schools. Some 2,200 students completed short, non-credit courses.

Continued education after release from prison

Norwegian statistics are not very good in this area. The total student capacity in follow-up classes is 121 places. There are also students who leave prison and enter the regular school system (upper secondary school, 
an adult education center, a university or institute of higher education) rather than a follow-up class. There is evidence that many former prisoners work hard to establish good contact with the regular school system, but there are no statistics as to how many actually participate in regular schooling. The prevailing principle should be that any educational activity begun in prison should be part of a comprehensive plan, and that the prisoner should have something to go to (work or school) upon release.

\subsubsection{Qualitative results}

Survey of prisoners' living conditions

Friestad and Skog Hansen (2004) carried out a living condition survey in 2003 of a representative sample of individuals in Norwegian prisoners. The results indicated that:

- The upbringings of two thirds of the prisoners were characterized by one or more serious problems.

- Three out of ten had been in contact with the child welfare authorities before the age of 16, and the same proportion had family members who had served time.

- Prisoners have weak educational backgrounds, with a pattern almost the opposite of that of the general population. Four out of ten had not completed any level of education beyond nine-year compulsory school. Very few had studied at higher than upper secondary level.

- Prisoners had weak links to the labor market. Only three out of ten had been in work at the time of their imprisonment. Beyond income from employment, social welfare and criminality were the sources of income most often stated by the respondents.

- Four out of ten were living under subsistence level, and prisoners generally had substantially lower gross incomes than the general population. A large number were also in debt, many owing to having been sentenced to fines or to pay damages.

- One third of the prisoners were homeless.

- Many prisoners are in poor health. Half had one or more chronic illnesses or psychiatric disorders, which is a much higher figure than for the general population. 
- Six out of ten prisoners had substance abuse problems. The majority of these prisoners mixed drink and drugs. Female prisoners more often had substance abuse problems than male prisoners. The more serious the abuse, the greater the health consequences, as well as the poorer the family bonding, and the weaker the individuals' financial situation was.

- More than half the prisoners had children, and the majority of them had contact with their children weekly or more frequently.

- The living conditions of prisoners are particularly problematic, because their problems tend to be cumulative: three quarters of the respondents had problems in relation to two or more aspects of their living conditions. The cumulative effect of these problems was found to be correlated with the upbringings of the prisoners: the more problematic their upbringings, the more complex were their living conditions as adults.

The researchers concluded that no isolated measures can assure successful reintegration in society; it is necessary to have a holistic point of departure and an understanding of the scope of marginalization of this group.

\section{Research-based evaluations}

By way of conclusion of this section, we would like to describe the extensive research-based evaluation the Norwegian parliament requested the government to commission in 1998. The parliament unanimously requested a research-based evaluation of the role of prison education and proposals for measures to strengthen this area of the Prison and Probation Service. The evaluation examined the system level, the pedagogical organization and the individual level. The research project was completed in 2003. The summary of the key findings is as follows:

Prison education was consistently positively evaluated by the prisoners. There was a consensus among prison school students that attending school was rewarding. Prison school students often have inadequate educational backgrounds and negative experience from their previous school situations in the community. They felt that prison education provided a good opportunity to gain self-confidence and motivation to continue schooling. With all this in mind, the evaluation reports pinpoint various 
measures that should be launched by the educational authorities, the Prison and Probation Service and other key stakeholders, to strengthen the area of prison education:

- More subjects could be offered, including more vocational education, creative subjects, short credit-giving courses, ICT courses.

- Better cooperation and integration are needed between the work and school activities offered in prison, in order to provide more educational options.

- Better guidance and advisory services are needed in relation to educational and vocational options.

- Educational options need to be more flexible and varied for different age groups, for women and men, in relation to minority languages, in relation to all prisoners with a right to education, and in relation to prisoners serving both long and short sentences.

- More needs to be done to coordinate measures undertaken by the different stakeholders both in prison and after release, in terms of "sentence plans" and the work done by personal contact officers.

- Follow up after release needs to be reinforced.

- Day release privileges for schooling should be more regularly used.

- Sentence enforcement has been seen as an end in itself, and as superordinate to all other activities. This poses obstacles to good resource utilization and makes it difficult to provide prisoners with systematic, integrated, structured education.

According to Skaalvik, Finbak, and Pettersen (2002) the aim of prison education has not been clearly elucidated. Neither teachers nor other prison staff knew what the official objectives are, or in what documents they could be found. The authors described prison schools as organized according to the same model as and as branches of state upper secondary schools. When prison schools are subordinate to a larger institution with a very special type of organization unlike most other institutions in society, it becomes difficult to provide continuity and follow up. The linking up of prison education with the municipal system and with state upper secondary schools did not have the expected effects. Both Rognaldsen and Skaalvik et al. are of the opinion that the national level management of prison education (delegated to the County Governor of Hordaland) should 
be reinforced and extended. (Rognaldsen, 2003. In Norwegian. English equivalent title: Assessment of prison education with the emphasis on the systemic level and the full range of educational activities in the prison service), (Skaalvik, Finbak and Pettersen, 2003. In Norwegian. English equivalent title: Education in Prison: on an even keel?).

\section{Women prisoners}

Educational options for women prisoners have long been criticized as being too restrictive, offering too little variation, and being poorly adapted to the female prison population. In her evaluation of education for women prisoners, Sandvik indicated that like the general female population, the female prison population is a varied group with different educational needs. Sandvik pointed out many obstacles in terms of structures, traditions, the layout of prison premises, and subject areas, all of which result in discrimination of women prisoners in comparison with their male counterparts. In Sandvik's view, women prisoners should be more encouraged to study vocational subjects, more ICT courses should be offered, and the range of educational options should be extended to include more practical subjects such as creative arts, music, dance and drama, gardening and animal husbandry. (Sandvik, 2003. In Norwegian. English equivalent title: What's Right for Women? Education of Female Prisoners in Four Norwegian Prisons).

\section{Prisons of non-Norwegian backgrounds}

The proportion of foreign prisoners in the Norwegian prison population is rising. Viljugrein evaluated prison education for foreign male prisoners and found that they, too experience schooling in an extremely positive light. In Viljugrein's view, Norwegian language courses should also be offered that are adapted to the needs of the various groups of foreign prisoners. Many prisoners who are second generation immigrants have problems with Norwegian, in spite of having attended state comprehensive and upper secondary schools. This is a serious signal to the state school system, that language and Norwegian classes for immigrants need to be reinforced. According to Viljugrein, non-Norwegian prisoners who are not interested in learning Norwegian ought to be offered English classes. (Viljugrein, 2002. In Norwegian. English equivalent title: Learning, 
Language, and Prison: Teaching male minority-language prisoners in four Norwegian prisons).

Survey of prisoners' educational backgrounds, rights to education, needs for education, learning disabilities, and learning strategies

One of the aims of Another Spring was to clarify statistically how many prisoners had a right to education. The Ministry also wanted a survey of the scope of learning disabilities among prisoners. For this reason, the County Governor of Hordaland commissioned the University of Bergen to carry out a number of surveys concerning the educational backgrounds, educational needs, educational preferences, motivation to participate in prison education, and learning disabilities among individuals in Norwegian prisons. These surveys have filled an important function in documenting educational needs in Norwegian prisons, and resulted in increased budget allocations for this purpose.

Among the findings, it can be noted that $84 \%$ of the prisoners between the ages of 18 and 25 had not completed their upper secondary education (Eikeland, Manger, and Diseth 2006). Another finding was that one third of the prisoners in Norwegian prisons had a right to education, while nearly $60 \%$ stated that they would like to participate in prison educational activities. Vocational training was the most frequently-cited preference. The prisoners also reported having learning disabilities to a large extent. Four out of ten prisoners stated that they had "some" or "serious" literacy difficulties, and roughly half that they had "some" or "serious" numeracy difficulties. According to the survey the highest completed level of education of more than one out of ten (13.9\%) prisoners was courses or a degree from a university or other institute of higher education.

In another report, (Manger, Eikeland, Diseth, and Hetland, 2006) the results indicated that the main source of motivation for prisoners to participate in prison educational activities was the desire to change or gain mastery over the future. Three reasons for not participating in prison educational activities were approximately equally strong: the prison did not offer educational activities, the prisoners did not receive information about the educational activities, and the prison did not offer educational activities suited to the needs of the prisoners.

Yet another survey (Diseth, Eikeland, and Manger, 2006) indicated that inadequate access to ICT equipment created problems for nearly half of the 
prisoners who were participating in prison educational activities. In other respects this study showed that prisoners who were participating in educational activities were generally satisfied with the quality of the teaching.

In Another Spring, the Ministry expressed concern regarding the fact that so many prisoners have reading, writing and numeracy difficulties to cope with. As a follow up to this report, the County Governor of Hordaland commissioned the University of Bergen to initiate a pilot project at the Bergen prison to survey the reading and writing disabilities of the prisoners there in greater detail. The results of this pilot project were presented in three reports, and indicated that a large proportion of the prisoners had problems with basic reading skills that fall within the scope of the definition of "specific reading disabilities". Prisoners were also found to have a clear tendency to overoptimistic reporting of their own reading skills (Asbjørnsen, Manger, and Jones, 2007).

This study also indicated that prisoners read much more in prison than when they were at liberty in the community. One of the reasons may be that prisoners with good access to literature and who also read a great deal when they were at liberty continued to do so while serving their sentences, borrowing books more often than they would have done if they were at liberty. Another finding in this report was that approximately three out of four of the prisoners stated that they seldom read anything but the newspaper (Asbjørnsen, Jones, and Manger, 2007).

In their third report, the authors found that the prisoners' reading skills were less good than would be anticipated in comparison with their age groups in general. Between 50 and 70\% were found to have reading difficulties serious enough to satisfy the diagnostic criteria for reading disabilities (Asbjørnsen, Jones, and Manger 2008).

The University of Bergen, with some financial support from the County Governor of Hordaland, is now carrying out a national study on a representative sample of prisoners to investigate reading and writing skills among prisoners in Norway. The study, being performed as a commissioned $\mathrm{PhD}$ project, will be completed in 2010. 



\section{Sweden}

by Svenolov Svensson

\subsection{History}

Prison education has taken different forms in the Swedish prison system over time. In the nineteenth century the clergy were very important, particularly in teaching reading skills. Ambitions in terms of thinking that prisoners should also learn a trade or vocational skills have also been documented. For example, in 1874 the Uppsala county prison employed a person skilled in carpentry to teach vocational skills. An annual report from 1889 reads:

\footnotetext{
As long as mechanical, monotonous work from which they [prisoners] can learn very little is all they are offered, it will be easy for their thoughts and lively imaginations to be occupied with demoralizing ideas (as quoted in Arnelund, 1994. In Swedish. English equivalent title: History of the Uppsala Prison).
}

In the early twentieth century, Arnelund notes, prisoners were only allowed to write one letter per month, although there were also various privileged exceptions. The right of the prisoner to read was also generally extremely restricted. All a prisoner was actually permitted to study were the "cell books", i.e. the New Testament, the hymnal and a devotional volume with the English equivalent title: In Solitary Hours.

The general prison system was based on incarceration in individual cells. Prisoners were not meant to be in contact with each other, because they might influence one another negatively. Once the Comprehensive School Statue was put into effect in 1842, all prisoners under the age of 
35 had to participate in educational activities. This made the correctional system quite pioneering in the area of adult education in Sweden. From the early twentieth century a progressive system was introduced, by which good behavior was awarded with the right to read non-fiction and other literature with religious and ethical or educational and generally useful content from the prison library (Eriksson. Two works, both in Swedish. English equivalent titles: On the Treatment of Criminals, 1966, and Prison Custody, 1967). In accordance with the principle of single cell prisons, the classrooms were constructed so that prisoners sat and studied in little cubicles and were able to see the teacher but not their fellow prisoners (Lundberg. 1997. In Swedish. English equivalent title: Härlanda Prison: a mirror of its time).

\section{The dominance of the folk high schools}

With the introduction of the 1916 Enforcement of Sentences Act and the reform of sentence enforcement regulations in the 1940s, prisoners began to be allowed to spend time in each other's company and to have more contact with the outside world. From the 1950s through the mid-1970s, folk high schools were the main arrangers of prison education. These institutes of adult education, as representatives of society external to the correctional services, were considered the natural organization to take on the task of providing prisoners with further adult education. In practice, a folk high school in geographical proximity to the prison would set up a branch in the prison, using the school's teaching staff to run courses corresponding to those offered by the folk high school in Swedish, mathematics, civics, English, and Swedish for immigrants. To some extent, each folk high school left its own characteristic mark on the content and organization of education in the prison where it had a branch. During the same period, there were also teachers employed by The Prison and Probation Service who ran practical, vocational courses, mainly at youth penitentiaries.

\section{Basic education - a civil right}

When "basic education for adults" was introduced in conjunction with the problem that it had proven difficult for prisoners to continue studies they had begun in prison after release, beginning in the mid-1970s the Prison and Probation Service shifted responsibility for prison education to the community adult education authorities at municipal level. This was also 
in accord with the new legislation that came into force after the 1974 reform of the correctional system, based on the principles of normalization and proximity. Pursuant to these principles, the correctional service was to use the regular community services whenever possible rather than constructing parallel systems of their own, with an emphasis on the proximity of the outside world for prisoners. Therefore, the Prison and Probation Service began to cooperate with the National Agency for Education and the National Labor Market Board. General education in prison was to be organized under the auspices of the municipal adult education authorities and the national adult education establishments, and vocational education in prison was to be provided on equal terms as in the community, i.e. in the form of labor market training courses. The National Labor Market Board allocated funding for the vocational training, and the National Agency for Education earmarked funding for municipalities with prisons. Towards the end of this phase, the county boards of education took over responsibility for education at the Swedish national prisons and remand centers.

Swedish legislation on the right to basic education for adults (corresponding to the first seven years of comprehensive school) did not distinguish between prisoners and other citizens.

\section{Decentralization and shift of responsibilities}

Extensive decentralization in Sweden during the 1980s resulted in the abolition of funding at central level from the National Labor Market Board for special vocational courses in prisons. This responsibility now rested directly with the county labor market boards which, in turn, delegated it to the local employment services, so that the employment services nearest each prison took responsibility for that prison. In the early 1990s, when the National Agency for Education was restructured, direct allocation of funding for general education for prisoners also disappeared. On the basis of a proposal from the Prison and Probation Service, the Ministries of Education and Justice adopted a decision that funding corresponding to the funds previously allocated for prison and remand center education would be transferred from the former to the latter ministry. This agreement also implied that the funds would be used to procure the corresponding education from the relevant municipal and national adult 
education institutions. It was assumed that procurement would take place on a not-for-profit basis for the educational provider.

The Adult Education Act was also amended to clarify that municipalities were no longer obliged to provide prison education (the Swedish Code of Statutes 1985:1100 and the Swedish Code of Statutes 1992:232). Although it was not clearly stipulated in the law it appears to have been understood that the Prison and Probation Service would take over this responsibility and the obligation to offer education to any prisoner who had a legal right to education, since the corresponding funding was transferred to the Prison and Probation Service.

A government commission report with the English equivalent title Crowning Knowledge (Swedish government commission report 1993:23) found that both national and municipal level procurement of educational services had failed to follow the directives stipulated in the Public Procurement Act. Services had been procured from the municipal education providers without being open to competition from other providers of education. As a result, contracts for prison educational services were convened with several new providers. At one point this meant that the Prison and Probation Service had contracted 21 different providers, only three of which were authorized to issue grades independently.

Criticism of prison education - the development of modern "Learning Centers"

The Swedish report from 1998 Prisoner education under the auspices of the Prison and Probation Service - survey, problem description and recommendations (Roitto \& Sjöberg, 2001) analyzed the current state of affairs and put forward proposed changes with a view to improving and leveling quality. The main recommendation was to ensure that there was pedagogical expertise at prison management level, with a clear link to the state educational system, in order to ensure comparable quality. Over a two-year period, a new system was gradually introduced, establishing "Learning Centers" (Lärcentra) at every prison facility. Each Learning Center has one or more teachers who are qualified to teach at upper secondary school. They are employed by the Prison and Probation Service. Since 2008, each prison region also has a headmaster, who is directly responsible for education in his or her region. The headmasters form a network, coordinated by a national prison education coordinator. Educa- 
tional activities are based on the needs and preferences of each individual. Access to web-based technology means that no student is dependent on the particular competence of the teacher(s) at his or her prison facility. Instead, all prisoners, irrespective of the facility they are in, are able to study on the basis of an individual study plan and with access to all the teachers on the staff of the Prison and Probation Service. Prisoners and teachers correspond via a closed loop Internet-like network. Thanks to this technology, there are now more study options available, the study options are open to a larger potential group, and there is more continuity when, for example, a prisoner is transferred from one facility to another.

\subsection{Legislation and other regulatory documents}

\section{Abolition of a right}

Until the early 1990s, prison education was an integral part of Swedish adult education policy, with its emphasis on special efforts for adults with inadequate educational backgrounds and the people who have had least access to society's resources. Until then, prisoners had the same rights to basic education as all other citizens. After funding was transferred from the Ministry of Education to the Ministry of Justice, this legal right no longer applied. Chapter 11 of the Adult Education Act stipulates, with regard to municipal adult education, that every inhabitant of a municipality who does not have the skills to be achieved in comprehensive school has the right to participate in basic adult education from the age of 20. However, it also states that "The stipulations in this article do not apply to prisoners”. Thus, since 1992, prison education has been regulated by the Act on Correctional Treatment in Institutions.

The Ministry of Education initiates important developments

A significant change in prison education took place in 2007, when the Ministry of Education issued a regulation "on education in correctional care in prisons" (SFS 2007:152) Pursuant to this regulation, it became possible for the Prison and Probation Service to offer educational activities corresponding to municipal adult education (SKOLFS 1994:2), as well as Swedish language courses for immigrants (SFS 1994:895). According to this legal clarification, such educational activities are to be 
directed by the headmaster, and must follow the relevant curricula for municipal adult education. The Prison and Probation Service is now authorized to issue grades, and is under the supervision of the National Agency for Education. The grades are not to reveal that the studies were pursued at a prison facility.

Briefly, under the new system, prisoners, wherever in Sweden they are placed, are offered educational activities that are equivalent both from prison to prison and with municipal adult education as offered in the community. It should not be formally difficult for prisoners to continue studies begun at one facility after transfer to another facility or release. Studies are graded in the same way as at schools in the community. This means that prison education is now an integrated aspect of regular adult education.

On the basis of the regulation issued by the Ministry of Education, the Prison and Probation Service has issued special guidelines for prison education (2007:4). The guidelines describe the objectives and limitations of these educational activities and how they are to be run.

\section{The vision of the Prison and Probation Service - Better Out!}

Prison education is thus an integral part of the Swedish Prison and Probation Service and one aspect of Better Out, the plan of visions and ambitions for the future according to which the Service is to implement measures to help prisoners return to a life free from crime. The plan also states that the activities run under the auspices of the service are to be characterized by a humane attitude, helping prisoners to develop, and striving actively to influence their development while maintaining a high level of security, and respect for individual integrity and legal rights. The work of the Service is to focus on bringing about changes in the life situation of prisoners as well as their attitudes toward the life that resulted in their committing crimes. The remit of the Service is, at least in some areas, to improve the skills, knowledge or thought patterns of the prisoner so that they will be better equipped upon release to manage to live in society and comply with its laws. The document outlines six basic principles that are to guide the work of individuals in the Service, two of which are to: 
- interact with prisoners and others with whom we work in an honest, open and humane way at the same time as we comply with the regulations regarding the protection of society.

- encourage and assist prisoners to work towards changing their criminal behavior patterns, and induce them to better respect others.

This means that during the time they are serving their sentences, prisoners are to be encouraged to learn, to gain skills, to raise their educational levels, and to participate in activities that help them analyze and find ways out of the lifestyle that led them into criminality. (The Swedish Prison and Probation Service vision, 2001. In Swedish. English equivalent title Better Out).

\section{Collaboration with the Swedish National Public Employment Service}

For vocational training there is an agreement regarding collaboration between the Prison and Probation Service and the Swedish Public Employment Service, which guarantees that prisoners will have the same rights to services and programs as other citizens. Many prisoners have weak connections to the labor market, because they have very little work experience and incomplete educational backgrounds. Even in periods when the labor market is strong, most prisoners require support to find their way to a job. The agreement stipulates that:

- Prisoners in the custody of the Prison and Probation Service have the right to service on the same terms as other users of the employment services.

- Irrespective of where in Sweden the prisoner is, the employment service is to provide uniform services.

- Prisoners in the custody of the Prison and Probation Service have the right to service irrespective of the prevailing labor market situation and the economic cycle, prisoners in the custody of the Prison and Probation Service - like other vulnerable groups in society - will require extra support. 
- The mission of the Prison and Probation Service requires collaboration with the employment service and, in conjunction with the sentence plan for each individual; the Service is to promote opportunities for the prisoner to participate in labor market training courses, etc., if needed.

This concluding point is of particular interest, in that it points out the dependence of the Prison and Probation Service on the Swedish Public Employment Service in order to fulfill its mission.

The Swedish Public Employment Service and the Prison and Probation Service also have a national forum for collaboration, for exchange of knowledge, discussion and analysis of their cooperation, as well as local agreements concerning cooperation at local levels.

\subsection{Description of prison education and its place in relation to adult education in society}

The primary function of the Swedish Prison and Probation Service is to enforce the sanctions adjudicated by the judiciary. That role requires combining the protection of society with the rehabilitation of the individual prisoner.

\section{Prison education - one piece of a puzzle}

Education is one piece of a larger puzzle where the various pieces, the stakeholders, are to be described in a sentence plan for each prisoner, adapted to his or her needs and providing a platform on the basis of which the individual will be better equipped to return to life in the community "better out". Education has a two-pronged function in this work with prisoners. It is both part of the whole and, at the same time, it has a very particular and independent value for the individual. The first of these functions is rehabilitating, while the other applies, in fact, to all human beings - education has its value in developing our knowledge, skills, and insights into the potential society has to offer and our responsibility vis à vis society, at a workplace, in the family, amongst friends. The success of the first function can be measured in terms of reduced recidivism, while the other can only be measured in terms of value-oriented parameters. 


\subsubsection{Description of prison education}

Formal adult education under the auspices of the Prison and Probation Service is subject to the statute on prison education (SFS 2007:152), and the Swedish National Agency for Education is the supervisory body. When applicable, prison educational activities follow the national instruments regulating the corresponding educational activities in the community. Examples of aspects that are mandatorily regulated are: qualifications for teachers, prioritization in terms of acceptance and selection procedures, course content, and grading. What is always borne in mind is that prison education is adult education, rather than schooling for children and young people. The terminology used in adult education is "students" and "support for adult learning" rather than "pupils" and "classroom teaching", with an emphasis on each individual's personal responsibility for his or her studies, rather than the responsibility of the teacher. Using the concept of "Learning Centers" for education under the Prison and Probation service helps the students find the corresponding activities in the community after their release.

Most municipalities in Sweden also have Learning Centers today (although with slight variations in terminology: they are sometimes called Study Centers or Competence Centers). Each local Learning Center provides a study environment and a meeting place for adult students, as well as services, support, and help in organizing and carrying out adult education studies.

The levels of prison education in Sweden are:

- basic adult education (primary and lower secondary levels, including Swedish for immigrants),

- upper secondary education,

- vocational education,

- university and other higher education,

- other education (study circles, parenting courses, etc.).

All these levels are offered as part of the structured activity programs in Swedish prisons. Thus "program" is an umbrella term covering various goal-oriented activities including: education (general and practical), work, criminality and abuse-related programs, library activities, creative activities, physical activities, and sports and social skills training. 
Vocational training is arranged and funded by the Public Employment Service. This Service, in collaboration with the Prison and Probation Service, determines what vocational training will be offered and where it will take place.

Because prison education is one aspect of the national educational policy ambitions concerning adult education, priority is given first and foremost to individuals who have not completed compulsory school or the equivalent form of adult education. Next, priority is determined on the basis of the same principles as for municipal adult education, meaning that individuals with less prior education have first priority, as well as individuals who:

- wish to complete studies begun in accordance with an individual study plan,

- need further education for a job they already have,

- need education for planned or future professional choices.

All participation in both general and practical education takes place on the basis of a sentence enforcement (treatment) plan, individual for each prisoner. Activities that are part of the agreed plan are to be arranged for thirty to forty hours per week. They are obligatory, and remuneration is paid for them. As this implies, prisoners must participate in organized activities. However, participation in educational activities is voluntary. To participate, prisoners must apply, and must be motivated. Participation in educational activities takes place on the basis of an individual study plan, focused on life after release. Work and educational activities are remunerated in accordance with a fixed hourly salary, although a piecework/performance rate may be paid in addition for some types of work.

\subsubsection{Education for individuals in remand}

Most individuals in remand are in custody on suspicion of having committed a crime. The duration of their remand will depend both on why they are being held and on how complex their case is to investigate. Average remand duration is one to two months. An individual being held in remand may be subject to restrictions regarding contact with the outside world for reasons relating to the investigation. Such restrictions may in- 
clude a prohibition on contact with other prisoners, or censoring of letters and packages inspection of packages.

In, January 2008 there were 31remand centers in Sweden, with a total of 1,832 places (Official Statistics from the Swedish Prison and Probation Service, 2008). Individuals are placed in remand centers for one of two reasons: either they are under arrest at the decision of the public prosecutor, or they are being held in remand at the decision of the court. Sometimes individuals who have been convicted of a crime may be held at a remand center while waiting to be transferred to a prison, to some other treatment center or, in the case of foreign citizens, to be deported.

In contrast to prisoners, individuals in remand are not subject to any legal obligation to participate in activities, which also means that the Prison and Probation Service does not have to offer activities. Sweden was criticized by the Committee on the Torture of Prisoners of the Council of Europe for keeping individuals in remand overly isolated. Swedish remand centers, as opposed to prisons, often have unsatisfactory premises for activities and groups. Remand times are supposed to be short, and convicted prisoners are supposed to be moved to a prison as soon as they have been sentenced. The criticism received has led to a gradual renovation of remand centers so that individuals not subject to restrictions are able to spend more time in groups.

\section{Education offered at remand centers in 2007}

Teachers at remand centers are the main sources of information to prisoners concerning educational options offered by the Prison and Probation Service and others. A teacher and a prisoner may have an introductory meeting about studies, and draw up a long-term study plan. Individuals held for a long period in remand may be given the opportunity to begin studying, studies which can later be continued either at a prison or in the community. When a very young individual who was pursuing upper secondary studies is being held in remand, it is possible, with the individual's permission, for a teacher to immediately contact the upper secondary school in question, so that the prisoner does not have to disrupt his or her studies while in remand. In 2007, over 400 remand prisoners participated in prison educational activities. 


\subsubsection{Education for prisoners}

In January 2008, there were 61 prisons in Sweden, with a total of 5,212 places. Of these, 1,351 were in open prisons (Official Statistics from the Swedish Prison and Probation Service, - 2008). There is an inevitable, built-in contradiction between the reasons society has for needing to incarcerate people and the ambitions society also has to rehabilitate these same people so they can live normal lives. Correctional treatment in institutions is therefore structured so as to promote prisoners' reintegration into society as well as counteracting the harmful effects of deprivation of liberty. In Sweden, a prison sentence may range in duration from two weeks to life. Now that various types of alternative sanctions have been adopted (electronic monitoring, community service, etc.) the formerly large group of individuals serving sentences of short durations in Swedish prisons has basically disappeared.

The Better Out program envisages people who have been in prison leaving the care of the Prison and Probation Service better equipped for a law-abiding life. By participating in work, education, criminality and abuse related programs, etc. on working hours, as well as in structured recreational activities, prisoners can satisfy their individual needs and prepare for their release.

Since 2007, general education in prisons is taught by teachers employed by the Prison and Probation Service. Every region has a headmaster, with overall responsibility for all prison educational activities. These activities take place at "Learning Centers" modeled on those used in municipal adult education. This facilitates the transition to society for prisoners wishing to continue to study after release, who will feel familiar with both the environment and the organization of studies. The teachers at the prisons have experience of education and are qualified to teach at upper secondary level as well as at more basic levels. The key tool to prison educational activities today is a computerized platform, Nätcentrum, ("Net Center"), enabling every student, on the basis of his or her own individual study plan, to study the subjects he or she needs, in order to achieve the established goals. Remote studies give students access to subjects and teaching competence beyond what is available in the prison where they are serving time. The relevant teachers have responsibility for their own subjects and for giving grades, via the Net Center, telephone and postal contact. At their prison schools, students also have access to 
general educational support thanks to the teacher(s) working there. Students carry out their remote studies from the same facilities/at the same Learning Center where other studies are pursued. Remote study is a valuable option in that it increases access to education and contributes substantially to increased possibilities for individualization. Because it is not tied to any specific time or place, it is also a type of education that is less vulnerable in relation to transfers.

\section{Vocational education}

Vocational training is usually carried out in conjunction with the local employment service, which also organizes and funds it. It takes the form of labor market courses, with the same quality demands as for courses in the community. The cooperation between the Prison and Probation Service and the employment services follows a central agreement with the Swedish National Public Employment Service stating that prisoners have the right to services on the same conditions as other users of the employment services (In Swedish, English equivalent title: Collaboration between the Employment service and the Prison and Probation Service, Kriminalvården 2008). This cooperation agreement also clarifies that, in addition to their criminal backgrounds, many prisoners have the problem of having had very little experience of the labor market. This absence of work experience contributes to their difficulties in getting and keeping a job, as does their often incomplete schooling. Even in times of economic boom, prisoners and former prisoners often need extra support in finding work. Advisory services, job application courses, preparatory and vocational education are examples of what the employment service can offer.

In many parts of Sweden there is also a special type of cooperation for former prisoners known as KrAmi which has been very successful. In KrAmi the employment service, the Prison and Probation Service and the local social welfare offices work together to help former prisoners find and keep a place on the labor market (Nyström et al., In Swedish. English equivalent title: Investing in work, 2002). A recent $\mathrm{PhD}$ thesis finds that:

The benefit-cost ratios were 17.8-12.7 for the two KrAmi programs and 5.15.8 for the two non-custodial programs. KrAmi rates are higher for rehabilitation rate (pension points), rehabilitation rate compared to investment costs and benefit-cost ratio, pay-off time is the shortest. The results of both the effect 
study and socioeconomic study suggest that social improvements for the prisoners corresponded with socioeconomic profitability.

(Jess, Kari, In Swedish, English equivalent title: Useful counting: socioeconomic evaluations of social work, Stockholm University, 2005)

The scope of prison education in 2007

In 2007, about 890,000 hours of prison education were carried out in prisons (Agresso 2007), which corresponds to $14 \%$ of the total of program activities (work, education, criminality and substance abuse related programs, social skills training, creative activities, etc.). A total of 3,800 prisoners participated in education, according to the system regulating prisoners' allowances. Approximately $7 \%$ of these prisoners were women. This may be compared with the percentage of women in the total prison population, 5.3\% (Official Statistics from the Swedish Prison and Probation Service, 2008).

\section{The orientation of prison education in 2007}

The majority of educational activities, $40 \%$, are at upper secondary level, followed by basic general education corresponding to nine-year compulsory school, $34 \%$, and vocational training, $22 \%$. Approximately $4 \%$ of the studies pursued are at university or higher education level (Sjöberg, 2008, unpublished). The nature of prison educational activities has changed markedly since the model using Learning Centers and remote studies was introduced in 2006-2007. Previously, prisoners could only choose courses the local teachers were qualified to teach, while now they can, in principle, be in contact with the teachers who have the qualifications that best suit their own needs, irrespective of where both student and teacher are located. For an individual student, this means an increase in the course options from, perhaps, five or six local courses to more than one hundred subjects.

\section{National action plan}

A national action plan for activities at Learning Centers has been adopted in order to develop a comprehensive, coherent educational system. The action plan provides a common point of departure for activities by:

- clarifying the common platform for teaching,

- supporting teachers and educational activities, 
- providing guidance for teachers in terms of pedagogy and activity development,

- drawing up follow up and evaluation materials.

\section{Local action plan}

The national action plan specifies that a local action plan is also to be drawn up by each Learning Center. The objective of these plans is to set out uniform routines for working with prisoners from their arrival at the facility, until they have completed their studies and received documented grades, The local action plans are also to including follow up and evaluation, and to document, one calendar year at a time, specific goals decided on locally to improve and develop the educational activities offered.

Vocational education may take the form of "labor market courses" organized and financed by the Public Employment Service. Such courses may include: welding licensing course, cutting processing, industrial technology, wood products technology, fork lift truck license, institutional kitchen training, and tile setting.

Many individuals in Swedish Prisons are from non-Swedish backgrounds. Some of them need to study the Swedish language. Such courses, known as Swedish for immigrants (sfi) are offered. Individuals from non-Swedish backgrounds come from a wide range of educational backgrounds as well, spanning from individuals who are illiterate to individuals with higher education degrees. The Swedish National Agency for Education has drawn up national syllabi including grading criteria for courses in Swedish for immigrants, and these are used in the Prison and Probation Service as well.

University education and other types of higher education have not been given very high priority to date, accounting for $4 \%$ of the total number of study hours completed. In spite of this small percentage, the teachers whose job it is to assist prisoners with their remote studies consider studies at this level to be demanding in terms of resource utilization, because all external computerized communication must be rigorously monitored.

\subsubsection{The transition from prison education to education in the community}

Educational activities are among the instruments at the disposal of society to increase the chances that prisoners who have served time under the 
auspices of the Prison and Probation Service, will be able to create a life for themselves in society free from crime and drugs. The various objectives for prison education range from development of prisoner's competence, to helping them be better able to go on studying after release or getting a job, as well as developing informal competence, helping them take responsibility, take part in teamwork, and function in groups. To put it simply, formal competence can (in the long run) lead to a job, and informal competence can contribute to being able to keep that job and otherwise improve one's quality of life.

In light of the above, all education under the auspices of the Prison and Probation Service should be rooted in the local community, so that studies begun in prison can be continued outside or, if they are concluded while the prisoner is serving his or her sentence, be evaluated on equal terms with studies pursued outside prison. It must be possible to assess performance, so that the individual will not have to start over again. The regulation from the Ministry of Education (SFS 2007:152) assures prisoners that courses they begin while in prison can be completed and supplemented with continued studies in the community after release.

Studies in the community with day release privileges

One way of improving prisoners' chances of studying on equal terms is the use of day release privileges so that prisoners can leave the institution and participate in studies at a municipal Learning Center outside the Prison and Probation Service.

Opportunities for studying with day release privileges are regulated in the instructions and general guidelines from the Prison and Probation Service concerning special measures for transition to the community (KVFS 2008:5), including day release, halfway houses, and "close supervision release". Prisoners on close supervision release live at home but with electronic shackle supervision, and participate in studies or work. The aim of close supervision release is to make it easier for the prisoner to have a job, and thus to develop a stable lifestyle after release.

In determining whether or not to grant a prisoner close supervision release, issues to be taken into account include whether the prisoner needs a period of becoming accustomed to working life and whether close supervision release can be assumed to substantially improve his or her chances of making a living upon release. Prisoners with highest priority for close 
supervision release are those who do not have a place on the labor market and therefore require an introduction to working life.

According to the guidelines, it should also be possible to grant day release privileges for studies or vocational training to prisoners who have weak educational backgrounds, i.e. who have not completed upper secondary level education. Day release privileges for university or higher education should also be able to be granted if they would improve the prisoners' possibilities of gaining a foothold on the labor market. The Prison and Probation Service has not kept separate statistics concerning day release privileges for studies, but estimates that 150 to 200 prisoners participate annually in studies with transitional arrangements such as day release, halfway houses, and close supervision release.

\section{Internet-based education - new opportunities via the "hole in the wall"}

All the teachers and local Learning Centers are under the umbrella of the National Learning Center, thus enabling all prisoners to study, wherever they are. Both the use of flexible learning and teachers in different prisons teaching different subjects provide support to the students in their learning processes. A student can have a teacher anywhere in the country, and keeps that teacher from the beginning until the end of a course , even if he or she is transferred from one prison to another. The teaching is totally individualized concerning, for example, courses, study pace, and starting date, thanks to the Net Center.

It is mainly used for communication between teachers and students when they are not in the same place. A separate virtual room is created for each student where he or she is connected to a remote teacher. Only one student and one teacher have access to each room, a forum for their communication. It is possible to attach a file, such as a Word document, to a message, as well as a video clip or a sound file. The students' individual study plans are also registered with the Net Center.

The Swedish Prison and Probation Service has guidelines for the use of ICT by prisoners. In order to have access to ICT equipment, the prisoner must sign an agreement.

The Net Center is an Intranet for prisoners and teachers - InIT (Prisoners IT). Although prison teachers have full access to the Internet, students can only use the Internet with permission and under supervision. They are, however, free to use all the Intranet services. 


\subsubsection{Financial aspects}

In 2007, the total cost of general prison education and prison vocational training exceeded EUR 12 million. The Prison and Probation Service provided the majority of the funding.

\subsection{The results of prison education}

\subsubsection{Quantitative results}

For many years prior to the introduction of the Learning Centers, the Prison and Probation Service had no reliable statistics concerning the results of prison educational activities, In a study carried out by the National Agency for Education in the late 1980s, criticism was leveled at the Prison and Probation Service. The study found, after investigating the dropout rates for basic adult education, that dropout figures were particularly high (35-40\%) for students studying under the auspices of the Prison and Probation Service (Thång, 1988, In Swedish. English equivalent title: Who studies in municipal adult education, and what are the results?). However, what the study was unable to show was that a relatively large number of these dropouts were attributable to transfer of prisoners to different facilities. Thus some prisoners who appear to have dropped out may not in reality have done so. Probably many of these transferred prisoners went on to study at their new prisons, but were still registered in the dropout statistics.

Dramatic increase in the number of grades given

The introduction of the system of individual study plans, together with the fact that it is now possible for prisoners to study the subjects that are in accord with their own needs has led to a dramatic increase in the number of grades given. One of the main objectives underpinning the introduction of Learning Centers was for prisoners to be able to complete studies they began, and to be given grades upon completion of courses. In the past, only a small number of grades were given. In 2006 there was an increase in comparison with 2005, and again in 2007 in comparison with 2006, and the trend continued in 2008. In two years, the proportion of prisoners studying at compulsory school or upper secondary level and 
receiving grades increased from $5 \%$ to over $20 \%$, and in real numbers of grades from 197 to 938 . At the same time, in contrast, the number of hours prisoners spent in educational activities decreased.

This decrease can probably be explained by the fact that prison educational activities have higher status now, prisoners are able to use their time more efficiently, and the number of prisoners simply participation in educational activities "to make the time pass" has decreased considerably. There may also have been a shift in terms of which prisoners choose to participate in educational activities, toward individuals who have given more serious thought to why they wish to study.

For vocational training, a follow up carried out at three prisons in 2006 by the Public Employment Service and the Prison and Probation Service indicated that 1.5 years after release over $60 \%$ the prisoners who completed labor market courses had jobs or were continuing their studies.

Just under $40 \%$ of prisoners in Sweden have completed no more education than compulsory level.

A report from 1999 on prisoners' living conditions stated that there is a great need for education for prisoners (The Living Conditions of Prisoners, 1999). This study was based on interviews with a random sample of prisoners, 411 in all. Every seventh prisoner, or approximately 15 out of every hundred, had not completed compulsory school or basic vocational education. This figure may be compared with the corresponding figure of less than $1 / 100$ in the general population. Approximately 7 out of every 10 individuals deprived of their liberty were unemployed at the time of imprisonment, as compared with 3 out of every 10 in the general population.

In a survey of a representative sample of prisoners carried out by researchers at Linköping University it was found that the general educational level of prisoners is low, and that $11 \%$ had no completed level of education at all in 2007 (Eriksson-Gustavsson and Samuelsson, Kriminalvården, 2008). Just under $40 \%$ had completed no more education than compulsory level, while $34 \%$ had completed a two to four year upper secondary school program. A total of $36 \%$ stated that they were participating in some educational activity while serving their sentences. 


\subsubsection{Qualitative results}

In a report from Linköping University (Herkner and Samuelsson, 2005, In Swedish, English equivalent title: Education under the auspices of the Prison and Probation Service - effects on prisoner literacy), the effects of prison education in terms of prisoners' reading and writing skills were investigated. The findings were that as a group, prisoners are in a substantially weaker position than others in terms of both education and on the labor market. The report highlights literacy skills as particular prerequisites for an individual to learn, both in the classroom situation and in working life.

Another study from Linköping University, (Herkner, 2001 In Swedish, English equivalent title: How common is dyslexia among prisoners in Sweden?) found that prisoners did not have a significantly higher proportion of dyslectic literacy disorders than a group of adults with similar educational backgrounds in the general population. The primary reason for poorer literacy skills among prisoners was that in their everyday or working lives they had very little need to exercise their reading and writing skills. The above-mentioned study from 2005 found, on the basis of material consisting of prisoners from two facilities, that the educational activities offered by the Prison and Probation Service contributed greatly to strengthening the participants' writing skills. In an open question about what motivated prisoners to participate in educational activities, short, concise answers were given clearly indicating the utility aspect - educational activities were a way of using the prison time constructively and of preparing for future studies or work.

Some of the answers given were:

- "Studies get you somewhere. Other activities are a complete waste of time and energy. I want to make the best of my situation."

- "I'm finally getting around to studying. Crassly, it makes something good about being in prison. Now I can make my dreams come true."

- "I'm tired of living a life of crime. I want to learn welding so I can get a job when I get out. I also want to improve my old grades.”

Approximately $75 \%$ of the responses to this question brought up the utility aspect of studying. This report (Linköping University, 2005) stated that although one cannot, of course, guarantee that studying will lead to a 
reduction in recidivism, it does considerably strengthen the individual's prerequisites for coping and functioning in society and satisfying the demands of the labor market.

A questionnaire study from Linköping University (Eriksson-Gustavsson and Samuelsson, 2008) distributed to a representative sample of all prisoners, both prisoners who were and who were not participating in prison educational activities, found very similar reasons for wanting to study as the report from 2005. Prisoners who were studying stated clearly that their reasons were to get a job or continue to study after release, and to better cope in society.

Prisoners who were not participating in prison educational activities, approximately $60 \%$, per cent, stated a number of reasons for not participating. These were related to a sense of not knowing what it would make sense to study, not getting information, and a feeling of not being good enough to study. These answers provide important information to the Prison and Probation Service in their efforts to further improve prison educational activities. Outreach efforts must be made to find prisoners who are uncertain about their abilities, and who may be in greatest need of improving their reading and writing skills but are reluctant to make their way into educational activities. Since prison is one of the outposts of society, the Prison and Probation Service has a unique opportunity to reach individuals whose needs are high on the agenda of the decision makers who draw up adult education policies. 



\section{The prison population}

by Erlendur S. Baldursson, Torfinn Langelid, Marianne Mäki, Kaj Raundrup, and Svenolov Svensson

This chapter contains descriptions of the prison populations in the five Nordic countries, the main developmental trends expected in the future, their possible consequences in terms of educational options, and how they could or should be organized.

\subsection{Descriptions of the prison populations in Denmark, Finland, Iceland, Norway and Sweden}

The prison populations (per 100,000 inhabitants) in the five Nordic countries are very similar, with the exception of Iceland where the figure is only about half that of the other countries. Prisoners, in comparison with the general population, are a unique group both demographically and socioeconomically. The vast majority of the individuals are men, often with negative life experience, very little experience of working life, substance abuse problems, and weak social networks. In addition, many convicted prisoners have previously received help from the psychiatric services.

Over the last 20-30 years, the proportion of foreign prisoners has increased dramatically. In Denmark, Finland, Iceland and Norway, this figure ranges between 7 and 16\%, in Sweden it is 28\%. During the same 
period, the number of women prisoners has remained constant, between 4 and $6 \%$ in all five countries.

Table 7.1 Prison capacity in 2006, number of places

\begin{tabular}{lrrrrr}
\hline & Denmark & Finland & Iceland & Norway & Sweden \\
\hline Open prison places & 1,520 & 1,032 & 14 & 1,071 & 1,387 \\
Closed prison places & 943 & 2,575 & 110 & 2,218 & 3,543 \\
Remand center places & 1,706 & - & 12 & - & 1,847 \\
\hline Total & 4,169 & 3,607 & 136 & 3,289 & 6,777 \\
\hline
\end{tabular}

Proportionally, Denmark and Norway have the most open prison places (36-33\%). From 1997 to 2006 the occupancy of the available places has increased substantially in all countries except Iceland.

Table 7.2 Average figures regarding deprivation of liberty in 2006

\begin{tabular}{lrrrrr}
\hline & Denmark & Finland & Iceland & Norway & Sweden \\
\hline $\begin{array}{l}\text { Average number of individuals deprived of } \\
\text { their liberty per 100,000 inhabitants }\end{array}$ & 76 & 72 & 48 & 71 & 79 \\
\hline
\end{tabular}

Average figures regarding deprivation of liberty are relatively similar in the Nordic countries, with the exception of Island, and are highest in Denmark and Sweden.

Table 7.3 Average numbers of sentences begun to be served in 2006

\begin{tabular}{lrrrrr}
\hline & Denmark & Finland & Iceland & Norway & Sweden \\
\hline $\begin{array}{l}\text { Number of sentences begun to be served } \\
\text { per } 100,000 \text { inhabitants }\end{array}$ & 197 & 88 & 68 & 202 & 115 \\
\hline
\end{tabular}

In comparison with table 7.2, the figures for Norway and Denmark are higher in terms of the number of sentences begun to be served per 100,000 inhabitants during the course of a given year. (Kristoffersen. R. (2008): Correctional Statistics of Denmark, Finland, Iceland, Norway and Sweden 2002/2006. Correctional Service of Norway Staff Academy, Oslo). Our interpretation of these figures is both that relatively more individuals in Denmark and Norway serve prison sentences, and that the average time of serving sentences is shorter there. (The figures for Sweden also include prisoners serving the final part of their prison sentence with electronic supervision). 


\section{Duration of prison sentences}

The durations of prison sentences are often measured either in terms of the number of prisoners incarcerated on any given day or of the number of prisoners incarcerated over the course of a year. Both statistics are of interest in relation to prison education, the question being how long a period of time prisoners have to fill in the gaps in their educational backgrounds. Because different methods are used to measure prison sentence durations, the project group has simply determined that between 70 and $90 \%$ of individuals convicted to prison in the Nordic countries are serving sentences shorter than one year.

\section{Sex, age and nationality}

As mentioned above, the vast majority of prisoners are men, with approximately $5 \%$ being women. Most of the male prisoners are over 30 , and only 3-5\% are under twenty.

Table 7.4 Some groups of prisoners on a given day in 2006

\begin{tabular}{lrrrrr}
\hline & Denmark & Finland & Iceland & Norway & Sweden \\
\hline Women & $97(3.9 \%)$ & $168(5.9 \%)$ & $5(5.0 \%)$ & $136(5.1 \%)$ & $271(5.2 \%)$ \\
Foreign citizens & $14.3 \%$ & $6.8 \%$ & $10.9 \%$ & $15.4 \%$ & $28.2 \%$ \\
\hline Main age groups & $25-34$ & $30-39$ & & $23-40$ & $30-44$ \\
$<20$ & $3.6 \%$ & $3.2 \%$ & & $1.8 \%$ & $5.8 \%$ \\
$15-17$ & $10(0.4 \%)$ & $4(0.1 \%)$ & $1(1.0 \%)$ & $9(0.3 \%)$ & $0^{1}$ \\
\hline Serving life sentences $^{2}$ & $16(0.6 \%)$ & $136(4.7 \%)$ & - & - & $151(2.9 \%)$ \\
\hline
\end{tabular}

1 Young offenders are sentenced to care for young prisoners in a closed institution under the administration of the non-correctional services (Kristoffersen. R. (2008)). Our interpretation of these figures is both that relatively more individuals in Denmark and Norway serve prison sentences, and that the average time of serving sentences is shorter there. (The figures for Sweden also include prisoners serving the final part of their prison sentence with electronic supervision)

2 Brief description concerning each country

Denmark: According to the Enforcement of Sanctions Act, the Prison and Probation Directorate may, under certain conditions, release a prisoner sentenced to lifetime imprisonment on parole after twelve years of the sentence has been served. If such an application is rejected, the matter may be reviewed by a court after one year.

Finland: In Finland, life sentence prisoners may be released on parole when at least twelve years of the sentence has been served. If the offense was committed when the individual was under 21 years of age, the relevant period is ten years. The release of a life sentence prisoner is decided by the Helsinki Court of Appeal. The President also has the right to grant a pardon.

Iceland: Not relevant.

Norway: Not relevant.

Sweden: According to the current range of sanctions, there are only two alternatives for long sentences in Sweden a) ten years or b) lifetime imprisonment. The sanctions of most criminals sentenced to lifetime imprisonment are converted to a specific term of imprisonment by the court if an application is filed after ten years have been served. The minimum determined term is at least eighteen years; to date the range has been twenty-one to thirty-three years. The use of longer sentences, between ten and eighteen years, is currently being discussed. An individual who commits a crime before the age of twenty-one cannot be sentenced to lifetime imprisonment. 


\section{Substance abuse}

Studies from all five countries demonstrate that $60-70 \%$ of the total prison populations have substance (illegal narcotics and/or alcohol) abuse problems. The number of substance abusers has risen steadily over the last $15-20$ years.

\section{Work experience and educational background}

As indicated in the table below, only about one third of the prisoners were employed at the time they began serving their sentences. The figures for Finland and Norway stand out, in that more of the prisoners had completed compulsory school, and from one third to half had completed a three-year upper secondary school or a three-year vocational school. A small number of prisoners were studying at university or other higher education level.

Table 7.5 Education

\begin{tabular}{|c|c|c|c|c|c|}
\hline & Denmark & Finland & Iceland & Norway & Sweden \\
\hline Completed compulsory school & $33.9 \%$ & $27.7 \%$ & $48 \%$ & $35.3 \%$ & $45.0 \%$ \\
\hline $\begin{array}{l}\text { Completed upper secondary or } \\
\text { vocational school }\end{array}$ & $50.4 \%$ & $57.7 \%$ & $27 \%$ & $44.6 \%$ & $34.0 \%$ \\
\hline $\begin{array}{l}\text { University or other institute of higher } \\
\text { education }\end{array}$ & $4.2 \%$ & $7.4 \%$ & $9.0 \%$ & $12.9 \%$ & $10.0 \%$ \\
\hline
\end{tabular}

The information in table 7.5 was previously published in the report: Education in Nordic Prisons: Prisoners' educational background, preferences and motivation (Nordic Council of Ministers TemaNord 2009:508 Copenhagen).

The numbers of prisoners in the Nordic countries is quite similar. Most are between 25 and 35 years of age. The number of prisoners under 20 is small in relation to the entire prison population, owing to the alternative sanctions used for young offenders. The number of foreign prisoners varies. It is substantial in all the Nordic countries - greatest in Sweden, where more than every fourth prisoner is foreign. There are major substance abuse problems in all five countries, with $60-70 \%$ of the prisoners having drink or drug problems, and often both.

Thus the typical Nordic prisoner can be described as: over 30, having left school early, with a very little experience of the labor market and, in 
many cases, a substance abuse problem. Not a surprising picture, and readily recognizable.

Against this background, we can also describe some of the characteristic needs which ought to be reflected in the educational options offered at prisons if the aim is to offer education that will give prisoners a better point of departure to return to society, live a life without crime and drugs, and develop as individuals (see also sections 9.2.1, 9.4, 9.5 and 9.7).

\subsection{Key developmental trends}

In recent years the size of the prison population in the Nordic countries has increased gradually. At the same time, these countries' correctional systems have been characterized by short prison sentences as well as alternative sanctions to deprivation of liberty.

The prison population has clearly changed over the past two decades. Far more prisoners are abusers, are or have been psychologically disturbed, have behavioral problems, have been convicted of serious crimes (violent crimes, sexual offenses, grand theft) today than 20 years ago. Not least important, they are older. In Denmark a particular increase in "motorcycle gang” prisoners (Hells Angels and Bandidos) have had their own special impact on everyday life in closed prisons. These characteristics of the prison population are expected to remain. In addition, after EU enlargement - from a European Union of 15 to 27 - more of the prison populations can be expected to come from the new member states. This may come to mean that an even larger proportion of the prison populations than at present will be comprised of foreigners, and this will pose many challenges, particularly in terms of prison education. There are many factors underpinning the general increase in the number of prisoners, and it is clear that the consequences, including overcrowding and difficulty in offering prisoners a reasonable range of activities, may have negative effects for the prisoners. Although overcrowding is sometimes solved by temporarily increasing the number of prison places, this is seldom reflected in a corresponding increase in the number of educational and vocational places made available.

Larger prison populations mean increasing costs or deteriorating conditions - or both - in relation to prison education as well. One of the fre- 
quent consequences of larger prison populations tends to be a shift away from treatment - including prison education-toward simple lock-up or custodial functions.

\section{Summing up}

As a consequence of the trends regarding the prison populations described above, changes can be expected in terms of educational options, educational methods, and choice of educational materials, particularly access to ICT equipment and the Internet. Expectations also include increased differentiation and individualization with a view to satisfying more of the particular needs and interests of prisoners, as well as increased flexibility in terms of adaptation of prisoners' working time to enable combining vocational experience in workshops, education and participation in one or more treatment programs, all as parts of the resocialization process. Moreover, there should be better, more focused collaboration with the social services system and with the employment services, in order to improve both the transition from prison to freedom and the individual's integration onto the labor market. 


\section{Relevant international recommendations}

by Torfinn Langelid, Marianne Mäki, Kaj Raundrup, and Svenolov Svensson

This chapter describes a selection of the international recommendations and conventions ratified by the Nordic countries and of significance in relation to prison education. These include the European Prison Rules (2006), based on the Standard Minimum Rules for the Treatment of Prisoners (adopted by the United Nations in 1984), the Council of Europe

Recommendations on Education in Prison, the UNESCO Recommendations for Adult Education, The United Nations Convention on the Rights of the Child, and the European Convention on Human Rights.

\subsection{The European Prison Rules (2006)}

Pursuant to the updated European Prison Rules from (Articles 28.1-28.7), every prison is to ensure that each prisoner has the right to as comprehensive educational programs as possible, that satisfy their individual needs and preferences. The rules stipulate that:

Particular attention shall be paid to the education of young prisoners and those with special needs. Priority shall be given to prisoners with literacy and numeracy needs, and those who lack basic or vocational education.

Education shall have no less a status than work within the prison regime and prisoners shall not be disadvantaged financially or otherwise by taking part in education. 
Every prison is to have a library accessible to all categories of prisoners. The library is to have a wide range of literature for both leisure reading and education. Wherever possible, prison libraries should be organized in cooperation with community library services.

As far as practicable, the education of prisoners shall:

- be integrated with the educational and vocational training system of the country so that, so that after their release prisoners may continue their education and vocational training without difficulty; and

- take place under the auspices of external educational institutions.

\subsection{Education in Prison (1989)}

In 1988, the European Committee on Crime Problems (CDPC) presented an extensive report, Education in Prison, which covered subjects including the aims of prison education, the place of education in the prison system, methods in adult education, vocational training, creative and cultural activities, and the relationship between education in the prison system and in society at large.

Subsequent to the publication of the report, the Council of Europe published 17 recommendations, and appealed to the member states to take them into account in their work with prison education. (Recommendation R (89) 12 adopted by the Committee of Ministers of the Council of Europe on Prison education on 13 October 1989). The recommendations refers both to Recommendation R (87) 3 on European Prison Rules and Recommendation R (81) 17 on adult education policy. They deal with both the school system and the correctional services, and call upon the relevant parties to ensure that prisoners have access to a broad range of educational options, which should also continue after release. The recommendations are as follows:

1. All prisoners shall have access to education, which is envisaged as consisting of classroom subjects, vocational education, creative and cultural activities, physical education and sports, social education and library facilities. 
2. Education for prisoners should be like the education provided for similar age groups in the outside world, and the range of learning opportunities for prisoners should be as wide as possible.

3. Education in prison shall aim to develop the whole person, bearing in mind his or her social, economic and cultural context;

4. All those involved in the administration of the prison system and the management of prisons should facilitate and support education as much as possible.

5. Education should have no less a status than work within the prison re-gime and prisoners should not lose out financially or otherwise by ta-king part in education.

6. Every effort should be made to encourage the prisoner to participate actively in all aspects of education.

7. Development programs should be provided to ensure that prison educators adopt appropriate adult education methods.

8. Special attention should be given to those prisoners with particular difficulties and especially those with literacy or numeracy problems.

9. Vocational education should aim at the wider development of the individual, as well as being sensitive to trends in the labor market.

10. Prisoners should have direct access to a well-stocked library at least once a week.

11. Physical education and sports for prisoners should be emphasized and encouraged.

12. Creative and cultural activities should be given a significant role because these activities have particular potential to enable prisoners to develop and express themselves.

13. Social education should include practical elements that enable the pri-soner to manage daily life within the prison, with a view to facilitating his return to society.

14. Wherever possible, prisoners should be allowed to participate in education outside prison.

15. Where education has to take place within the prison, the outside community should be involved as fully as possible.

16. Measures should be taken to enable prisoners to continue their education after release.

17. The funds, equipment and teaching staff needed to enable prisoners to receive appropriate education should be made available. 
This is an extensive list, intended to establish equality of opportunity between education in prisons and education in the outside world. The 17 recommendations have been translated into 25 languages, see the web site of the European Prison Education Association (EPEA) www.epea.org

\subsection{UNESCO Recommendations for adult education (UNESCO 1985)}

One of the cornerstones of the Council of Europe recommendation Education in Prison (Recommendation R (89) 12) is the UNESCO recommendations for adult education from the fourth international conference on adult education, held in Paris in 1985. The "right to learn" is set out in the final declaration from that conference as one of the prerequisites for individual growth and for the development of citizens. The right to learn is defined as:

- the right to read and write;

- the right to question and analyze;

- the right to imagine and create;

- the right to read one's own world and to write history;

- the right to have access to educational resources;

- the right to develop individual and collective skills.

According to the 1985 UNESCO declaration, this right to learn is not a luxury to be saved for some future date when all other fundamental rights have been satisfied. There can be no human development without the right to learn. The right to learn must be recognized as an inalienable right of every person regardless of race, religious opinions, and social status. In short, the UNESCO declaration sees this right as one of the best possible contributions to solving the fundamental problems of humanity. This declaration was, in its turn, based on a previous declaration drawn up at a UNESCO conference held in Nairobi in 1976 and adopted by 539 delegates from 122 member states. 


\subsection{The United Nations Convention on the Rights of the Child (1989)}

As more and more minors are being convicted of crimes, prison and probation services have had to become increasingly aware of safeguarding childrens' rights in accordance with the United Nations Convention on the Rights of the Child, and in this context particularly article 28 on education and article 37 on torture, capital punishment and imprisonment.

Article 37 on torture, capital punishment and imprisonment reads:

Article 37

States Parties shall ensure that:

(a) No child shall be subjected to torture or other cruel, inhuman or degrading treatment or punishment. Neither capital punishment nor life imprisonment without possibility of release shall be imposed for offences committed by persons below 18 years of age;

(b) No child shall be deprived of his or her liberty unlawfully or arbitrarily. The arrest, detention or imprisonment of a child shall be in conformity with the law and shall be used only as a measure of last resort and for the shortest appropriate period of time;

(c) Every child deprived of liberty shall be treated with humanity and respect for the inherent dignity of the human person, and in a manner which takes into account the needs of persons of his or her age. In particular every child deprived of liberty shall be separated from adults unless it is considered in the child's best interest not to do so and shall have the right to maintain contact with his or her family through correspondence and visits, save in exceptional circumstances;

(d) Every child deprived of his or her liberty shall have the right to prompt access to legal and other appropriate assistance, as well as the right to challenge the legality of the deprivation of his or her liberty before a court or other competent, independent and impartial authority, and to a prompt decision on any such action.

Article 37 concerns deprivation of liberty, torture and inhumane treatment of children, and requires the states parties to guarantee a number of key rights of the child. It requires a firm commitment on the part of the States, and is one of the articles in the Convention that goes farthest in providing concrete protection for children. Article 37 applies to all treatment of children, with special emphasis on protection during deprivation of liberty in conjunction with criminal proceedings. 


\subsection{The European Convention for the Protection of Human Rights and Fundamental Freedoms}

The Protocol to the European Convention for the Protection of Human Rights and Fundamental Freedoms of 4 November 1950 entered into force on 18 May 1954, and was signed by member state governments of the Council of Europe. They agreed, inter alias, to the following:

Article 2 - Right to education

No person shall be denied the right to education. In the exercise of any functions which it assumes in relation to education and to teaching, the State shall respect the right of parents to ensure such education and teaching in conformity with their own religious and philosophical convictions.

All the Nordic countries have enshrined this European Convention in their national legislations. 


\section{Evaluation, analysis and recommendations}

by Vuokko Karsikas, Kirsti Kuivajärvi, Torfinn Langelid, Marianne Mäki, Kaj Raundrup, and Svenolov Svensson

In this chapter, the project group provides a more detailed evaluation and analysis of the findings, based on both our survey and the description given of the prison populations, followed by a number of recommendations. Our recommendations refer to the various international conventions and to Nordic legislation. They also concern the right to education, the various models for education used by the prison and probation services, descriptions of education in prisons, course options, teaching methods, and the place of education and training in the overall correctional system, the needs and options for lifelong learning, documentation and research, cooperation between the correctional system and other stakeholders, and the costs of prison education. The project group uses the term "prisoner" to apply both to convicted prisoners and to individuals being detained in remand. 


\subsection{Legislation and prisoners' rights to education}

\section{Legislation}

\section{Recommendations}

The project group recommends that the educational authorities in the Nordic countries ensure that their legislations clearly state the legal right and obligation to provide prisoners with the same right to education as other citizens, in accord with international conventions and recommendations. The legal authority stipulated in the Education Acts should also be stipulated in the legislation of the different countries relating to enforcement of sentences. When the right to education has been elucidated, this will have consequences in terms of resource allocation.

\section{Considerations}

It is a basic requirement and provides the overarching perspective for ensuring that prisoners receive education on equal terms with others in society that their right to education must be clearly stipulated in the legislation. Although the authorities in all the Nordic countries stress the necessity of lifelong learning and skill enhancement for adults, our survey indicates that the right of prisoners to education is not clearly enshrined in all Nordic legislation. Thus it must be clearly stated in the legislation applying to the correctional authorities that the only thing of which an incarcerated individual is to be deprived is his or her liberty. In principle, all other rights are to be upheld.

\section{Denmark}

In Denmark prisoners have a clear, unambiguous legal right to education, which is the same as that of all citizens in Denmark. The Act on General Adult Education stipulates that all adults have the right to education. The Danish institutions regulated by the prison and probation service consequently have the right to provide education in accordance with the Act, upon approved application. This is followed up in the Sentence Enforcement Act, which stipulates that prisoners must have the right and the obligation to work, study, and participate in other approved activities. 


\section{Norway}

In Norway, pursuant to the Education Act, there is a general right and obligation to attend compulsory school, and everyone who has completed compulsory school has the right to three years of upper secondary education. Adults who have completed compulsory school but not upper secondary school also have, upon application. the right to additional upper secondary education. They also have the right to supplementary basic education, and to special education. The recently-adopted Enforcement of Sentences Act also stipulates that the correctional services, in collaboration with other state institutions, must ensure that prisoners receive the services to which they are entitled by law. The instructions accompanying the Act stipulate the details of this obligation, stating that prisoners have the same right of access to services, and the same obligations and responsibilities, as the general population. Thus the Prison and Probation Service in Norway has a maximum undertaking to ensure that the relevant authorities offer the services to prisoners which they are obligated by law to offer, and to ensure that prisoners are able to utilize these services.

\section{Finland}

In Finland basic education (comprehensive education, primary and lower secondary) is regulated by law, and the legislation stipulates that it is a universal right. The authorities are also obligated to ensure the equal opportunity of all to education beyond compulsory education, irrespective of the financial status of the individual and on the basis of his or her needs. Although this is not a legislated right, the aim of educational policy is for everyone, including prisoners, to be offered education beyond compulsory level, on the basis of individual needs.

The Ministry of Education is responsible for determining what schools are to offer upper secondary education, and who is responsible for vocational education. The legislation makes it possible for prisons to offer apprenticeship training in workshops.

\section{Sweden}

Opportunities to pursue education in Swedish prisons is regulated both in the Act on Correctional Treatment in Institutions and a statute from the National Agency for Education (SFS 2007:152). The Act on Correctional Treatment states that prisoners who need education should be offered it 
whenever possible, while the statute determines that education given in institutions is to be carried out on the basis of the same curricula as that applying to traditional adult education. The prison education headmaster is authorized to issue grades in the same way as headmasters at community schools. Prison education activities are fully compatible with municipal adult education, and sets priorities for inclusion in the same ways, meaning that individuals lacking basic skills have the highest priority. The National Agency for Education is the supervisory authority for prison education.

\section{Normalization}

\section{Recommendation}

The project group proposes that the principles of normalization and openness be applied to as great an extent as possible, by utilizing the public services of society such as schools, libraries, treatment services, etc.

\section{Comments}

This can be accomplished both by giving more prisoners the opportunity to make the transition to the community through alternatives to incarceration, day release privileges, halfway houses, and by the construction of a larger number of open correctional facilities and the increased use of alternative sanctions such as electronic supervision. Day release privileges can even be arranged for some prisoners who are serving their sentences at higher security prisons, mainly by having special units for prisoners with day release privileges. Future correctional facilities must be built with units for prisoners with day release privileges.

\section{Considerations}

Once the right to education has been clearly enshrined in legislation, it will be natural to review the implementation of and criteria for providing optimal teaching conditions in prisons. Traditionally, most of the teaching that takes place in Nordic prisons takes place in closed institutions. Denmark is the exception. There, most prisoners are placed in open institutions, and thus they have far greater access to day release privileges for education and work than other Nordic prisoners. The most recent Norwegian government report to the parliament on the Prison and Probation 
Service, Prisons that Work, recommends greater use of day release privileges, more opportunities to serve one's sentence in an open prison, and the construction of more halfway houses.

On the basis of the principles of normalization, integration, openness and responsibility, the view of the project group is that prisoners should have much greater access to the state educational system. One of the ways in which this can be achieved is by greater use of day release privileges, enabling prisoners to attend community schools and thus to be more involved in and closer to everyday society than when they attend prison schools.

Another way of integrating prisoners into the ordinary educational system is through access to modern technology, such as Internet-based education. More and more adult education in Sweden is offered as remote learning via the Internet. This makes it possible to tailor both the educational activities and study schedules to the needs of the individual. It is also well suited to the needs of prisoners, making them less dependent on being physically present in the right place at the right time. The use of Learning Centers in Sweden utilizes technology that makes it possible to provide prison education as remote learning. One of the results is that the number of grades issued in a large number of subjects has risen.

Research results from Denmark (Holstein 1986) also indicate that prisoners granted day release privileges for schooling are less inclined towards recidivism. In other words, day release privileges serve as an instrument of crime prevention. Moreover, having prisoners serve their sentences in open correctional facilities is cost-beneficial as compared with the building of a large number of closed institutions to which various services have to be "imported".

\subsection{Models for implementation of education in prisons}

The Nordic countries differ from one another both in terms of their legislation and the rights to education for prisoners, and therefore different comprehensive objectives have been set out and models developed for implementation of education in prisons. These models can also be seen as expressions of cultural differences and differences in emphasis. 
Our survey of the prison education systems in the Nordic countries indicates that practices can be described using four different models, each with its own special features. Roughly, these are: in Denmark export and self-sufficiency models, In Finland a combination model, in Norway an import model, and in Sweden a variant of the self-sufficiency model. The implementation of each model is described briefly below.

\section{Denmark}

Most of the teaching done in the prison is carried out by teachers employed full-time by the Ministry of Justice. More than $50 \%$ of the teaching done in remand centers is also given by prison teachers, and the rest by teachers who are employed locally and paid on an hourly basis.

\section{Finland}

In Finland there are three categories of employees: teachers employed by the local educational institutions (the main category), teachers employed by the Ministry of Justice (at three facilities) and contracted teachers.

\section{Norway}

All teaching in prisons is carried out by full and part-time teachers employed by the educational authorities.

\section{Sweden}

Teaching is carried out by teachers employed by the Prison and Probation service. The teachers are directly responsible to the regional prison education headmasters. Teaching takes place both as classroom and remote education, following the same curricula as municipal adult education in the community, and the National Agency for Education is the supervisory authority.

\section{Models for education in prisons}

In the following analysis of the models for implementation of education in prisons described above, the project group specifies the advantages and disadvantages of each model as well as the general demands they imply for both the educational authorities and the correctional services. 


\section{The export model}

\section{Teachers employed by the educational authorities}

In this model, the educational authorities bear the responsibility for the content, organization and financing of education. Payment, however, is disbursed per participant and subject. The education legislation is universally applicable; prisoners are no exception. They have the same range of educational options as all citizens. The teachers are the regular teachers from the local community. The classroom situation is the same as for all citizens.

Requirements that must be fulfilled if the export model is to function well:

- For this model to work, prisoners must be allowed to leave the correc-tional facility in order to participate in education in the community. This requires either national guidelines for education in prisons or ve-ry clear stipulations in the legislation governing the prison and proba-tion service regarding the rights of prisoners to leave the premises for education. This, in turn, means that the options regarding day release privileges for prisoners have to be adapted to the needs of each speci-fic prisoner. It also ensures a smooth transition to continued schooling in the community after release.

- One important aspect of cooperation between the prison and probation services and the educational authorities is that schoolwork must be well integrated into the overall planning work done by the prison and probation service with and for each prisoner, so that it becomes a na-tural element of the formal "future plans" drawn up for prisoners. This requires the necessary pedagogical competence in the prisons for the assessment of each prisoner's educational needs, for communication with guidance counselors, etc.

- Another requirement is a detailed security policy, not least in conside-ration of the possibility that prisoners might ask others who have been on day release, to bring drugs back with them into the prison.

- Education should become a natural element of the sentence plans drawn up by the correctional services.

- Advantages 
- This model may contribute to minimizing stigmatization and thus to increasing normalization, integration and accountability. With day release privileges, it also allows prisoners access to the full course range in the community.

- The system results in utilization of the full range of educational options in the local community, and thus promotes normalization, socialization, sense of accountability, and openness. It reduces exclusion, and improves contact with day-to-day community life for prisoners to a greater extent than otherwise in the penal system. In addition, the in-terface with marginalized, groups, including prison convicts, can lead to development of new pedagogical methods.

- On the basis of the legislation, the Danish Prison and Probation Servi-ce can make substantial use of the possibility of prisoner's having day release privileges and thus leaving the institution for both work and education.

\section{Comment}

Although the legislation in the other countries is positive in relation to day release privileges, practice varies greatly.

\section{Disadvantages}

- Day release privileges can be a great strain on the prisoner implying continual fluctuations between freedom and confinement.

- Problems may arise in motivating prisoners who have considerable learning difficulties and previous negative experience of the traditional school system to attend school in the community.

\section{The self-supply model}

Teachers employed by the Ministry of Justice

Education for prisoners is regulated in the legislation on both the prison and probation and the educational services. Ultimate responsibility is in the hands of the former, as this service has financial responsibility for education for prisoners. In as far as is possible, prisoners are to have access to the same educational options as others in the local community. National guidelines are needed for prison education to ensure that na- 
tional curricula are followed and, as far as possible, the equivalent teaching methods used. The prison and probation service and the educational authorities have to cooperate in order to maintain equality of educational opportunities. In this model, education is carried out under the supervision of the National Agency for Education.

Requirements that must be fulfilled if the self-supply model is to function well:

- Education must become a natural element of the services available to prisoners under the auspices of the correctional authorities. Teachers are appointed by the prison and probation services. Pedagogical exper-tise must be available at management level nationally, regionally and locally. Ideally, the person in the position of superiority to the teachers will be a headmaster whose competence corresponds to that of the in-dividual in the corresponding position for municipal adult education. In addition to the competence of the teaching staff, the prison and pro-bation authorities must have access to specialist competence in adult education. Equal opportunities in education must also apply, as far as possible, in terms of classroom facilities and equipment.

- The system must issue grades and certificates equivalent to those issued elsewhere in the school system, as a quality guarantee for the teaching given. In order to ensure a smooth transition to schooling in the community, the teaching offered in prisons must be considered equivalent to the teaching given in the community under the supervisi-on of the educational authorities.

- As ICT equipment becomes increasingly integrated into regular adult education, prison education must keep pace with these developments.

- Education must be a natural element of sentence plans drawn up by the correctional services.

\section{Advantages}

- Services can be better coordinated and regulated. Education becomes a natural part of the total package of services offered to prisoners. The teachers are also an integral part of the prisoner's personnel contact network when serving his or her sentence, and can, for 
example, help the prisoners find information, etc. relating to their schooling.

- People working at the various levels of the prison and probation service have better access to a comprehensive picture of the services each prisoner requires.

- When teachers are employed by the Ministry of Justice, their working hours and conditions are regulated in accordance with the services agreement of the prison and probation service, and thus they work to the rhythm of the correctional facility. They also have the same regul-ations regarding vacation time as other personnel working in prisons. Teachers also serve on the regular consultation bodies and commit-tees, and are thus considered members of the prison staff. These teach-ers work under a special working time agreement for prison teachers.

\section{Disadvantages}

- This system may result in the perspectives of the prison and probation service and the prison professionals being given so much priority that the pedagogical aspects of prisoner's needs may be seen in too narrow a light. There is also a risk that teachers can become so well-integrated into the prison and probation service that they lose sight of their over-arching pedagogical perspective.

- There may be too little turnover amongst the teaching staff, and thus the organization may become static, with too little debate regarding educational methods and creative thinking. Because prison schools are small and have few teachers, discussions about pedagogical methods and development work may be restricted or even lacking. There is a risk, over time, that these teachers will become isolated from the state school system.

\section{Comments}

There are a number of other aspects of this model that are difficult to pigeonhole as advantages or disadvantages. What are the consequences of putting financial and other responsibility for prison education in the hands of the correctional services? In times of financial constraints, might this result in difficulties about giving priority to prison education? There is reason to assume that equality of opportunity will be respected in this 
area when prison schools are accorded the same status as other adult education facilities, and there is to some extent a guarantee of this in that prison education would be covered in both the education and correctional legislation. Still, the question must be asked as to whether prison education managed in accordance with this model really is equivalent to education offered in the community. If the special pedagogical needs arising in the context of prison education are to be taken fully into account, specialists in education and pedagogy will have to be employed by the correctional services. The model probably also requires national guidelines for prison education.

2A. The self supply model under the supervision, control and regulation of the National Agency for Education

The model used in Sweden, with teachers employed by the Prison and Probation Service, differs somewhat from the "basic model" described above. The Swedish model was developed on the basis of the previouslyused "contract model” with a procurement procedure by which all educational activities were purchased from a large number of providers. In the new model, the Prison and Probation Service has regional headmasters who are directly responsible for the teachers employed at the various regional prisons.

A regulation issued by the National Agency for Education gives The Prison and Probation Service responsibility for carrying out adult education corresponding to that offered as municipal adult education. The same curricula are followed and the same grades given, and certificates issued must not indicate that the courses were given at a prison. Most of the teaching is carried out using a closed loop Internet-like system, in order to satisfy as wide a range of prisoners' needs as possible. The overall competence of all the prison teachers in Sweden can thus be utilized and prisoners can have individual, tailor made study plans. The National Agency for Education is the supervisory body. For further details, see Chapter 6, pp. 124/125.

Advantages (beyond those in the basic model described above)

- The fact that there are headmasters to provide professional management for the teachers reduces the risk that teachers will lose contact with their pedagogical identity, and ensures that they will remain up- 
dated concerning educational developments outside the prison and probation service.

- Greater opportunities to individualize educational options, with access to the overall competence of all the prison teachers in Sweden.

- State-of-the-art technology is used, and participants get training in using it (although not to the extent of having full Internet access).

- Prison educational activities are under the supervision of the National Agency for education, as is all municipal adult education.

- Disadvantages

- One of the aims of using a modified model was to minimize the disadvantages of the basic model.

\section{The import model}

Teachers employed by the educational authorities

In this model, the educational authorities in every county have the overall responsibility, including the financial responsibility, for education in the prisons. The education legislation does not distinguish between education offered at a correctional facility and in the community. The education offered at correctional facilities is considered equivalent to the corresponding education offered elsewhere in the community. In principle, the same courses are also offered in prisons and in the community, and the teachers have the same levels of competence.

Requirements that must be fulfilled if the import model is to function well:

- There must be good cooperation between the correctional services/ prison and the school administrator(s), and a clear understanding of who decides what (an ideal model is if the prison school is, organizationally, a "branch" of the local school).

- Equivalent demands must be made regarding classroom facilities and equipment as in the community.

- Upon release, there must be a smooth transition to educational options in the community.

- Education must be a natural element of the prisoners' sentence plans drawn up by the prison and probation service. 


\section{Advantages}

- Better normalization and insight into the system, and greater independence from the penal system.

- Responsibility for and financing of education in the prisons rests with those who normally deal with these matters in the community. The education legislation does not distinguish between education in prisons and other education in society.

- Teachers have continuous access to a broad pedagogical forum with professional expertise, and do not run the risk of losing contact with the educational environment in the state school system. Although teachers in prisons have the same competence as all other teachers, there is still a risk of institutionalization. It may be easier for teachers employed under this model to make proposals for changes and ask critical questions. The same salary levels apply as in the general educational system.

- This model better ensures the allocation of resources for education. It may also make it easier to get funding for research and development work.

- Easy transitions to the community school system are ensured, for example by having follow-up classes and good contacts with the regu-lar school system and the employment services.

\section{Disadvantages}

- In principle, this system implies access to the same course options as in the community, but because the institutions are small, this is never the case in reality, and cannot be so until prisoners from closed institu-tions have day release privileges for schooling and work. Situations can easily arise in which no one is prepared to accept responsibility. The prison and probation service encompasses a wide variety of servi-ces, and frequently there is no one with responsibility for coordinating them.

- Owing to the fact that education for prisoners is such a small part of education in general, there may be problems at administrative levels nationally, regionally and locally. In cases of "branch schools" problems may arise in terms of inadequate contact with the "main school". If "loose ends" remain untied in the system, there may be integration problems and the educational activities may be regarded as separate 
from other activities in the prison. Sometimes prison schools also end up with teachers considered unfit for the normal school system.

- Teachers in this system work under the working time agreement of the state school system with regard to school vacation periods. One exam-ple of the consequences of the prison school having a working time agreement that is out of line with other working hours in the prison is that the prison school would be closed during school vacation periods and, in the worst case, the prisoners might have to spend all day loc-ked up in their cells. The Norwegian parliamentary report on prison education, Another Spring, contains a recommendation concerning the introduction of year-round educational activities.

\section{The contract model}

Teachers employed by the educational authorities and contracted by the prison and probation service

This system gives access to the same educational options as in the community, with education regulated by the laws and ordinances applying to the correctional system. The prison and probation service has overall and financial responsibility. Good cooperation between the prison/prison and probation service and the educational authorities is required to maintain equality of opportunities.

Below follows an example from Danish vocational training. When the VOKS counseling and competence program was introduced, contracts were signed with vocational schools/labor market training centers concerning courses to be held at prisons. The prison facilities and the prison workshop supervisors who were participating in the VOX program were then approved, and the supervisors functioned as teachers on behalf of the contracted schools. The prisons received $70 \%$ of the funding allocated by the state to the vocational schools and/or labor market training centers for running these courses.

This made it possible to offer some of the basic courses at the prison, as well as short courses such as fork lift truck driving license courses and courses in scaffolding construction, so that prisoners could begin or even 
complete them while in prison and not have to wait until the last part of their sentence, which is when day release privileges are usually granted.

Requirements that must be fulfilled if the contract model is to function well:

- This model requires national guidelines for education in prisons. The prison and probation service must also have specialist competence in the field of adult education, in order to provide correct specifications in calls for tender.

- It must be ensured that classroom facilities and equipment must corre-spond to those in the state school system.

- With the right technical specifications for the contracts, it is possible to ensure a smooth transition to education in the community after release.

- Education should be a natural element of the prisoners' sentence plans drawn up by the prison and probation service.

\section{Advantages}

- In principle, this system affords the same access to educational options as in the community.

- Education is a natural part of the other services offered to prisoners by the correctional authorities. Every prisoner can receive the education he or she requires, although this is contingent upon the length of the contract with the education provider in relation to changes in the pri-son population and consequent new educational needs. The contrac-ting system gives the institutions greater financial autonomy and freedom.

- Diversity of contracting parties may fill a positive function.

\section{Comment}

Because they are working on the basis of time-restricted contracts, teachers will probably be more motivated and committed to providing good education.

\section{Disadvantages}

- The prison and probation service would have to have pedagogical expertise in order to set out the correct specifications in their calls for 
tender. The fact that contracting parties will come and go may make it difficult to coordinate services in relation to the correctional authori-ties. And with individuals coming and going, it may be difficult for the teachers to obtain an understanding of the place of education in the prison and probation service and for the prisoners.

- If they will only be staying in the system for a short time, teachers will be less committed in this kind of employment situation. This may lead to a long-term decrease in course options, and a lack of continuity in the teaching staff.

- Prison teachers do not all know each other, and there is a risk that they will not build up a professional identity as a group.

- Prisoners may find that the educational options differ greatly from one facility to another. There is a risk that this system would lead to a lack of equality in educational options.

\section{Comments}

This model, too, gives rise to questions that are difficult to answer unambiguously. Does it allow prisoners to receive an education equivalent to that available in the community? Does this model assure prison teachers equivalent competence with others? Questions also arise in relation to the teaching environment: whether premises and equipment are properly utilized, or whether in the long run they will deteriorate. There are also questions related to the constantly shifting situation with contracting parties, and whether these parties are able to maintain stable, regular contact with the schools and workplaces in the community. Another question is whether this model can possibly result in the development of firm, structured forms for cooperation between the correctional and the educational authorities.

The model in which educational activities are procured from external providers was used during the 1990s and the early twenty-first century in Sweden. A study (Roitto, Sjöberg 2001) found the system to be disadvantageous because so many of the contracted parties were not authorized to issue grades, the teachers felt both isolated and insecure regarding whether their contracts would be renewed after expiry (they usually ran for 1-3 years), too little pedagogical guidance, lack of cooperation among the teachers at different institutions, difficulties for prisoners to have continuity of educational activities if they were transferred, and the fact 
that the educational activities were often clearly just a way of passing the time, with no clear objectives for the individual prisoner.

Two distinct changes were notable when the contract model was replaced with the new Learning Center model in Sweden: the number of grades issued increased dramatically and the number of study hours decreased.

\section{The combination model: Teachers employed by both the Ministry of Justice and the Educational Authorities}

The education legislation does not distinguish between education in prisons and other education. This model requires national guidelines for education of prisoners, both in the state school system and in correctional institutions. The model also requires a clear distribution of workload and responsibilities. Two parallel organizations have to share both overall and financial responsibility.

Requirements that must be fulfilled if the combination model is to function well:

- There must be no differences as regard teacher competence. The prison and probation service must have expertise in adult education.

- The same courses are offered as in the community. Education becomes one of the many services offered to prisoners by the correctional services. It is important that there be good contact between the prison and probation service and the school system, to maintain equality of opportunity.

- The educational options must be equivalent to those offered in the community in general as regards premises, equipment, etc.

- Education should be a natural element of sentence plans drawn up by the Prison service.

\section{Advantages}

- In this model, education is one integral aspect of the overall activities offered at the facility. This can result in a wider range of course options, and "imported" teachers can also teach part of the time elsewhe-re in the local school system. At these facilities teachers can serve as a "social interface - contact officer" for prisoners with day 
release privi-leges who attend the local schools. This can contribute to continuity in the transition from prison to freedom.

- The fact that the teaching staff consists of individuals employed by two different authorities can contribute to greater inspiration in terms of teaching methods, and to livelier discussions.

\section{Comments}

Teachers who work with target groups both within the prison school and in the state school system may be more motivated and challenged. Competition could, however, arise between the groups if prisoners tended to choose their teachers more on the basis of personality than subject area (Or they might find that there were advantages in the prison environment if they chose "the prison teacher" instead of a teacher coming from outside, or vice versa).

\section{Disadvantages}

- The involvement of two different authorities subject to different rules and regulations can give rise to ambiguities with regard to responsibility.

- The combination model does not make equal opportunities in education as self-evident as the other models.

- Two groups of teachers with different working hours, etc. can give rise to trade union and policy conflicts.

\section{Comments}

This model, too, contains variables that are difficult to clarify. Overall and financial responsibility rests with two parallel organizations, which requires clear distribution of workload and responsibility. Good cooperation between the prison and probation service and the schools is important, and there must be clarity as to which authority has the ultimate responsibility for prison education.

\section{Equal opportunities in prison education}

\section{Recommendation}

The project group proposes that irrespective of which model is used, there must be pedagogical expertise at management level to provide quality 
assurance for the educational activities offered. Teaching staff are to have the same status, authority, and competence as in the state school system.

\section{Considerations}

The main prerequisite for equivalence of educational opportunities for prisoners in closed facilities, as indicated above, is that the legislation is crystal clear. Guidelines or standards for education in prisons should be drawn up on the basis of the laws and international conventions and recommendations. This should be accomplished in cooperation between the educational authorities and the correctional services.

Teaching staff must possess competence in line with the special educational needs of prisoners. This may apply to their needs for different teachers and, with regard to prisoners from other countries, to language skills, religion and culture. Teaching staff must be afforded both further training as teachers and updates with regard to working in the prison system, to stimulate debate and thus counteract institutionalization.

In order for the teaching to be up-to-date and to utilize resources in a satisfactory way, the teaching facilities must maintain the same standards and be as well equipped as in the state school system. Today, many correctional institutions are housed in old premises with no separate educational arrangements.

\subsection{Description of education in prison facilities}

\section{Recommendation}

The project group proposes a joint Nordic description of education in prison facilities, based on the assumption that ICT is a natural part of all education. Prison education should include:

- Compulsory education (corresponding to nine years of basic education, through secondary school)

- Upper secondary education (corresponding to general upper secondary school, vocational training, and higher preparatory courses).

- Internet-based education and remote learning

- Special education. 
- Immigrant education, minority group education (Sami, Roma, etc.) and education for second generation immigrants.

- University and other higher education.

\section{Comment}

As part of any teaching, all schools/students should have access to a wellstocked library which also serves as an information center and a knowledge database.

\section{Considerations}

Education in prisons should mirror the national educational system. Research indicates that many convicted prisoners have similar shortcomings in their educational backgrounds that correspond to those found in the general population. On the basis of various perspectives, including the principles of the right to education, humanitarianism and rehabilitation, education in the prison system should be broadly defined. It is assumed that well-developed systems for prison education are investments in crime prevention in the sense that they will encourage more prisoners to continue their education and training and to be integrated on the labor market after they have served their time.

This survey of education in the prisons of the Nordic countries shows that the definition of the concept of "prison education" varies from country to country. Education in all the prison systems should implement perspectives that emphasize lifelong learning for the general population, a greater focus on adult education, the needs of the adult population for skill enhancement, and the increasingly multicultural nature of the Nordic societies.

A brief summary of descriptions of prison education in the Nordic countries follows:

\section{Denmark}

Education in prisons is broadly defined as any education the content of which is pursuant to the various laws issued under the Ministry for Education: These include special education, preparatory adult education in the subjects of Danish and mathematics, basic education in grades 5 to 9 (secondary school), general adult education corresponding to grades 9 and 10, upper secondary adult education, Internet-based courses, univer- 
sity studies, prison workshops (enabling a combination of introductory vocational training and general comprehensive - primary and lower secondary - education), vocational education and education for prisoners of foreign origin.

\section{Finland}

The legislation is crystal clear as regards the right to comprehensive schooling, but it is ambiguous regarding upper secondary education and vocational training. There is also a lack of clarity with regard to who is responsible for prison education. Prison education is described as comprising basic education, upper secondary education and vocational training, and education in the national languages for immigrants, education for Roma, and university level education. To some extent it also includes courses offered by folk high schools and adult education institutions.

\section{Norway}

The legal basis for prison education is clear and unambiguous in terms of primary, secondary and upper secondary education, in both the Educational Act from the Ministry of Education and Research, and in the Enforcement of Sentences Act. Accordingly, prison education is described as comprising comprehensive and upper secondary education (general and vocational). It is stressed in the instructions accompanying the Act that young prisoners with inadequate educational backgrounds are to be particularly encouraged to make use of the opportunity to receive education while in prison. This legislation does not cover university or other higher education for prisoners, nor are the rights of immigrant prisoners to education clarified in Norwegian legislation.

Although the right to education for all is enshrined in both international conventions and recommendations and in Norwegian law, in practice there has been great variation in the educational opportunities for foreign prisoners. For this reason, in the parliamentary report Another Spring, the Ministry of Education and Research focuses particularly on ensuring foreign prisoners' right to education, if necessary through legislation and regulations. 


\section{Sweden}

A statute issued by the Swedish National Agency for Education sets out the prerequisites for general adult education in prisons. Prison education is the education needed by each prisoner and includes basic adult education (grades 1-9, primary and lower secondary comprehensive education), Swedish for immigrants, special education for prisoners with literacy difficulties, and upper secondary education. There is an agreement between the Prison and Probation Service and the Public Employment Service governing both the focus and scope of vocational training, including labor market skills training. University and higher education is offered as remote learning by all Swedish institutions of higher education, with individual tutoring given to the prisoners by the regular prison teachers, and other forms of education such as study circles and informal education, such as courses on parenting.

\subsection{Educational opportunities}

\section{Recommendations}

The project group sets out the following proposals for educational activities to satisfy prisoners' needs regarding both formal education and informal skills enhancement: All the national surveys as well as the Nordic survey highlight the need for more vocational training. In consideration of the need to help prisoners with the transition to community and working life, vocational training should be more closely integrated with external industries. Educational activities must satisfy prisoners' needs and preferences. The applies particularly to prisoner with special needs, to whom extra attention should be paid when recruiting prisoners to educational activities.

\section{General education}

- Basic education.

- Special/remedial education, with a particular focus on the prisoners with the most inadequate educational backgrounds (there is a unique opportunity to spend time with and motivate such individuals while they are serving a prison sentence). 
- Adult upper secondary education, with course options as extensive as those offered in the community.

- Being able to study with day release privileges is an important option, giving the individual more freedom of choice, and the prison prisoner the chance to spend time in a "normal" study environment.

- Education which satisfies the needs of foreign prisoners.

- Remote learning with some personal tutoring may play a role in satisfying individual needs.

\section{Vocational training}

- Vocational training in collaboration with the employment service in order to offer training that will prepare the individuals for the labor market.

- Cooperation should be encouraged between schools (theory) and prison workshops (practice). As a result of such cooperation, some activities could earn educational credits. When educational needs are assessed, prisoners' previous formal and informal experience should also be taken into account. This can mean a great deal to individuals whose school grades are not very good and educational experience not very positive.

- Assessment of prisoners' formal educational backgrounds and informal learning experience should be integrated as a natural aspect of prison education.

- Some vocational training could be given in other languages. This could also be useful to prisoners who are going to be deported after release, and who could thus gain competence that will be of value to them when they return to their home countries.

- Digital competence: it is important that while they are serving their sentences, prisoners, who are a marginalized group in society, have the same opportunity to acquire ICT skills as citizens in the community.

- ICT courses of the same kinds offered in the regular schools in the community (both to master the techniques themselves and to use the new technologies in other subject studies) should be made available. ICT is also a necessary tool to be able to access various educational options outside the prison - it is a natural tool in relation to the expan-ding range of Internet-based adult education possibilities in 
society. Being able to communicate on-line with a university in a foreign pri-soner's home country is one example of the possibilities.

Creative activities, libraries, etc.

- Education in the arts with a view to improving self-development, life skills and motivation raises individuals' social skills. Participation in both creative activities and well-rounded physical activities often encourages prisoners to go on to other kinds of education.

- There should be access to a well-stocked library, and its services should be organized in collaboration with the community library.

Women prisoners

- All the items above apply equally to women prisoners who, precisely like their male counterparts, must be offered a wide range of educational opportunities adapted to their individual needs. For women, who otherwise run the risk of being considered a small, costly target group, the new technologies may be particularly important in terms of opening up a large number of options (unless the possibility of mixing men and women in prison education groups is considered).

Education as one piece of the puzzle

- Education can become more effective if it is combined with work, treatment programs, and other approved activities. Very few prisoners can cope efficiently with full-time studies. Great flexibility and "tailor-made" weekly schedules should be available for each prisoner. Education is one important piece of a larger puzzle. If that piece falls into place, it may be decisive both to the success of the prisoner's schooling and to his or her life as a whole. The national studies and the joint Nordic survey all emphasize the need for individual study plans, plus good information and counseling concerning educational options.

- Facilities and equipment. There must be access to purpose-suited faci-lities and state-of-the-art equipment equivalent to that available in community adult education facilities or elsewhere in society. 


\section{Considerations}

Irrespective of which model for prison education they use, the Nordic countries have a shared point of departure in the conviction that education is a right for prisoners as for other citizens. Education is offered for the benefit of the prisoner, for his or her own personal development, as well being one aspect of the general effort of creating a better platform to stand on after release from prison - hopefully to a life free from criminality and drugs. The orientation, options, methods and priorities of the prison education system should therefore all be based on the situation of each individual prisoner. Who are the users of the prison education system? What are their needs and who determines them? The aim of this section is to scrutinize the chain of user needs and to ask: how well do educational options correspond to today's needs? What would ideal educational options be? To begin with, it is very difficult to define educational needs. They may differ greatly, spanning the spectrum from subject-specific knowledge to skills required on the labor market, as well as including an individual's personal desire to learn a language, for example, or to know more about his or her country's history, or to understand what his or her lifestyle has to do with global events or with environmental issues. However, when we discuss needs below, we do so on the basis of the first perspective just mentioned - needs as assessed from the outside, when staff and teacher make an objective evaluation of a prisoner's needs. Still, the other perspective must be borne in mind and respected, and should also be part of the overall assessment when possible. The prisoner's needs as others see them must always be based on each individual prisoner's situation.

The discussion of needs below begins with the schematic description of the users of prison educational services in the Nordic countries given in chapter 7, where it is clear that the prison populations in the Nordic countries are fairly similar. Approximately one out of every ten prisoners in Nordic prisons has not completed any level of education. In Norway and Sweden roughly one out of every ten prisoners has studied at a university or other institute of higher education, while the corresponding figure for Denmark is only $4.2 \%$. The age of most of the prison populations is 25 to 35, with a very small number of prisoners under the age of 20 in relation to the overall prison population, owing to the fact that young offenders are sentenced to other treatment rather than imprison- 
ment. Although number of prisoners of foreign origin varies from country to country it is substantial, particularly in Sweden, where every fourth prisoner is of foreign extraction. There are substantial drug problems, with $60-70 \%$ of the prisoners in all the countries estimated as having substance or alcohol abuse problems.

In recent years, many prisons and prison schools in the Nordic countries have participated in the Nordplus Framework Program, which "offers financial support to a variety of educational cooperation between partners in the area of lifelong learning from the eight participating countries in the Baltic and Nordic regions". (See website: http://www.nordplusonline. org/eng/framework_programme/about_nordplus). Many prison schools also participate in various EU-funded education programs, such as the Grundtvig program. One of the results of such participation is increased attention from the participating staff members to the prison at which they work, with a focus on developing and improving the educational options. A subject area that has developed especially rapidly thanks to such participation is art education. More access to art education has helped many prisoners to better self-esteem and motivation to continue their education.

\subsection{Educational background}

According to the Nordic survey (Eikeland, Manger, and Asbjørnsen (eds.), 2008). The Nordic prison education systems have many shared features but also some variation. Basically, they can be described as having three parts: level 1 is basic or compulsory education, level 2 comprises all upper secondary education, including vocational training and the higher preparatory course; while university and other higher education makes up level 3. At each level there are various possible specializations and programs, often widely diverse and concerning, to take vocational training as an example, the type of trade toward which the training is oriented, the degree of specialization and expertise reached in the different trades, what level job a person is eligible for after completion, and how much theory and practice are included in the training program.

According to the survey, between 7 and 16\% of the prisoners had not completed any level of education. The highest figure (16\%) was for Iceland, where the prison population is very small, the lowest for Finland 
and Norway (both at 7.2\%). Approximately every ninth prisoner in both Denmark and Sweden had no completed level of education. In Sweden, the group of prisoners with the weakest educational backgrounds were also most often represented among prisoners who chose not to participate in any prison educational activities. The surveys as a whole indicate that young prisoners in the Nordic countries are those who most often have weak educational backgrounds. A particularly worrying figure was that $83.7 \%$ of the prisoners under the age of twenty-five in Norway had not completed three-year upper secondary school. The educational level of prisoners in Norway corresponds to that of the general population some twenty years ago (Eikeland, Manger, and Diseth, 2006).

The proportion of prisoners for whom compulsory school is the highest level of education completed varied from approximately one fourth in Finland to nearly half in Iceland and Sweden, In Denmark and Finland slightly more prisoners had completed upper secondary school than in the other countries. Iceland had the lowest percentage of prisoners who completed upper secondary education.

In Norway and Sweden, approximately one out of every ten prisoners had some form of higher education, while Denmark had the lowest percentage in this category (4.2\%).

The percentages of prisoners who were not participating in any prison educational activities was very similar in all five Nordic countries. Iceland had the lowest percentage in this respect (55\%), and Denmark the highest, with approximately three out of every four prisoners not participating. In the other countries, the surveys indicated that roughly two out of every three prisoners were not participating in any form of formal education or informal prison educational activity.

The main reasons given for not participating in prison educational activities were that the prison did not offer any such activities, or that there were no activities on offer suited to the needs of the prisoner, for instance vocational training.

Prisoners who were participating in educational activities were generally pleased with the activities and the teaching. Inadequate (or inadequate access to) ICT equipment was the main problem or obstacle to completing prison educational activities, as stated in all the surveys (Eikeland, Manger, and Asbjørnsen (eds.), 2008). 


\section{Recommendations}

- Education for more prisoners

Every person in a prison and probation situation who has a right to and wants to participate in educational activities must be able to do so. It is particularly important that the educational needs of young prisoners with weak educational be satisfied. Measures:

- more frequent surveys of the educational backgrounds, preferences and needs of prisoners,

- better information concerning existing educational opportunities.

- Classroom facilities

Existing resources could be better utilized if classroom facilities were large enough to hold groups of eight to twelve participants. The prison and probation authorities must take their responsibility in this respect and draw up plants for renovating the classroom facilities.

- Quality and scope. Measures:

- A wider range of educational activities, emphasizing vocational trai-ning. Vocational training can be extended through a better structured, more goal-oriented collaboration with the prison workshops, many of which have been approved as teaching workshops. The prison schools can offer the general courses, while the workshops can offer the prac-tical work experience involved in vocational training. When the transition to more vocational training is made, this will place demands in terms of both educational equipment and resources.

- Educational activities should be offered on a year-round basis, to satisfy the needs of prisoners to be able to participate in educational activities no matter when they are serving their sentences.

- $\quad$ Prisoners serving short sentences

Short sentences must not pose an obstacle to embarking on educational activities. Measures:

- Assessments of formal and non-formal educational experience must be carried out. 
- $\quad$ Plans for completing upper secondary education must be drawn up.

- If the curriculum corresponds to that used in municipal adult education, even short educational activities in prison may be valuable (for continued education after release).

- More motivational activities are needed, such as practical/esthetic courses (music, drama, arts and crafts, etc.).

- More courses that give credit toward work life qualifications are needed. Educational activities on a year-round basis (see above) can be used to satisfy the needs of prisoners serving short sentences.

- Learning difficulties. Measures:

- More detailed surveys of prisoners' learning difficulties. Research and assessment funds must be allocated to studying prisoners' literacy and numeracy difficulties.

- $\quad$ ICT/ the Internet

Greater awareness is needed concerning the impor-tance of ICT/the Internet in prison educational activities, as well as funding that will make ICT equipment/Internet access available for prisoners who participate in prison educational activities.

- Higher education

More must be done to facilitate for prisoners wish-ing to participate in higher education, not least in terms of Internet access and tutored net-based educational activities.

\subsection{Methods}

\section{Recommendations}

The project group proposes the following approaches in order to fulfill the needs of prisoners for both formal and informal adult education:

The same pedagogical points of departure for lifelong learning in adult education shall apply to adults in prison as in society at large - with the same adaptation to the target group as must always be used for any spe- 
cific educational group, in prison or elsewhere. The methods implemented should be based on the idea of assessing the needs of each individual and, on that basis, giving him or her space in which to develop, in terms of knowledge and experience and also as an individual with civil rights and duties.

The particular features of prison education - often a short time frame, a great need for individualization, and students who may be at very different points along the route to acquiring life competence, places high demands both in terms of methodological flexibility and in terms of teachers being adaptable in their educational strategies.

Digital competence is an essential tool for participation in civil society, and for this reason ICT skills should be integrated into all aspects of prison education.

\title{
Considerations
}

\begin{abstract}
It is probable that outreach teaching methods, theme studies linked to the local community and everyday life would motivate and stimulate the prisoners in terms of their education more than traditional teaching or individual tutoring that follows textbooks strictly.

(In Swedish. English equivalent title: Reports from the National Agency for Education, R89:35)
\end{abstract}

This quotation is from a report published by the Swedish National Agency for Education in 1989. The report also states that prisoners require both individualization and cooperation, as well as training in social skills. It is clearly a challenging task to be a prison teacher. Qualities required, according to the report, include dedication to the task, patience, kindness, social commitment, firmness, flexibility, self-confidence, and toughness, as well as the abilities to individualize, to be forceful in difficult situations, and to exercise diplomacy. At the same time, it is important that teachers not take on a role beyond that associated with the teaching profession. Efforts are of added value when prison education personnel and the other treatment staff cooperate. According to the report, teachers in the correctional service who were polled about their own needs most often mentioned the need for working methods that encourage motivation, detailed courses on the prison system, in-depth subject studies, and methods courses. 
Many reports point out that prisoners serving sentences often have negative experience from their own school days. Another subject raised is dyslexia, and in this context many reports indicate that a large number of prisoners have literacy problems. However, a recent study indicates that dyslexia is not overrepresented in the prison population as compared with the same age groups in the general population. (Herkner, 2001. In Swedish. English equivalent title: How common is dyslexia among Swedish prisoners?). Nevertheless, many prisoners do have serious literacy and numeracy problems. One study states that prisoners found it difficult to help their children with their homework, that they found it embarrassing not to be able to read and write, and that they had a tendency to conceal their weaknesses. (Ohlsson, 2000. English equivalent title: Literacy/dyslexia education at the Malmö prison).

All these issues lead to the question about what teaching methods and what teacher competence is needed in prison education. Claesson refers to the qualities mentioned above, such as dedication to the task, patience, kindness, social commitment, etc. as "didactic tact", a term coined by van Manen (1988) in The Tact of Teaching (van Manen, 1990). According to Claesson, in short, there seems to be an understanding that students in prison have special needs, although opinions are divided as to how the problems should be tackled - but in any case some "didactic tact" is required, and possibly also training in special needs education. Claesson highlights one feature that may distinguish a prison teacher from his or her "normal" teaching colleagues, relating to the social aspects of the teaching profession. This does not mean that there are no social aspects to teaching in the non-prison setting, but that these skills are particularly important for teachers in prisons. However, the fact that many of the prisoners in this study complained that their prison teachers had too little specific subject knowledge indicates that in practice it is necessary to find teachers with a good combination of the qualities needed and wellbalanced teaching competence (Claesson, Dahlgren, In Swedish, English equivalent title: Studying in Prison, 2002).

Skaalvik et al. indicate, in a report from 2003, that there are great discrepancies regarding what school administrators, teachers and prison staff consider the objectives of prison education. Administrators tend to put more emphasis on formal aspects such as following the curriculum and getting a diploma, teachers stress the importance of motivation, gaining 
self-confidence and developing social skills, while prison staff members emphasize the opportunities for prisoners to improve their basic skills such as reading, writing and mathematics. The objective a person feels to be most important will, of course, affect his or her view of what methods are suitable and what teaching strategies should be used in prison education. This report also points out that teachers experience the classroom situation in prisons as different from the classroom situations in public schools in many ways. For instance, there tends to be rapid student turnover in prison schools, interruptions of schooling for shorter or longer periods are common, and students often have a negative attitude on the basis of their previous educational experience, inadequate basic skills, and poor selfconfidence. (Skaalvik et al., 2003. In Norwegian, English equivalent title: Observations and Ambitions Regarding Prison Teaching).

According to this report, if there were a spectrum with the students' points of departure at one end and long-term goals at the other, it would also span the spectrum of opinions about the objectives of prison education amongst prison school administrators and teachers and other prison staff.

\begin{tabular}{|c|c|c|c|}
\hline $\begin{array}{l}\text { Individual points } \\
\text { of departure }\end{array}$ & $\begin{array}{l}\text { Educational } \\
\text { objectives }\end{array}$ & $\begin{array}{l}\text { Formal } \\
\text { objectives }\end{array}$ & $\begin{array}{l}\text { Long-term } \\
\text { objectives }\end{array}$ \\
\hline $\begin{array}{l}\text { - Feeling comfortable } \\
\text { in the classroom } \\
\text { - Motivation } \\
\text { - Self-confidence }\end{array}$ & $\begin{array}{l}\text { - Knowledge } \\
\text { - Skills } \\
\text { - Social } \\
\text { development } \\
\text { - Attitudes }\end{array}$ & $\begin{array}{l}\text { - Diplomas } \\
\text { - Course } \\
\text { certificates }\end{array}$ & $\begin{array}{l}\text { - Mastering } \\
\text { life skills }\end{array}$ \\
\hline
\end{tabular}

Figure 9.1 The objectives of prison education seen as a time spectrum

For the teacher, the person who works with the students in practice, knowing the individual's point of departure is essential to know in order to prison school administrator, on the other hand, coming from experience of the state school system, formal objectives are central. In any case, each new prisoner must be approached with awareness of these factors in mind, and from the perspective of lifelong learning, without bias and in an honest attempt to see where on the spectrum he or she is starting out, in order to use the most appropriate methods in working with that individual. For one prisoner, working toward a specific goal may be just right, while for another the most important thing is to start with basic skill improvement. It is very likely that prison teachers face greater challenges 
than other adult education teachers when it comes to finding the right keys to unlock each individual student's learning abilities.

A government commission report (1996:27 in Swedish, English equivalent title A Strategy for the Adult Education Initiative and Lifelong Learning) highlights the fact that lifelong learning is meant to provide individuals with the competence they require to be able to solve the problems they encounter as citizens, in their professional roles and in everyday life. Lifelong learning has a two-pronged perspective, including both the factual knowledge needed to go on to further education, and the skills needed to continue the learning process in society. Thus, in the prison setting as well, education must be characterized both by opportunities to develop personal skills such as self-confidence, problem-solving abilities, creativity, to improve one's ability to learn, and to take in and assess information.

In cooperation with the other personnel groups in a prison, teachers are involved in a process of encouraging change, which is often difficult to pursue in a setting that also stimulates other processes. Skaalvik et al. describe, for example, how the socialization process in prisons, with the aim of activation through education and other activities, is counteracted by what they call "prisonification". Similar processes are described in the report Survival and Change (In Swedish, 2002. Prison and Probation Service research committee), an investigation into the possibilities of achieving change in work with sex offenders.

Links to the outside world are equally important to teachers as to incarcerated students, irrespective of whether or not the prison school is run as a branch of a public school. According to Skaalvik et al., a prison school exists in a field of tension between the world of education and the world of institutions, and where the latter often prevails. This makes further education and other opportunities for renewal and new perspectives all the more important for the teachers whose task it is to keep the learning process alive in the prison environment and to equip prisoners with the tools they need for individual personal development. 


\subsection{The place of education in the Prison and Probation Services}

\section{Recommendations}

The project group proposes that:

- The educational authorities and prison and probation services at the national, regional and local levels together discuss the scope of and need for educational opportunities (seen from the point of view of the needs of both the prison population and the institutions) and what courses are to be offered. There should be equal opportunities for work, education and other approved activities in the prisons, all available during normal working hours. From the point of view of equality, the same remuneration should be paid to prisoners for the different activities, not least so as to avoid competition between the activities offered.

- The recognized need of activation for prisoners (as part of the process of resocialization) is to be the main starting point when the various prison activities are prioritized. There should be flexible teaching arrangements, as a prisoner should be able to organize his or her activities as a combination of work, schooling, programs, and other approved activities.

- Teaching shall be provided by trained educational staff with certified subject area competence. Education should be part of each prisoner's future plan, extending up to and beyond release. A person with pedagogical expertise should assess the needs of the prisoner for education. release to a situation with work, schooling or other activities - must be prepared in good time and in consultation between the prisoner and other parties involved.

\section{Considerations}

A prison sentence is one of the ways society is able to react to undesirable actions. This reaction builds on the instruments available to the Prison and Probation Service to promote the reintegration of the prisoner into society. Many different professional categories contribute to this effort. In other words, institutions run by the Prison and Probation Service are staffed by representatives of various stakeholders who may also have differ- 
ent, contradictory, objectives. The educational authority is the national agency meant to ensure that convicted prisoners receive the education to which they have a legal right. The Prison and Probation Service has responsibility for coordinating the measures implemented by the various state authorities so that prisoners have well-organized, positive options.

One of the objectives of education in the Prison and Probation Service is to ensure that prisoners have the same range of course options as is available in society at large.

\section{Denmark}

All prisoners are required to participate in activities: work, education or some other approved activity. The national Prison and Probation Service, in collaboration with local prison management, draws up the "activity regulations" determining how many full-time students each prison is to have. The "activity planning" for each institution determines the balance between education, programs and other activities, on the basis of the needs of the prison population. The physical dimensions of the facility set the limits for all the various activities, including work, schooling and other activities. This is reflected in the number of prisoners able to be offered educational activities which, in turn, determines the level of activity and, in turn, the number of teachers employed. The "occupation plans" are discussed and revised at the annual "contract meetings" held between the management of the national prison and probation authorities and local prisons. Experienced prison administrators are quick to see when their prison populations change, and immediately notify the authorities of necessary changes in the activities offered. Every prisoner serving a sentence longer than four months must have a future plan containing, amongst other things, the activities (including schooling) in which he or she will participate while in prison and upon release. Moreover, irrespective of sentence length, every 15-17-yearold must draw up a future plan. As a rule, a member of the prison staff is responsible for seeing to it that the plan is drawn up. That staff member continues to take responsibility for implementation, and for collecting the necessary information. 


\section{Finland}

Every prisoner serving a sentence is obliged to participate in activities, i.e. to participate in work, education or other activities arranged or approved by the prison.

Each district prison has an assessment and allocation unit, to which prisoners are called, and where they receive a detailed plan of their sentence term based on a risk and needs assessment and an assessment of the functioning capacity of the individual. The allocation institution is chosen according to the activity and rehabilitation needs of the prisoner as well as the required level of security in the institution. The measures recorded in their sentence plans aim to help prisoners to live without crime and promote their reintegration into society. The plan is also intended to counteract recidivism in the institutions and during prison leaves or day release privileges. The allocation unit is responsible for the implementation and updating of the sentence plan.

Prisons are to have facilities for appropriate vocational training and necessary education. The activities and their scopes are set in annual discussion between the regional and local authorities. The regional authorities and the local prison authorities strive to coordinate the schooling offered to prisoners in each region or district. Prisoners are to be placed in work or other activities corresponding to the goals of their sentence, and with a view to maintaining and developing their vocational skills and/or improving their abilities to function in society. It is up to the director or assistant director of each prison to decide who will be offered schooling, but the matter is also discussed in the advisory committee, which includes representatives of the various prison staff groups and, in some places, also of the teachers.

\section{Norway}

It is the task of the Prison and Probation Service to ensure that prisoners are offered daytime activities. Prisoners may satisfy this activity requirement through work, schooling, programs, etc. The Norwegian Parliament allocates earmarked funds annually for education under the auspices of the Prison and Probation Service. On behalf of the Ministry of Education and Research, The County Governor of Hordaland disburses these budgeted funds to the county administrations. The budget distribution and educational options are discussed every year by the educational authori- 
ties and the Prison and Probation Service at national, regional and local levels. Every prisoner serving a sentence longer than 6 months must have a "sentence plan", stating what activities the individual will participate in while in prison and after release. A personal contact officer at the prison is responsible for collecting and coordinating information from the various stakeholders in the prison system.

\section{Sweden}

The Ministry of Justice has signaled clearly that it is incumbent upon the Prison and Probation Service to ensure that prisoners have access to basic education, upper secondary education and vocational training. Education is one aspect of what the Swedish Prison and Probation Service define as "program activities". All prisoners are required to participate in activities, defined as work, schooling, "criminality and abuse related treatment programs" and other structured activities. The regional office and local prisons meet twice a year to discuss the organization and scope of required activities/activities offered by each prison. The decision of who participates in education is made in accordance with a structure through which each prisoner's study objectives are clarified and the remote learning options determined when necessary. When this has been done, a meeting is held, at which the individual's studies are examined in a larger context.

\subsection{Options and needs for lifelong learning}

\section{Recommendations}

The project group proposes that:

- Every prisoner be given the opportunity and the necessary counseling to set out his or her educational needs in relation to working life and personal development, resulting in an individual educational plan.

- Prisoners always have their non-formal learning assessed.

- Once a convicted prisoner/prisoner in remand has had his or her nonformal learning assessed, educational options must be provided that correspond to the needs of each individual, and individuals must be sent to the prisons that can offer the options they require or give them the opportunity to have day release privileges for work or schooling. 
- Education must be defined broadly enough to include, in addition to subject competence, social skills and activities of daily life.

\section{Comments}

It is important to organize the education for each prisoner on the basis of what he or she knows and has mastered. This is the starting point from which it is possible to give each prisoner a long-term chance of having his or her educational needs satisfied. It is incumbent upon each prison school and/or the Prison and Probation Service to ensure that each school has sufficient expertise to assess the prisoners' formal and informal competence, or has contract with an organization in the community that can perform such an evaluation.

\section{Considerations}

In the European Union as a whole and in individual European countries, authorities focus on providing young people and adults with the qualifications and skills enhancement they require to be able to perform the new tasks in a society in constant change. Individuals unable to utilize these opportunities for skills enhancement will find themselves marginalized from general educational and the labor market. In this context, prison populations are vulnerable groups. It is a prerequisite for satisfying the needs of different groups regarding education and skills enhancement that the educational authorities have the ability and instruments to be able to quickly asses the educational options required by the different groups. The state school system has various means of assessing an individual's skill enhancement needs.

International and national studies of the literacy skills of young people and adults have pointed out that there is a large proportion of the population has inadequate basic skills. (for example see Eikeland, Manger, and Asbjørnsen (eds.) 2008). One Norwegian report focuses particular attention on the individuals with the weakest educational backgrounds, and who have been excluded from the labor market. When non-formal learning assessments have been implemented in relation to prison education, this may mean that, to a much larger extent than in the past, prisoners will be able to plan and structure their educational options on the basis of what they already know and of their needs. (The Informal Learning Project 
1999-2002 - At the finish line or on the starting blocks? Final report, VOX, Norwegian National Institute for Adult Education, Oslo 2002).

Prison populations are marginalized groups in society. Prisoners have a great deal of competence in many areas, but often use the knowledge they have in inappropriate ways, which results in negative consequences for themselves and others, as well as for society as a whole. They frequently lack the necessary motivation and self-confidence to enter into a regular school or work situation. Also, many recidivists have been in and out of prison work and school facilities for years, without having made any particular progress. A basic prerequisite for their having a chance to succeed is that their educational needs and points of departure be assessed, so that each prisoner can carry on from the level that suits him or her best.

\subsection{Documentation and research}

\section{Recommendations}

The project group proposes that systematic reporting, evaluation and research on education in prisons be carried out with a view to:

- documenting the work being done on education in prisons in comparison, for example, with treatment programs and other activities,

- evaluating whether the range offered as prison education corresponds to the educational needs of the prison population,

- obtaining a clear picture of which prisoners do and do not participate in, how students are recruited to prison education,

- assessing teaching methods and quality,

- obtaining a systematic evaluation of prison workshops in relation to the applying curricula,

- determining the place of prison education in the correctional services.

\section{Comments}

Research into prison education may provide new knowledge that can be applied in the state school system. Such knowledge may, in the long term, contribute to crime prevention in society. 


\section{Considerations}

All the Nordic countries have carried out national surveys of prisoners' educational backgrounds, needs, and preferences. In 2006, the Nordic Network for Prison Education took the initiative to a Nordic survey of prisoners' educational backgrounds. Funding was granted by the Nordic Council of Ministers, and the survey was carried out in 2006 and 2007. Research teams from all five Nordic countries were involved, and the results pointed out the similarities and differences between the Nordic countries in relation to prisoners' educations. The findings of the national and the overall Nordic survey have resulted in greater attention being paid by both politicians and decision-makers to prison education, and consequent improvements. There is also a comprehensive requirement in the Nordic countries for quality assurance in educational activities on the basis of various kinds of reporting, evaluation and research, in order to ensure a balance between the resources allocated and the education offered, and to give a clear picture of what educational activities are offered.

\subsection{Cooperation between the prison and probation services and other stakeholders}

\section{Recommendations}

The project group proposes increased contact between prisons and society at large and that:

- The state social service authorities must provide the services as required by law, which would result in structured, systematic, inter-agency cooperation. There must be better contact and cooperation between agencies such as the educational authorities, the correctional services, the labor market authorities, the main trade unions, and the employment services.

- Prisoners should more frequently be placed in open institutions allow-ing more day release privileges for education and work, which would result in automatically making better use of traditional social services.

- As part of the transition to release, the use of supervised probationary freedom should be increased so that more prisoners would study, 
work, or participate in rehabilitation activities with some form of probationary freedom.

- The release of a prisoner should be prepared in cooperation with the social, health care, employment, and education services in the commu-nity as well as third sector organizations, so that the prisoner will re-ceive sufficient support upon release. In the release phase, every pri-soner should receive an assessment of his or her need for services and ability to cope in society. Assessment methods, which could detect the risks that should be taken into account when considering coping after release, should be developed.

- There should be better utilization of the expertise and options of the labor market authorities for prison convicts, in order to ensure smoother transitions back into society.

- Internet-based education with satisfactory security solutions will provide a supplementary tool for utilization of the state educational servi-ces. Internet-based education will: a) be a contribution to normaliza-tion b) offer more options - enable prisoners to participate in a wider range of courses c) reach more prisoners - facilitating individualiza-tion and d) enable greater educational continuity and thus increase the possibility of completing certificates and being awarded diplomas. Information and communication technology (ICT) must be used as a tool in prisons in the same way as in society at large.

- Cooperation between prison school administrators, workshop managers, and representatives of the employment services must be improved. Prisoners must be given vocational experience in the workshop and education in the classroom. This would give them more options and probably increase their motivation, because they would know that the activities in which they were involved would be beneficial after release. This would also make vocational training in prison an integral part of the skills enhancement work that continues after release. See also section 9.7.

Concrete plans and routines should be drawn up for cooperation between the prison and probation services and the various stakeholders at national, regional and local levels. 


\section{Considerations}

A prison term served in a closed institution automatically reduces contact with society at large to some extent. Every year, substantial resources are spent on prison institutions where individuals are incarcerated for periods of time of varying duration.

Historically, these resources have been utilized in a far too fragmented way, with too little investment in programs to promote normalization and integration. In a comprehensive societal perspective, it is important that future measures and programs be coordinated so as to promote reintegration of prisoners into society.

Good cooperation between the prison and probation services and other authorities is an important factor in satisfying prisoners' educational needs. There must be strategic planning for expansion of the range of educational options offered in prisons. Better cooperation and planning would give an overview of the needs for education amongst various groups of prisoners, and thus result in a broad range of educational options with satisfactory utilization of resources.

\section{Denmark}

Normally, a prison sentence will be served in an open institution. Prisoner's needs of various social services such as dentistry, drug treatment, and education are to be met in the local community. The principle of normalization is implemented by extensive use of day release privileges from these open institutions. (The average Danish prison has an average of 1,400 prisoners, 100 of whom exercise day release privileges - approximately 8\%). The principles of normalization and openness are regulated in the "Principles Program". It is general practice that prisoners in open institutions have full access to Internet-based education (using the Internet and email).

\section{Finland}

In 2007, a total of 150 prisoners had day release privileges (for education). Long-term prisoners approaching release are to have a release plan, drawn up in consultation with the social services and other relevant stakeholders. If the prisoner is to be released on parole, the probation services are also involved in the planning. If the prisoner has been involved in prison education, the teacher and study counselor should en- 
courage the prisoner to continue his or her studies upon release. Vocational training is organized in modules, making it easy to continue at a later time.

\section{Norway}

Very few prisoners in Norway have day release privileges for school and work. In 2007, 642 prisoners, mainly in open institutions, made the transition to day release privileges. Only three violated their privileges by escaping. In the parliamentary report Punishment that Works, the government proposes making it possible for prisoners to have day release privileges from the first day of sentence enforcement when defensible from a security viewpoint, and with a special focus on young prisoners. The report describes day release privileges as a very good instrument for the transition to society, giving prisoners access to community life at the same time as the prison and probation service has adequate means of monitoring them. Exercising day release privileges is a positive way for prisoners to use their time, assuming that they have possibilities for either education or vocational experience they will be able to build on after release. Norway has a unique arrangement referred to as "follow-up classes" in the community. These classes were established to enable prisoners receiving prison education to continue attending the same classes upon release. One follow-up class has developed a model for inter-agency cooperation with the student in focus, where the social services have more responsibility than elsewhere. The labor market authorities have become far more involved in reintegration of prisoners into society since agreements between the labor market and correctional authorities were drawn up at national, region and local levels.

\section{Sweden}

Sweden has an interesting national project known as KrAmi, with systematic cooperation between the correctional services, the labor market authorities and the municipal social services. Prisoner counseling for both incarcerated prisoners and prisoners on probation, the KrAmi project for prisoners on probation, and labor market courses held at prison facilities are all run in accordance with a national level agreement between the Prison and Probation Service and the Public Employment Service. A project on Internet-based education at university level has been initiated 
in order to assess security problems, as well as technical and pedagogical issues.

\subsection{The cost of prison education}

\section{Recommendation}

The project group suggests continued, extended funding for prison education, because the needs in this area are great. While a prisoner is serving his or her sentence, educators have a unique opportunity to reach many individuals who have high educational priority but who are difficult to reach via traditional adult education channels, owing to the fact that their negative prior educational experience discourages them from seeking out adult education for themselves.

\section{Comments}

Today the demand for prison education far outstrips supply. According to the Nordic Report Nordic Prison Education: Prisoners' educational backgrounds, preferences and motivation (Eikeland, Manger, and Asbjørnsen, 2008), between 7 and 16\% of the prisoners had not completed any level of education. The highest figure (16\%) was for Iceland, where the prison population is very small, the lowest for Finland and Norway (both at 7.2\%). Approximately every ninth prisoner in both Denmark and Sweden had no completed level of education. In Sweden, the group of prisoners with the weakest educational backgrounds were also most often represented among prisoners who chose not to participate in any prison educational activities. The surveys as a whole indicate that young prisoners in the Nordic countries are those who most often have weak educational backgrounds. A particularly worrying figure was that $83.7 \%$ of the prisoners under the age of twenty-five in Norway had not completed three-year upper secondary school. The educational level of prisoners in Norway corresponds to that of the general population some twenty years ago (Eikeland, Manger, and Diseth, 2006).

The group with the greatest educational needs is a group which is also often difficult to recruit to schooling in the state school system, and thus the opportunity should be taken to begin to fulfill the ambitions expressed 
by society in terms of the "adult education initiative” and lifelong learning when the individuals from this group are incarcerated.

Today, education accounts for only a small fraction of the costs of a prison sentence. From a socioeconomic point of view it would undoubtedly be beneficial to invest more in prison education.

\section{Considerations}

It is difficult to compare statistics on the cost of prison education. Education is organized differently from country to country, and is sometimes also financed by different authorities. Moreover, it may be difficult to distinguish the costs of prison education from the costs of other education. Nonetheless, the project group has attempted to collect either actual or estimated figures for each country. Owing to the inherent uncertainty, we have restricted our statistics to the few specific measurements we regarded as most interesting to consider. The statistics submitted by each country but not included in this report provide material for further study.

One interesting figure to compare is the cost of prison education in each country relative to the total cost of a prison term per prisoner and day. Such figures may provide an indication of the level of ambition regarding prison education in each country.

Table 9.1 The costs of prison education (in Euro)

\begin{tabular}{lrrrr}
\hline Cost & Denmark & Finland & Norway & Sweden \\
\hline $\begin{array}{l}\text { Total annual cost of prison education } \\
\begin{array}{l}\text { Annual cost of full-time education per } \\
\text { study place? }\end{array}\end{array}$ & $8,960,662$ & $3,982,000$ & $21,171,891$ & $11,978,980$ \\
$\begin{array}{l}\text { Cost, per day for prison education per } \\
\text { prison/remand place }\end{array}$ & 26,200 & 13,185 & $16,763^{2}$ & 21,848 \\
$\begin{array}{l}\text { Percentage of total cost per day ac- } \\
\text { counted for by prison education }\end{array}$ & 9.7 & 3.7 & 6.6 & $4.8^{3} / 6.7^{4}$ \\
\hline
\end{tabular}

1) Estimated on the basis of the total number of classroom hours in relation to the number of hours per year considered full-time activity for a prisoner (1,850 hours in Denmark, 2,000 hours in Finland, 1,425 hours in Norway and 1,610 hours in Sweden).

2) in Norway, full-time studies are 38 weeks per year (1,425 hours), which raises the relative cost per student per year.

3) including remand prison places.

4) excluding remand prison places.

5) total cost of one prisoner per day (average). 


\section{Comments: "A pack of cigarettes a day"}

As indicated in the table, the cost of prison education relative to the total cost per prisoner and day is small, in spite of the fact that millions per year are allocated by each country for education. Proportionally, prison education accounts for between 3\% and just over 9\% of the total cost of a prison place. Seen from a different perspective, education can be described as costing the prison and probation services in the Nordic countries the equivalent of one pack of cigarettes per prisoner and day.

Another variable that would be an interesting challenge to measure would be the total cost of the educational needs in the prison systems. This could be measured either on the basis of the actual needs or on the basis of the expressed ambitions of each country regarding the educational needs of the prisoners. It would at least have to include the needs for supplementary basic and further education, since this corresponds to the basic competence required at most workplaces in society. Below, we sketch a theoretical model to service as a point of departure for further discussions.

\section{Invest more now to reduce future costs}

Is it reasonable, in a time of financial constraints, to discuss increasing the educational activities in prisons? Raising the arguments put forward here to a socioeconomic level, we can say that every single prisoner who breaks a vicious circle of drug dependence and criminality means a benefit to society of several million Euro. A report from the Swedish National Board of Health and Welfare describes the estimated socioeconomic benefit of a number of cooperative projects run by the correctional services, the employment services and the municipal social services as follows: the return on investment to society for every Euro invested in these projects was between 10 and 18 (Jess, 2005).

A report on socioeconomic accounting in a project known as "The Way Out” states that:

Until the day we are prepared to take risks with our long-term efforts to prevent ill health and to rehabilitate the marginalized, we will see the safe, shortterm, and often bad decisions prevail. Perhaps we need new welfare institutions, prepared to take those fundamentally human and economically viable risks. This investment analysis made in socioeconomic bookkeeping is an attempt to trigger that kind of long-term thinking about rehabilitation. 
Every participant in “The Way Out” project in 2005 meant a socioeconomic benefit of roughly SEK 980,000. Thus the investment in rehabilitation made by society for "The Way Out" project in 2005 has paid itself back approximately ten times over, or $1,060 \%$. Not a bad result in any investment context.

The project worked with development of companies based on social responsibility, and of course some of the benefit of society came from taxes, etc., but a great deal had to do with reduction of costs to society owing to decreased criminality. In short, the net losses to the companies involved in "The Way Out" in 2005 were SEK 0.35 billion, while the gain to society was approximately SEK 37 billion. Two of the main winners in the process were the judicial system with a profit for the year of SEK 14 billion, and the category referred to as "others" with a profit for the year of SEK 14.5 billion (In Swedish. English equivalent title: From the perspective of society. Summary of the report Socioeconomic Account for “The Way Out!" program 2006).

These are fantastic results seen in relation to the perspective of the budget of each of the agencies concerned. Thus we conclude that if the broader perspective were considered in relation to allocations for prison education, decision-makers in society would have a sounder basis for planning both investments and cutbacks. This conclusion was also drawn in a previously published report on the KrAmi project (Nyström et al. In Swedish. English equivalent title: Investing in Work, 2002). 



\section{Joint Nordic recommendations}

by Torfinn Langelid, Marianne Mäki, Kaj Raundrup, and Svenolov Svensson

This chapter presents an overview of the recommendations set out in the previous chapters. Together with the international recommendations and conventions, these provide a platform for development and further development of prison education in the Nordic countries and adjacent areas, and to other countries in their efforts to develop their prison education systems.

\section{Legislation}

The project group recommends that the educational authorities in the Nordic countries ensure that their legislations clearly state the legal right and obligation to provide prisoners with the same right to education as other citizens, and that it must in all ways be in accord with international conventions and recommendations.

The legal authority stipulated in the Education Acts should also be stipulated in the legislation of the different countries relating to enforcement of sentences. When the right to education has been elucidated, this will have consequences in terms of resource allocation.

\section{Normalization}

The project group proposes that the principle of normalization and openness be applied to as great an extent as possible by utilizing the public services of society such as schools, libraries, treatment services, etc. 
Equal opportunities in prison education

The project group proposes that irrespective of which model is used, there must be pedagogical expertise at management level to provide quality assurance for the educational activities offered. Teaching staff are to have the same status, authority, and competence as in the state school system.

\section{Description of prison education}

The project group proposes a joint Nordic description of education in prison facilities. The assumption of the project group in this respect is that ICT will be included as a natural took for all education. Prison education should consist of:

- Compulsory education (corresponding to nine years of basic education, through secondary school)

- Upper secondary education (corresponding to upper secondary level and vocational training, and the higher preparatory course).

- Internet-based education and remote learning

- Special education

- Immigrant education, minority group education (Sami, Roma, etc.) and education for second generation immigrants

- Higher/university education.

\section{Comment}

As part of any teaching, all schools/students should have access to a wellstocked library which, in itself, serves as an information center and a knowledge database.

\section{Educational opportunities}

The project group sets out the following proposals for educational courses to satisfy prisoners' needs regarding both formal education and informal skills enhancement. The national surveys and the Nordic survey all indicate a serious need for more vocational training. Vocational training must be more integrated with external workplaces, with a view to the transition to life in the community. Educational activities offered must satisfy the educational needs of the prisoners, especially those with special needs, and those who should be the object of special recruitment attention. 


\section{General education}

- Basic education.

- Special/remedial education, with a particular focus on the prisoners with the most inadequate educational backgrounds (the time while they are serving a prison sentence is a unique opportunity to focus on and motivate such individuals).

- Adult upper secondary education, with course options as extensive as those offered in the community.

- Being able to study with day release privileges is an important option, giving the individual more freedom of choice, and the chance to spend time in a "normal" study environment.

- When educational needs are assessed, prisoners' previous formal and non-formal experience should also be taken into account. This can mean a great deal to individuals who do not have good grades or posi-tive educational experiences.

- Education which satisfies the needs of foreign prisoners.

- Remote learning with some personal tutoring may play a role in satisfying individual needs.

\section{Vocational training}

- Vocational training in collaboration with the employment service in order to offer training that will prepare the individuals for the labor market.

- Cooperation should be encouraged between schools (theory) and prison workshops (practice). As a result of such cooperation, some activities could earn educational credits.

- Assessment of formal and non-formal educational experience should be included as a natural part of educational activities.

- Some vocational training could be given in foreign languages. This could also be useful to prisoners who are going to be deported after release, and who could thus gain competence that will be of value to them when they return to their home countries.

- It is important that marginalized individuals such as prisoners have the same opportunities as citizens in the community to acquire digital competence while they are serving time.

- ICT courses of the same kinds offered in the regular schools in the community (both to master the techniques themselves and to use the 
new technologies in other subject studies). ICT is also a necessary tool to be able to access various educational options outside the prison - a natural tool in relation to the expanding range of Internetbased adult education options in society, for example as links to educational insti-tutions in their home countries for foreign prisoners.

Creative activities, libraries, etc.

- Education in the arts with a view to improving self-development, life skills and motivation raises individuals' social skills. Participation in both creative activities and well-rounded physical activities often encourages prisoners to go on to other kinds of education.

- There should be access to a well-stocked library and its services in collaboration with the library services available in the community.

\section{Women prisoners}

- All the items above apply equally to women prisoners who, precisely like their male counterparts, must be offered a wide range of educational opportunities adapted to their individual needs. For women, who otherwise run the risk of being considered a small, costly target group, the new technologies may be particularly important in terms of opening up a large number of options (unless the possibility of mixing men and women in prison education groups is considered).

Education as one piece of the puzzle

- Education can become more effective if it is combined with work, treatment programs, and other approved activities. Very few prisoners can cope efficiently with full-time studies. Flexibility and "tailor-made" weekly schedules should be available for all prisoners. Educa-tion is one important piece of a larger puzzle. If that piece falls into place, it may be decisive both to the success of the prisoner's school-ing and to his or her life as a whole. The national surveys and the Nordic survey all stress the need for individual study plans, and good information and counseling concerning educational opportunities. 


\section{Facilities and equipment}

- There must be access to purpose-suited facilities and state-of-the-art equipment equivalent to that available in community adult education facilities or elsewhere in society.

\section{Educational background}

- Education for more prisoners

Every person in a prison and probation situation who has a right to and wants to participate in educational activities must be able to do so. It is particularly important that the educational needs of young prisoners with weak educational be satisfied. Measures:

- more frequent surveys of the educational backgrounds, preferences and needs of prisoners,

- better information concerning existing educational opportunities.

- Classroom facilities

Existing resources could be better utilized if classroom facilities were large enough to hold groups of eight to twelve participants. The prison and probation authorities must take their responsibility in this respect and draw up plants for renovating the classroom facilities.

- Quality and scope. Measures:

- A wider range of educational activities, emphasizing vocational training. Vocational training can be extended through a better structured, more goal-oriented collaboration with the prison workshops, many of which have been approved as teaching workshops. The prison schools can offer the general courses, while the workshops can offer the practical work experience involved in vocational training. When the transition to more vocational training is made, this will place demands in terms of both educational equipment and resources.

- Educational activities should be offered on a year-round basis, to satisfy the needs of prisoners to be able to participate in educational activities no matter when they are serving their sentences. 
- $\quad$ Prisoners serving short sentences

Short sentences must not pose an obstacle to embarking on educational activities. Measures:

- Assessments of formal and non-formal educational experience must be carried out.

- Plans for completing upper secondary education must be drawn up.

- If the curriculum corresponds to that used in municipal adult education, even short educational activities in prison may be valuable (for continued education after release).

- More motivational activities are needed, such as practical/ esthetic courses (music, drama, arts and crafts, etc.).

- More courses that give credit toward work life qualifications are needed. Educational activities on a year-round basis (see above) can be used to satisfy the needs of prisoners serving short sentences.

- Learning difficulties. Measures:

- More detailed surveys of prisoners' learning difficulties.

Research and assessment funds must be allocated to studying prisoners' literacy and numeracy difficulties.

- $\quad$ ICT/ the Internet

Greater awareness is needed concerning the importance of ICT/the Internet in prison educational activities, as well as funding that will make ICT equipment/Internet access available for prisoners who participate in prison educational activities.

- Higher education

More must be done to facilitate for prisoners wishing to participate in higher education, not least in terms of Internet access and tutored netbased educational activities.

\section{Methods}

The project group proposes the following approaches in order to fulfill the needs of prisoners for both formal and informal adult education: 
- The same pedagogical points of departure for lifelong learning in adult education shall apply to adults in prison as in society at large with the same adaptation to the target group that must always be used for any specific educational group, in prison or elsewhere. The methods implemented should be based on the idea of assessing the needs of each individual and, on that basis, giving him or her space in which to develop in terms of knowledge and experience and also as an individual with civil rights and duties.

- The particular features of prison education - often a short time frame, a great need for individualization, and students who may be at very different points along the route to acquiring life competence, places high demands both in terms of methodological flexibility and in terms of teachers being adaptable in their educational strategies.

- Because digital competence is necessary today for participation in civil society, ICT must be an integrated aspect of all prison education.

The place of education in the prison and probation services The project group proposes that:

- The educational authorities and prison and probation services at the national, regional and local levels together discuss the scope of and need for educational opportunities (seen from the point of view of the needs of both the prison population and the institutions) and what courses are to be offered. There should be equal opportunities for work, education and other approved activities in the prisons, available during normal working hours. From the point of view of equality, the same remuneration should be paid to prisoners for the different activi-ties, not least so as to avoid competition between the activities offered.

- The recognized need of prisoners for activation (as part of the process of resocialization) is to be the main starting point when the different prison activities are prioritized. There should be flexible teaching arrangements. A prisoner should be able to organize his or her activities as a combination of work, schooling, programs, and other approved activities.

- Teaching shall be provided by trained educational staff with certified subject area competence. Education should be part of each prisoner's 
future plan, extending up to and beyond release. A pedagogical expert should assess the needs of the prisoner for education. Release or con-ditional release, to a situation with work, schooling or other activities - must be prepared in good time and in consultation between the prisoner and other stakeholders.

\section{Options and needs for lifelong learning}

The project group proposes that:

- All prisoners must be given the necessary counseling and the opportunity to formulate their educational needs in an individual education plan, taking account of both working life and personal development.

- Prisoners shall always have their non-formal learning assessed.

- Once a convicted prisoner/prisoner in remand has had his or her nonformal learning assessed, educational options must be provided that correspond to the needs of each individual, and individuals must be sent to the prisons that can offer the options they require or give them the opportunity to have day release privileges for work or schooling.

- Education must be defined broadly enough to include, in addition to subject competence, social skills and activities of daily life.

\section{Documentation and research}

The project group proposes that systematic reporting, evaluation and research on education in prisons be carried out with a view to:

- documenting the work being done on education in prisons in comparison, for example, with treatment programs and other activities,

- evaluating whether the range offered as prison education corresponds to the educational needs of the prison population,

- obtaining a clear picture of which prisoners do and do not participate in, how students are recruited to prison education,

- assessing teaching methods and quality,

- obtaining a systematic evaluation of prison workshops in relation to the applying curricula,

- determining the place of prison education in the correctional services. 
Cooperation between the prison and probation services and other stakeholders

The project group proposes increased contact between prisons and society at large and that:

- The state social service authorities must provide the services as required by law, which would result in structured, systematic, inter-agency cooperation. There must be better contact and cooperation between agencies such as the educational authorities, the correctional services, the labor market authorities, the main trade unions and the employment services.

- There should be more frequent placement of prisoners in open institu-tions allowing more day release privileges for education and work, which would result in automatically making better use of traditional social services.

- As part of the transition to release, the use of day release privileges/ temporary release should be increased so that more prisoners can study, work, or participate in rehabilitation activities as day release privi-leges/temporary release.

- The release of a prisoner should be prepared in cooperation with the social, health care, employment, and education services of the society as well as the third sector instances so that the prisoner would receive sufficient support when released. In the release phase, every prisoner should receive an assessment of his or her need for services and ability to cope in society. Assessment methods to detect the risks associated with coping in freedom, should be developed.

- There should be better utilization of the expertise and options of the labor market authorities for prison convicts, in order to ensure smoother transitions to society,

- Internet-based education with satisfactory security solutions will provide a supplementary tool for utilization of the state educational servi-ces. Internet-based education will: a) be a contribution to normaliza-tion b) offer more options - enable prisoners to participate in a wider range of courses c) reach more prisoners - facilitating individualiza-tion and d) enable greater educational continuity and thus increase the possibility of completing certificates and being awarded diplomas. Information and communication technology (ICT) 
must be used as a tool in prisons in the same way as in society at large.

- Cooperation between prison school administrators, workshop managers and representatives of the employment services must be improved. Prisoners must be given vocational experience in the workshop and education in the classroom. This would give them more options and probably increase their motivation, because they would know that the activities in which they were involved would be beneficial after release. This would also make vocational training in prison an integral part of the skills enhancement work that continues after release. See also section 9.6.

\section{The costs of prison education}

The project group suggests continued and extended funding for prison education in order to satisfy the huge need for prison educational activities. While a prisoner is serving his or her sentence, educators have a unique opportunity to reach many individuals who have high educational priority but who are difficult to reach via traditional adult education channels, owing to the fact that their negative prior educational experience discourages them from seeking out adult education for themselves.

\section{Concluding comments}

Today the demand for prison education far outstrips supply.

The group with the greatest educational needs is a group which is also often difficult to recruit to schooling in the state school system, and thus the opportunity should be taken to begin to fulfill the ambitions expressed by society in terms of the "adult education initiative" and lifelong learning when the individuals belonging to this group are incarcerated. Today, education accounts for only a small fraction of the costs of a prison sentence. From a socio-economic point of view it would undoubtedly be beneficial to invest more in prison education. 


\section{Bibliography}

The sources listed below are given under the country section where they are relevant, and are listed only by their original language titles. In this English text, references are mentioned at first occurrence by their year of publication and with an English equivalent title, by way of information. To find the original title of a work referred to in the running text by an equivalent English title, please use the author's name and year of publication to make the match with the Nordic original.

\section{Denmark}

Adamsen, M.L., Olsen, I., Raundrup, K. (2004) Preparatory Adult Education in the Prisons.

Andersen, E. (1992): Den lange vej. Kriminalforsorgens Uddannelsescenter. Uddannelsesmiljøet i åbent og lukket fængsel. Justitsministeriet.

Andersen, S.E. (1985): Forskningsrapport no. 26 - Strafafsoning i pædagogisk perspektiv. Justitsministeriet.

Andersen, S.E., Holstein , B., Skadhauge, F. (1980): Uddannelse 7 - om uddannelsesmiljøer, læring og medlæring. Undervisningsministeriet.

Bekendtgørelse 592 af 24. juni 2005:

Bekendtgørelse af lov om specialundervisning for voksne. Undervisningsministeriet.

Bekendtgørelse no. 736 af 25. juni 2007: Om indsattes adgang til at medtage, besidde og råde over egne genstande og penge i Kriminalforsorgens institutioner (genstandsbekendtgørelsen).

Bekendtgørelse no. 1081 af 13. september 2007: Om udgang til indsatte, der udstår fængselsstraf eller forvaring i kriminalforsorgens institutioner (udgangsbekendtgørelsen).

Betænkning no. 1058 - 3 bind (1986): Arbejde, undervisning og fritid. Udvalg under Justitsministeriet.

Betænkning no. 683 (1973): Betænkning om undervisning, erhvervsuddannelse og fritidsaktiviteter for indsatte i fængselsvæsenets anstalter. Statens Trykningskontor.

Dansk Videnscenter for ordblindhed (1997): Nyt om ordblindhed 12.

Det kriminalpræventive Råd (2000): Udvikling og perspektiver.

Direktoratet for Kriminalforsorgen (1993): Kriminalforsorgens principprogram. 
Direktoratet for Kriminalforsorgen (2001): Kriminalforsorgens statistik 2000.

Direktoratet for Kriminalforsorgen (2001): Nyt fra kriminalforsorgen no. 6.

Direktoratet for Kriminalforsorgen (2000): Placering af indsatte. Differentieringsudvalget.

Direktoratet for Kriminalforsorgen (april 2000): Vedrørende brug af internet.

Direktoratet for Kriminalforsorgen, 1998: "Vedrørende halvåbne afdelinger i Statsfængslet Møgelkær og Statsfængslet ved Horserød”, Differentieringsudvalget.

Direktøren for fængselsvæsenet (1952 ):

Reglement for undervisning. Justitsministeriet.

Direktøren for Kriminalforsorgen (1974): Indstilling om fængselsdømtes adgang til undervisning eller beskæftigelse.

Holstein, B., Skadhauge, F. (1976):

Rapport no. 1 - om uddannelsesog/eller beskæftigelsesplanerne omkring statsfængslerne i Nyborg og på Søbysøgård.

Holstein, B., Skadhauge, F. (1977):

Rapport no. 2 - om uddannelsesog/eller beskæftigelsesplanerne omkring statsfængslerne i Nyborg og på Søbysøgård.
Holstein, B., Skadhauge, F. (1978):

Rapport no. 3 - om uddannelsesog/eller beskæftigelsesplanerne omkring statsfængslerne i Nyborg og på Søbysøgård.

Holstein, B. (1986): Uddannelse og recidiv - en undersøgelse af sammenhængen mellem uddannelse under afsoning og kriminelt recidiv hos 1325 løsladte. Justitsministeriet Kriminalpolitisk forskningsgruppe.

Koudahl, Peter (2007): Indsatte i danske fængsler - Uddannelse og uddannelsesønsker.

Kildemoes, Vagn (1959): “Statsfængslet i Vridsløselille”, Nordisk Tidsskrift for kriminalvidenskab.

Lindgaard Adamsen, Mette, Raundrup, Kaj , Olsen, Itene (2004). Preparatory Adult Education in the Prisons.

Lov no. 590 af 24. juni 2005 - om almen voksenuddannelse (avu-loven).

Lov no. 16 af 7. januar 2005 - om forberedende voksenundervisning: (fvu-loven).

Lov no. 1337 fra 3. december 2007: Lov om fuldbyrdelse af straf m.v. Folketinget. Schultz Grafisk.

Lov af 15. april 1930: Lov om ikrafttræden af borgerlig straffelov m.v. Gads forlag.

Skadhauge, Flemming B. (1980-81): (side 102) Undervisning af indsatte

\section{Finland}

Aikuiskoulutuskomitean II osamietintö. Komiteanmietintö 28:1975.

Arviointiraportti, vankilaopetus, suljetut laitokset. Julkaisematon raportti. Rikosseuraamusviraston julkaisuita 3/2007.

Arviointiraportti, vankilaopetus, avolaitokset. Julkaisematon raportti. Opetushallitus 2004.
Annual Report of the Criminal Sanctions Field 2007

Criminal Sanctions Agency, Working group Report 5/2008: The clientele, work processes and rehabilitation of the criminal sanctions field, in Finnish: Rikosseuraamusalan asiakaskunta, työprosessit ja kuntouttaminen. Finlands grundlag 731/1999. Finlands lag. 
Fångvårdsförordning 431/1975.

Finlands lag.

Fångvårdsförordning 878/1995.

Finlands lag.

Fångvårdsväsendets och Kriminalvårdsföreningens principprogram och riktlinjer för verksamheten under den närmaste framtiden i Finland.

Helsingfors 1999.

Förordning om fångvårdsväsendet 1925, 1936 och 1950. Finlands lag.

Förordning om verkställighet av straff 28/1866. Finlands lag.

Förordning om verkställighet av straff 39/1889. Finlands lag.

Förordning om yrkesundervisningsanstalter 5/1959. Finlands lag.

Gymnasielagen 629/1998 och förordning 810/1998. Finlands lag.

Hartoneva, A., Kuivajärvi, K., Muilu, M-L. (1999): Alan miehestä ammattimieheksi,

Vankien ammatillinen koulutus 19481997, Helsinki: Oikeusministeriön vankeinhoito-osaston julkaisuja 4.

Hypen, Kimmo 1/2004. The released from prison in Finland 1993-2001 and the re-entered, in Finnish: Vankilasta vuosina 1993-2001 vapautunheet ja vankilaan uudestaan palanneet.

Kallinen, R., (1982): Kasvatusta ja keskitystä, Helsinki: Vankeinhoidon historiaprojektin julkaisuja 10.

Kivi, T., Mahlberg, S. (2002): Ulos osallisuuteen. Kuntoutuskokeilu Riihimäen vankilassa. Julkaisematon moniste.

Koski \& Miettinen (2007) Vangit koulutuksessa - Selvitys vankien koulutukseen osallistumisesta, oppimisvalmiuksista ja -strategioista sekä opetuksen laadusta. Opetushallitus 2007.

Koski \& Mäki (2006) Vankien ammatillista koulutusta koskeva selvitys. Opetushallitus 2006.

Koulutus ja tutkimus vuosina 20072012. Kehittämissuunnitelma. Opetusministeriö 2007.
Kuivajärvi, K., (1995): Basic education in Finnish prisons. Teoksessa Basic education in prisons. UNESCO institute for education. Hamburg.

Kuivajärvi, K., Sunimento, K. (2002)

Vankilaopetusjärjestelmän kuvaus, suhde ja kytkökset muuhun koulutusjärjestelmään.

Julkaisematon muistio pohjoismaista vankilaopetuskartoitusta varten. Rikosseuraamusvirasto 30.5.2002.

Lag 630/1998 och förordning 811/1998 om yrkesriktad grundutbildning. Finlands lag.

Lag 631/1998 och förordning 812/1998 om yrkesriktad vuxenutbildning. Finlands lag.

Lag 628/1998 och förordning 852/1998 om grundläggande undervisning 628/1998.

Lag om arbetskrafspolitisk vuxenutbildning 763/1990. Finlands lag.

Lag om läroavtalsutbildning 1605/1992. Finlands lag.

Lag om rannsakningsfängelse $615 / 1974$. Finlands lag.

Lag om yrkesundervisningsanstalter 154/1939. Finlands lag.

Lag om yrkesundervisningsanstalter 184/1959. Finlands lag.

Lag om ändring av förordningen om verkställighet av straff 128/1995. Finlands lag.

Lag om ändring av lagen om rannsakningsfängelse 129/1995. Finlands lag.

Lag om ändring av lagen om verkställighet av straff 137/2001. Finlands lag.

Lag om ändring av lagen om verkställighet av straff 580/2001. Finlands lag.

Mohell, U, (2002): Vankilaopetusta koskevat säännökset. Julkaisematon muistio pohjoismaista vankilaopetuskartoitusta varten. Rikosseuraamusvirasto 29.5.2002.

Numminen, L, (1995): Suonkuokkijasta konepuusepän ammattiin. Koulutustoiminnan kehittyminen Regeringens proposition till riksdagen om refor- 
mering av lagstiftningen om fängelsestraff och verkställighet av dem i straffanstalter samt lagstiftningen om rannsakningsfängelse 239/1972.

Rikosseuraamusviraston tilastoja 2007.

Salo Helena (2006) Lukivaikeus on sosiaalinen riski: lukemisen ja kirjoittamisen vaikeudet suomalaisilla miesvangeilla. Pro gradu -tutkielma. Turun yliopisto.

Toivonen, Merja, Opiskelu vankilassa kurjuuden maksimointia vai avain parempaan huomiseen? Julkaisematon muistio pohjoismaista vankilaopetuskartoitusta varten. Rikosseuraamusvirasto 15.11.2002.

Tuominen, Tiina. ADHD-piirteet, lukivaikeus ja kognitiivinen kapasiteetti suomalaisilla miesvangeilla. Väitöskirja, Turun yliopisto. Alustavat jul-

\section{Norway}

Asbjørnsen, E. A., Manger, T og Jones, Ø. L. 2007: Innsatte i Bergen fengsel: Leseferdigheter og lesevansker, Bergen: Fylkesmannen i Hordaland

Asbjørnsen, E. A., Manger, T. og Jones, Ø. L. 2007: Innsatte i Bergen fengsel: Delrapport 2: Lesevaner, leseerfaringer og leseferdigheter, Bergen: Fylkesmannen i Hordaland

Asbjørnsen, E. A., Jones, Ø. L og Manger, T. 2008: Innsatte i Bergen fengsel: Delrapport 3:

Leseferdigheter og grunnleggende kognitive ferdigheter, Bergen: Fylkesmannen i Hordaland

Avtale om statlig tilskudd til fengselsundervisningen. Brev fra Kirke- og undervisningsdepartementet 23.06.1988 til Fylkeskommunene og Fylkesskolestyrene.

Bødal, Kåre: Fra arbeidsskole til ungdomsfengsel. Klientell og resultater. Oslo 1969. kaisemattomat tutkimustulokset.

2007,

Vankeuslaki 767/2005

Valtioneuvoston koulutuspoliittinen selonteko eduskunnalle. Opetusministeriön julkaisuja 2006:24.

Vankilaopetuksen strategia vuosille 2008-2012, Rikosseuraamusalan strategiat, Rikosseuraamusvirasto 2008.

Vankilaopetustoimikunnan mietintö. Komiteanmietintö 1973:111. Helsinki 1973.

Vankilaopetustyöryhmän muistio. Opetusministeriön työryhmien muistioita 1988:27.

Helsinki 1988.

Vankisäännöstoimikunnan mietintö. Komiteanmietintö 7:1975.

www.minedu.fi Undervisningsministeriets hemsidor

Christie, Nils: Modeller for fengselsorganisasjonen i "I stedet for fengsel” Pax 1970.

Chylicki, Pavel: Att upphöra med brott. Vägar ut ur den kriminella karrieren. Lund University Press 1992.

De europeiske fengselsregler, Rekommendasjon Rec (2006 2 , Europarådet, Strasbourg 2006.

Den europeiske menneskerettskonvensjonen i Lov 1999-05-21 nr 30: Lov om styrking av menneskerettighetenes stilling i norsk rett (menneskerettsloven).

Diseth, Å., Eikeland, O-J og Manger, T. 2006: Innsatte i norske fengsel: Utdanningskvalitet, læringsstrategier og motivasjon, Bergen: Fylkesmannen i Hordaland.

Dokumentasjon og verdsetting av realkompetanse. Realkompetanseprosjektet 1999-2002. vox Voksenopplæringsinstituttet 2002. 
Eikeland, Manger og Asbjørnsen (red.) 2008: Innsatte i nordiske fengsler Utdanning, utdanningsønske og -motivasjon. TemaNord 2008:592, København.

Eikeland, Manger, and Asbjørnsen (eds) Education in Nordic Prisons Prisoners' Educational Backgrounds, Preferences, and Motivation. TemaNord 2009:508, Copenhagen.

Eikeland, Manger og Diseth. 2006. Innsette i norske fengsel: Utdanning, utdanningsønske og rett til opplæring, Bergen: Fylkesmannen i Hordaland.

FN's konvensjon om barnets rettigheter i Barnekonvensjonen, Rettigheter for barn i Norge, Redd Barna 1993.

Friestad, C og Skog Hansen, I.L 2004: Levekår blant innsatte. Fafo-rapport 429.

Fængselsstyrelsens Aarbog 19011902. II. Aarsberetning 1901-1902 nosiv 87 Krist. 1904.

Halvorsen, Gudrun: Eleven og de gode hjelperne. Bergen: Statens utdanningskontor i Hordaland. 2000.

Ingebrigtsen, Oddbjørn og Susegg, Brit Arna: Med mestring som erfaring og samfunnet som mulighet. Fylkesmannen i Hordaland 2006.

Innst. S. no. 196 (2004-2005) Innstilling fra kirke-, utdannings- og forskningskomiteen om opplæringen innenfor kriminalomsorgen.

"Kartlegging av behov og organisering av tilbud om grunnskoleopplæring for voksne" Sluttrapport fra det nasjonale prosjektet. Grunnskoleprosjektet. Statens utdanningskontor

i Møre og Romsdal 2002.

Kirke-og undervisningsdepartementets (KUD) rundskriv 6 As L 1969 24.10.69. Undervisning for unge innsatte i fengselsvesenets anstalter.

Kriminalomsorgens årsstatistikk 2007.

Kristoffersen. R. (2008): Correctional Statistics of Denmark, Finland, Iceland, Norway and Sweden
2002/2006. Correctional Service of Norway Staff Academy, Oslo.

Læreplanverket for Kunnskapsløftet. Midlertidig utgave juni 2006. Kunnskapsdepartementet Utdanningsdirektoratet.

Langelid, Torfinn: Straff og pedagogikk - To sosialiseringssystem i konflikt? Utvikling av undervisningstilbod ved to norske fengsel 1945-1980. Hovudoppgåve i Historie. Historisk Institutt, Universitetet i Oslo, Våren 1982.

Lie, Magnus: Waisenhusstiftelsen i Trondheim gjennom 300 år 1635-1935. Trondheim 1935.

Lov om fængselsvesenet av 12. des. 1958.

Lov om gjennomføring av straff 01.03.2002.

Manger, T., Eikeland O-J,, Diseth, Å og Hetland, H: Innsette i norske fengsel: Motiv for utdanning. 2006. Bergen: Fylkesmannen i Hordaland.

Opplæring i fengsel, Rekommendasjon nr R (89) 12, Europarådet, Strasbourg 1990.

Opplæringsloven med forskrifter. Pedlex Norsk Skoleinformasjon 2008.

Rapport Opplæring innanfor kriminalomsorga 2007, Fylkesmannen i Hordaland 2008.

Ravneberg, B: Undervisning og opplæring i det moderne fengslet. Dannende eller disiplinerende? Fylkesmannen i Hordaland, 2003.

Realkompetanseprosjektet 1999-2002 i mål eller på startstreken? Sluttrapport. VOX Voksenopplæringsinstituttet 2002.

Reglement for Fengselsvesenet. Gitt av Fengselsstyret 12. december 1961.

Rognaldsen, Svein: Evaluring av fengselsundervisningen med vekt på systemnivået og kriminalomsorgens totale opplæringsvirksomhet. Fylkesmannen i Hordaland, 2003.

Rundskriv G-1/2008 Rundskriv om forvaltningssamarbeid mellom opplæringssektoren og kriminalomsorgen 
fra Justis-og politidepartementet og Kunnskapsdepartementet 20.10.2008.

Sandvik, A.B: Hva passer for kvinner? Undervisning for kvinnelige fanger i fire norske fengsel. Fylkesmannen i Hordaland, 2003.

Skardhammar, Thorbjørn: Levekår og livssituasjon blant innsatte i norske fengsler. Institutt for kriminologi og rettssosiologi, Avdeling for kriminologi, Universitetet i Oslo K-serien no. 1/2002.

Skaalvik, E.M, Finbak L. og Pettersen, $\mathrm{T}$ : Begrunnelse og formål med fengselsundervisningen. Statens utdanningskontor i Hordaland 2002.

Skaalvik, E.M, Finbak L. og Pettersen, T: Undervisning i fengsel. På rett kjøl? Fylkesmannen i Hordaland 2003.

Skaalvik, E.M og Stenby, H.K: Skole bak murene. Trondheim: Tapir 1981. Statsbudsjettet 2000 Kap 430 Kriminalomsorg - Kriminalomsorg i anstalt - Tildeling av bevilgning, brev fra Justisdepartementet 29.12.99.

St. meld. nr 23, 1991-92, Om bekjempelse av kriminalitet.

St meld nr 27, 1997-98, Om kriminalomsorgen.

St.meld.nr.27 (2004-2005) Om opplæringen innenfor kriminalomsorgen "Enda en vår." English title: Short Version of Report no. 27 to the Storting (2004-2005) Education and
Training in the Correctional Services, Another Spring.

St.meld.nr.no. 37 (2007-2008) Straff som virker - mindre kriminalitet tryggere samfunn (kriminalomsorgsmelding), Punishment that Works less crime - a safer society. Report to the Storting on the Norwegian Correctional Services.

St prp nr 1, 2001-2002, fra Justis- og politidepartementet.

St prp nr 1, 2007-2008, fra Justis- og politidepartementet

St prp nr 1, 1994-95, fra Justis- og politidepartementet.

St prp nr 1, 2000-2001, fra Kirke-, utdannings- og forskningsdepartementet.

St prp nr 1, 2001-2002, fra Kyrkje-, utdannings- og forskingsdepartementet.

St.prp.nr.59 (2007-2008) Tilleggsbevilgninger og omprioriteringer i statsbudsjettet 2008 .

Unesco - Rekommendasjoner for voksenopplæring.

Viljugrein, T.: Skole, språk og fengsel. Undervisning av mannlige minoritetsspråklige fanger i fire norske fengsel. Statens utdanningskontor i Hordaland 2002.

www.epea.org www.fengselundervisning.net www.nordplusonline.org/eng/framework _programme/about_nordplus www.pipeline-project.org www.vox.no/templates/CommonPage. aspx?id=2475

2002:05, Institutionen för pedagogik och didaktik, Göteborgs universitet 2002.

Eriksson-Gustavsson och Samuelsson, Kartläggning av intagnas utbild-
Arnelund H, Uppsalafängelsets historia Länscellfängelset 1865-1912, Kriminalvårdsstyrelsen 1994.

Claesson S, Dahlgren H, Att studera i fängelse- klientutbildning vid tre kriminalvårdsanstalter, idp rapport 
ningsbakgrund - studiebehov, Kriminalvården 2008.

Eriksson T, Om brottslingars behandling

- hur modern kriminalvård arbetar, särtryck, Medéns Förlag ab 1966.

Eriksson T, Kriminalvård, Idéer och experiment, P.A. Norstedt \& Söner förlag 1967.

Herkner Birgitta, Hur vanligt är det med dysleksi bland intagna på svenska fängelser? D-uppsats, Institutionen för Beteendevetenskap, Linköpings universitet, 2001.

Jensen J, Lindgren M, WirsénMeurling A, Ingvar D och Levander S, Dyslexia among prisoners.

Jess, Kari, Att räkna med nytta: samhällsekonomisk utvärdering av socialt arbete, Stockholm University, 2005.

Kommunal vuxenutbildning, SKOLFS 1994:2.

Kriminalvårdens föreskrifter och allmänna råd om särskilda utslussningsåtgärder, KVFS 2008:5.

Kriminalvårdsstyrelsen, Fångars levnadsförhållanden, rapport från Kriminologiska Institutionen Stockholms universitet 1999.

Kriminalvårdsstyrelsen, Visionen "Bättre ut”, informationsmaterial 2001.

Nyström, Soydan \& Jess, Med arbete som insats, klienteffekter och samhällsekonomisk lönsamhet i socialt arbete, Socialstyrelsen, Centrum för Utvärdering av Socialt arbete, 2002.

Rapport Klientverksamhet i anstalt, Kriminalvårdsstyrelsen Förlaget 1996.

Ohlsson Lisbeth, Rapport angående "Läs och skriv/dysleksi undervisning” på kriminalvårdsanstalten i Malmö. Pedagogiska uppsatser no. 33. Pedagogiska Institutionen, Lunds universitet, 2000.

Om utbildning vid kriminalvård i anstalt (SFS 2007:152), Utbildningsdepartementet 2007
Roitto M \& Sjöberg H, Kriminalvårdens klientutbildning - kartläggning, problembeskrivning och förslag till åtgärder, Kriminalvårdstyrelsen 2001.

Kriminalvårdens Officiella Statistik 2007/8, Kriminalvårdsstyrelsen Förlaget 2007/8.

Samuelsson, Gustavsson, Herkner \& Lundberg, Hur vanligt är det med dyslexi bland intagna på svenska kriminalvårdsanstalter, Linköpings universitet 2000/2003.

Samverkan mellan arbetsförmedlingen och Kriminalvården, Kriminalvården 2008.

SOU 1996:27, En Strategi för kunskapslyft och livslångt lärande, Utbildningsdepartementet 1996.

SOU 1993:23, Kunskapens krona, Utbildningsdepartementet 1993.

SÖ-rapporter. Planering, uppföljning och utvärdering. Kommunal och statlig utbildning för vuxna i häkte och anstalt. R89:35 Stockholm: Skolöverstyrelsen 1989.

Svenskundervisning för invandrare, SFS 1994:895.

Thång, P.O. Vem går i grundvux och hur går det? Rapport nr 1988:04, Institutionen för pedagogik, Göteborgs universitet 1988.

UNESCO, 4th International Conference on Adult Education, Final Report, Paris 1985.

van Manen, Researching Lived Experience, Human Science for an Action Sensitive Pedagogy, USA The University of New York, 1990.

Ur samhällets perspektiv. Sammanfattning av rapport om Socioekonomiska bokslut för Vägen ut! 2006.

Utbildning inom kriminalvården effekter på intagnas läs- och skrivfärdigheter, Kriminalvårdens rapport no. 15, 2005. 



\section{Figures}

Figure 1.1 Prisoners and prison education in relation to society

Figure 1.2 The objectives of prison education seen over time

Figure 9.1 The objectives of prison education seen as a time spectrum 



\section{Tables}

Table 7.1 Prison capacity in 2006, number of places

Table 7.2 Average figures regarding deprivation of liberty in 2006

Table 7.3 Average numbers of sentences begun to be served in 2006

Table 7.4 Some groups of prisoners on a given day in 2006

Table 7.5 Education

Table 9.1 The costs of prison education (in Euro) 

Nordic Council of Ministers

Store Strandstræde 18

DK-1255 København K

www.norden.org

Nordic Prison Education -

\section{A Lifelong Learning Perspective}

In 1999, the Nordic Council adopted a recommendation on prison education in a Nordic perspective. In September 2001, a Nordic project group was appointed to carry out a study, with representatives from the prison and probation services and the educational authorities. The project was directed by the County Governor of Hordaland, Norway. A decision was adopted in 2007 to revise the report in relation to recent research, new surveys, and general developments in the Nordic countries.

The purpose of the project was to provide a concise, overall and updated comparative view of education and training in prisons in Denmark, Finland, Norway and Sweden, as well as a brief description of the situation in Iceland, Greenland, the Faeroe islands and the Åland islands.

If convicted prisoners are to be offered education on equal terms with others in society, the right to education must be clearly stipulated in the legislation.

According to this report, good cooperation between the prison and probation services and other authorities is one of the key starting points for satisfying prisoners' educational needs. The prison education offered today does not satisfactorily correspond to prisoners' educational needs. Increased investments in prison education would probably be of added value for society as a whole.

This report provides useful documentation for individuals working with any aspect of the wider problem complex relating to prison and probation services. 